\title{
Paul Philippe Sanguin de Jossigny (1750-1827), artiste de Philibert Commerson. Les dessins de reptiles de Madagascar, de Rodrigues et des Seychelles
}

Roger BOUR

Reptiles et Amphibiens, Département Systématique et Évolution, ISYEB, UMR 7205, CNRS MNHN UPMC EPHE, Muséum national d'Histoire naturelle, case postale 30, 75231 Paris cedex 05 (France)

bour@mnhn.fr

Publié le 25 septembre 2015

MOTS CLÉS

Paul Philippe Sanguin Philibert Commerson,

Pierre Sonnerat,

Madagascar,

Mascareignes,

Seychelles,

tortues,

lézards,

serpents,

dessins.

KEY WORDS

Paul Philippe Sanguin

de Jossigny,

Philibert Commerson,

Pierre Sonnerat,

Madagascar,

Mascarene Islands,

Seychelles,

turtles and tortoises,

lizards,

drawings.
urn:Isid:zoobank.org:pub:30F77120-7A62-4182-91D7-8FD895DFB459

Bour R. 2015. - Paul Philippe Sanguin de Jossigny (1750-1827), artiste de Philibert Commerson. Les dessins de reptiles de Madagascar, de Rodrigues et des Seychelles. Zoosystema 37 (3): 415-448. http://dx.doi.org/10.5252/z2015n3a1

RÉSUMÉ

Paul Philippe Sanguin de Jossigny était un militaire qui commença sa carrière à l'Isle de France (aujourd'hui île Maurice) comme aide de camp du gouverneur et la termina comme capitaine et ingénieur, avant de rentrer à regret à Paris. Sa renommée est fondée uniquement sur son œuvre de dessinateur pour Philibert Commerson; après la mort de celui-ci il apporta au futur Muséum d'Histoire naturelle de Paris les collections et les manuscrits du voyageur naturaliste. Parmi ces documents figuraient plus d'un millier de dessins exécutés par Jossigny lui-même ou par Pierre Sonnerat, représentant essentiellement les plantes et les animaux des Mascareignes et de Madagascar que l'on pouvait y observer en 1770 . Nous nous intéressons particulièrement aux vingt-deux planches figurant des reptiles, plus précisément des tortues (10), des lézards (8) et des serpents (4), reproduites pour la première fois dans leur ensemble.

\section{ABSTRACT}

Paul Philippe Sanguin de Jossigny (1750-1827), artist of Philibert Commerson.

The drawings of reptiles from Madagascar, Rodrigues and Seychelles.

Paul Philippe Sanguin de Jossigny was a trooper who began his career at the Isle de France (presently Mauritius) as an aide-de-camp to the governor and ended as captain and engineer before returning reluctantly to Paris. His fame is solely based on his work as artist for Philibert Commerson; after the death of the latter, he brought to the upcoming Muséum d'Histoire naturelle de Paris the naturalist traveller's collections and manuscripts. These documents included more than one thousand drawings made by Jossigny himself or by Pierre Sonnerat, mostly depicting the plants and animals that could be observed in 1770 in the Mascarenes and Madagascar. We pay special attention to the twenty-two plates depicting reptiles, precisely tortoises and turtles (10), lizards (8) and snakes (4), the whole here reproduced for the first time. 


\section{L'HOMME}

\section{PAul de JossignY}

Aucun des naturalistes s'intéressant à la flore et à la faune des îles de l'océan Indien occidental ne peut ignorer le nom de Jossigny, associé pour toujours à celui de Philibert Commerson (1727-1773), médecin, botaniste, voyageur, un Jossigny présenté comme son dessinateur, peintre ou artiste et parfois même comme son compagnon. Émile Oustalet (1896a, b), par exemple, décrivant à partir des dessins de Jossigny plusieurs espèces d'oiseaux éteintes, notait : "Ces dessins ont été exécutés, les uns, et ce sont les meilleurs, par un jeune dessinateur, nommé Jossigny, qui avait accompagné Commerson dans son voyage et qui demeura certainement avec lui à l'ìle de France [...]".

Si depuis deux siècles de nombreux travaux ont été consacrés à la vie et à l'œuvre du naturaliste Philibert Commerson, il n'y a pas une seule publication un tant soit peu détaillée rappelant qui était ce Jossigny. En fait, contrairement à ce que pourrait suggérer la liste qui suit, et comme me l'a rappelé Jean-Paul Morel (comm. pers. décembre 2014), il n’existe même pas de biographie satisfaisante de Commerson. Pour la période couvrant les dernières années du naturaliste, de son arrivée à l'Isle de France à sa mort, Morel (2010) a réuni et commenté l'ensemble des documents d'archives significatifs. Selon ce spécialiste de l'histoire des Mascareignes dans la seconde moitié du XVIII siècle, pour la biographie de Commerson uniquement, les autres sources que l'on peut considérer comme fiables, fondées sur des documents originaux, sont La Lande (1775), Cap (1861), Montessus (1889) et Monnier et al. (1993), auxquelles on peut ajouter la note publiée dans la Revue coloniale par Louis Bouton (1871). Les principales et fréquentes erreurs concernant Commerson aux Mascareignes et à Madagascar, ainsi que Sonnerat et Jossigny, sont signalées ici, suivies d'un astérisque $\left(^{*}\right)$. Dans des ouvrages ou articles comme ceux de Lamarck (1808), de Beauchamp (1818), Magon de Saint-Elier (1839), Anonyme (1873), Lacroix (1938), Role (1973), Ly-Tio-Fane (1976), Taillemite (1977), Pinault-Sørensen (1989), Serviable (1998), Allorge \& Ikor (2003), Lignereux (2004) et Crestey (2010), il y a plus ou moins d'inexactitudes et le rôle de Jossigny y est au pire ignoré, au mieux mentionné de façon anecdotique, et seulement pour la période s'étendant d'une arrivée imprécise aux Mascareignes à la mort de Commerson, rarement jusqu'à la remise des collections de Commerson au futur Muséum, à Paris. Par ailleurs un bon nombre de références, anciennes ou récentes, scientifiques, historiques ou de fiction, comme La Lande (1775), Cap (1860), Oustalet (1900), Grant et al. (1974), Touchard (1974), Merceron (1988), Christinat \& Forster (1993), Luminet (1999), Hupfeld (2007), etc. ainsi que Duprat (1964) et Schiebinger (2004) - ces deux dernières lui ayant de plus attribué le prénom de Pierre -, et même une bande dessinée (Autheman \& Dethorey 1999, 2000), présentent l'illustrateur Jossigny comme ayant pleinement participé à l'expédition de Bougainville, ce qui est erroné $\left(^{*}\right)$. Il faut reconnaître que même avec les outils de recherche dont nous disposons actuellement, sa propre biographie est encore bien confuse, comprenant des zones d'ombre étendues et nombreuses - Carole Christinat (1996: 90) a pu néanmoins attribuer à Jossigny une "personnalité peu saillante». Plus objectivement, j'ai tenté de préciser quelques étapes de la vie de cet inconnu célèbre malgré lui, militaire par nécessité, ayant dû quitter l'Isle de France - l'actuelle île Maurice contre son gré.

Jusqu'en 1860 (année de création des arrondissements actuels) les archives de l'état civil de Paris étaient déposées à l'Hôtel de Ville, mais elles ont été totalement détruites en mai 1871, les 23 (Hôtel de Ville) et 24 (copies du Palais de Justice), lors des évènements de la Commune, puis très partiellement reconstituées, à partir notamment des actes paroissiaux : de ce fait les références purement généalogiques relatives à Jossigny et à ses proches sont très incomplètes. Un arbre (Fig. 1) résume ce que j'ai pu rassembler. Les seuls documents détaillés concernant Jossigny sont ceux déposés aux Archives d'outre-mer (AOM). Déjà exploités par Madeleine PinaultSørensen, en 1989, les plus significatifs sont aujourd'hui transcrits par Jean-Paul Morel sur son passionnant site Pierre Poivre et Compagnie (Morel 2010). De plus ces archives sont partiellement scannées et numérisées, mais pour Jossigny elles ne concernent que le dossier personnel de la période des Mascareignes (AOM Col E 231: Anonyme 2013b); celles du dossier Commerson (AOM Col E 89: Anonyme 2013c) les complètent. Toutes les informations et citations présentées ici sans références précises sont tirées de ces documents des Archives nationales d'outre-mer accessibles par l'Internet.

Paul Philippe Sanguin " de Jossigny », fils de François Hippolyte (souvent orthographié, par erreur, Hyppolite) Sanguin et de Marie Françoise de Vallois, naquit à Paris le 1 er mai 1750 ; il fut baptisé en l'église Saint-Eustache, «église royale ", aujourd'hui située dans le 1er arrondissement. Paul Philippe eut au moins une sœur, Françoise Hippolyte, née en 1753, baptisée le 26 juin 1753, en l'église Saint-Jean-enGrève, et trois frères. L'aîné, Pierre, naquit, d'après son acte de décès ("âgé de soixante neuf ans six mois "), en juin ou juillet 1749 . Un relevé généalogique (Anonyme 2014b) mentionne la naissance de Pierre Sanguin de Livry, le 5 juin 1749, avec baptême en l'église de Saint-Nicolas-des-Champs; il n'y a pas d'indication sur les parents, mais il s'agit presque sûrement du même Pierre Sanguin, le frère aîné de Paul Philippe. En 1761 François Hippolyte Sanguin de Livry, père présumé ici, dépendait lui-même de la paroisse SaintNicolas-des-Champs (aujourd'hui rue Saint-Martin, dans le 3 e arrondissement de Paris), et nous verrons plus loin les problèmes irrésolus concernant les relations entre les familles Sanguin de Livry et Sanguin de Jossigny. À partir de 1767, engagé comme aide de camp à la Martinique, Pierre de Jossigny servit le commandant général des "Isles du Vent de l'Amérique ", le chevalier (puis comte) Charles Louis Emmanuel de Saint-Mauris (vers 1710-1787); il fut ensuite lieutenant (nommé sous-lieutenant le 9 novembre, lieutenant en premier le 30 novembre 1777) puis capitaine d'artillerie (23 avril 1788) aux Isles de France et de Bourbon. François, né en 1752, fut lieutenant en second à la Martinique (nommé le 18 avril 1772) puis, après un retour en France (1774), souslieutenant (1 ${ }^{\mathrm{er}}$ mai 1775) à Port-au-Prince, Saint-Domingue 


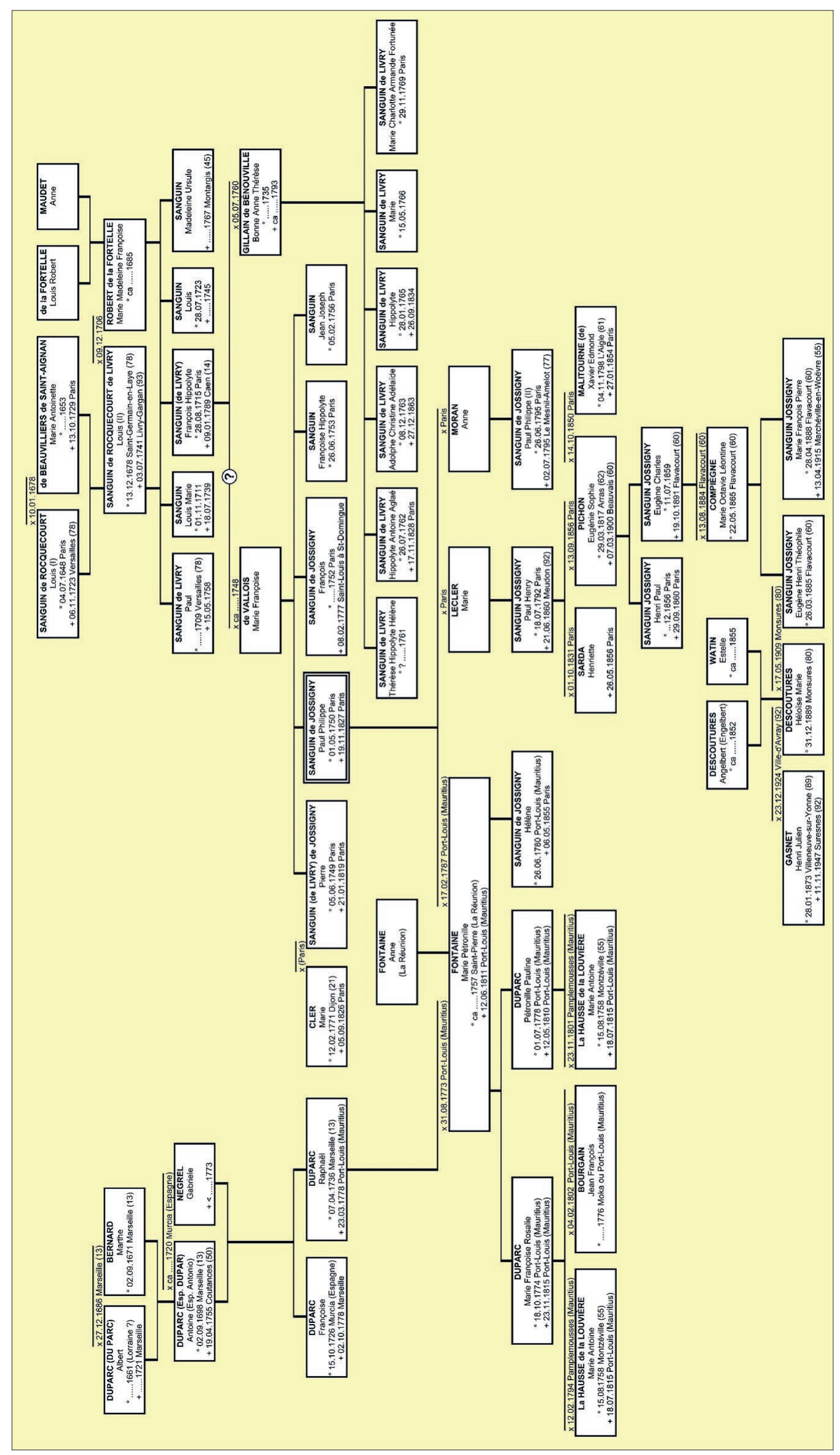


(aujourd'hui Haïti); il mourut dans cette île à Saint-Louis (du Sud), près des Cayes, le 8 février 1777 (Anonyme 2013a). Pas plus que de la sœur, nous ne savons rien du dernier frère, Jean Joseph, né en 1756, baptisé le 5 février 1756, église de SaintJean-en-Grève, peut-être précocement décédé. Un entête de dossier des Archives nationales d'outre-mer attribue cette date de naissance à son frère François, mais les quelques éléments disponibles actuellement ne permettent pas d'en conclure que François et Jean Joseph ne désignent qu'un seul frère. La formulation exacte des références aux baptêmes de la sœur et de ce dernier frère est "Sanguin Françoise-Hippolyte, née le 26 juin 1753, et Jean-Joseph, né le 5 février 1756, enfants de François-Hippolyte, chevalier non-profes [qui n'a pas fait ses vœux] de Malte, et de Marie-Françoise de Vallois (S. J. en G.)" (De Chastellux 1875: 558). Située tout près de l'Hôtel de Ville de Paris (aujourd'hui dans le 4e arrondissement), l'église de Saint-Jean-en-Grève fut détruite entre 1797 et 1800, vendue comme carrière de pierres; elle gardait les plus anciens registres paroissiaux de Paris.

Tout au long de son service dans les Mascareignes, de même que ses frères partis aux Antilles, Paul Philippe de Jossigny avait été régulièrement recommandé par une parente influente, la marquise Bonne Anne Thérèse Gillain de Bénouville (1735vers 1793), épouse de François Hippolyte Sanguin de Livry, né à Paris le 28 août 1715, mort à Caen le 9 janvier 1789. Il est évident qu'après la Révolution ces pratiques d'influences n'eurent plus cours, au moins quelque temps; de plus la marquise de Bénouville, devenue veuve l'année de la Révolution, avait perdu et sa fortune et son pouvoir. Une quinzaine de lettres de cette marquise, adressées aux diverses autorités, ministres et secrétaires d'état notamment, de 1774 à 1787, sont conservées dans le dossier d'archives de Paul de Jossigny, trois autres le sont dans celui de François. Les trois frères y sont distingués non par leur prénom, mais par ces dénominations : "l'aîné " (Pierre), "l'indien " (Paul), « le cadet " ou " le petit " (François). La marquise de Bénouville a évoqué dans une lettre trois orphelins : leur enrôlement à l'âge de dix-huit ans, suivi d'une carrière militaire, serait la conséquence de la disparition précoce d'un ou des deux parents. Le père de François Hippolyte, Louis (II) Sanguin (1678-1741), marquis de Livry, seigneur de Sevran, du Génitoy et du Raincy, lieutenant général des armées du Roi, avait été baptisé par Jacques Bénigne Bossuet (1627-1704), le roi Louis XIV et la reine Marie Thérèse d'Autriche étant parrain et marraine. François Hippolyte lui même fut au cours de sa vie marquis de Livry, seigneur du Génitoy, seigneur honoraire de Bénouville, seigneur et patron de Blainville (sur Orne), seigneur en partie d'Ouistreham et de Saint-Aubin-d'Arquenay, seigneur et patron de Soignolles, de Rouvres et Biéville; à cinq ans il était déjà chevalier des Hospitaliers de Saint-Jean (Malte); enseigne de marine (grade équivalent à lieutenant) à 16 ans, il fut nommé capitaine de vaisseau (grade équivalent à colonel) à 20 ans et devint à 45 ans chef d'escadre des Armées navales du Roi, puis premier maître d'hôtel du Roi et conseiller d'État. Ce grand personnage portait le même nom que le père de Paul Philippe ; plusieurs éléments concordants tendent à montrer qu'il était lui-même ce père.
Le nom même de Jossigny est énigmatique : on manque de documents pour savoir quand et comment le nom ou titre de Jossigny a été effectivement ajouté à Sanguin. Les plus anciens des manuscrits examinés (rédigés à partir de 1770) mentionnant les trois frères militaires, dont Paul Philippe, les nomment Sanguin de Jossigny, ou simplement Jossigny ou de Jossigny; aujourd'hui on peut rencontrer les patronymes erronés Sauguin (fréquent), Sanquin et Janguin. Sur l'acte de mariage de Paul Philippe avec Pétronille Fontaine (1787) est ajouté, pour le père François Hippolyte Sanguin, "Seigneur de Jossigny, Cher de l'ordre royal et militaire de St Louis ", mais ces précisions ont été données tardivement par Paul Philippe, qui n'avait probablement pas de document officiel. Beaucoup plus tard, sur l'acte d'état civil du décès de son frère aîné Pierre, survenu en 1819, l'association patronymique "Sanguin Levy dit Jossigny " apparaît trois fois, attribuée à Paul Philippe et à son frère Pierre, leur père François Hippolyte étant « Sanguin Levy ". Ce Levy est manifestement dû à une erreur de copie de Sanguin (de) Livry, car dans cet acte non original, mais reconstitué (en 1873), d'autres noms ont été écorchés, comme "Hipolite " et "Devalois ». Élément en revanche tout à fait fiable, enfin, en 1821 une ordonnance du roi Louis XVIII permit «Au Sr. Sanguin (Paul Philippe), né le 1er mai 1750 à Paris, y demeurant, ancien capitaine du génie, chevalier de l'ordre royal et militaire de Saint-Louis, d'ajouter à son nom celui de Jossigny, sous lequel il est connu et désigné depuis nombre d'années, et de s'appeler Sanguin de Jossigny" (Anonyme 1822a: 655). Il peut s'agir de la première reconnaissance formelle, confirmant une situation de fait, ou d'un rétablissement suivant une période de suspension. En fait, les uniques Sanguin reconnus " officiellement » (désignés ainsi dans les documents administratifs) comme de Jossigny ou Sanguin de Jossigny n'ont été que les trois frères et Hélène, la fille de Paul Philippe, le seul des trois à avoir eu une postérité. Au XIXe siècle ses descendants sont connus comme Sanguin Jossigny, mais l'ambiguïté perdura : sur l'acte de décès d'Eugénie Sophie Pichon, survenu le 7 mars 1900 à Beauvais, le nom de son défunt époux Paul Henry, fils de Paul Philippe, a été écrit Sanguin de Jossigny, puis le de a été raturé avec accord des témoins.

Les ancêtres des Sanguin sont identifiés depuis le milieu du XVe siècle; le patronyme Sanguin de Livry a pour origine la seigneurie de Livry en l'Aulnoye (aujourd'hui commune de Livry-Gargan, en Seine-Saint-Denis), acquise par Simon Sanguin (II) en 1499. Au fil des générations, cette famille s'appropria divers autres titres, dont, par alliance, celui lié à la seigneurie du Génitoy (puis Génitois, jadis Genestay). Situé jusqu'en 1825 sur la commune de Jossigny (Seine-etMarne), aujourd'hui appartenant à la commune de Bussy Saint-Georges, le château du Génitois, en ruine, n'est distant que de $1700 \mathrm{~m}$ de celui de Jossigny (lui resté sur la commune de Jossigny), construit en 1743, remplaçant un ancien manoir. Ce lien entre les Sanguin de Jossigny et ceux de Livry semble vraisemblable, mais non documenté. Bien qu'il ait existé une seigneurie de Jossigny, sise à Monthyon, près de Meaux (Seine-et-Marne), dans l'état actuel des connaissances aucune de ces deux familles n'a ni possédé ni même habité le château de Jossigny. En me fondant sur plusieurs éléments ténus mais 
complémentaires : homonymies, chronologie, relations, nom sous lequel est déclaré Pierre (Sanguin de Livry : voir plus haut), le fait que les deux François Hippolyte étaient chevaliers de l'Ordre de Malte - François Hippolyte Sanguin de Livry depuis le 25 novembre 1721 (il quitta la Croix de Malte en 1760)-, alors que La Roque (1891: 226) ne mentionne dans son Catalogue qu'un seul Hippolyte François Sanguin (de Livry) admis dans l'Ordre, j'en viens à émettre ici une hypothèse osée mais étayée selon laquelle François Hippolyte Sanguin de Livry et François Hippolyte Sanguin père des (de) Jossigny n'étaient qu'un. François Hippolyte Sanguin aurait d'abord vécu, au moins de 1748 à 1756, avec Marie Françoise de Vallois, dont il eut cinq enfants. Sa compagne mourut (d'où les trois orphelins) et le 6 juillet 1760 (il a déjà 45 ans), François Hippolyte Sanguin, devenu formellement marquis de Livry à la mort de son frère aîné Paul Sanguin (1709-1758), épousa à Paris, hôtel de Saint-Aignan, la riche héritière Bonne Anne Thérèse Gillain de Bénouville, âgée elle de 25 ans, dont il eut six enfants. Le contrat de mariage avait été signé par le roi Louis XV. Dans un travail sur le château de Bénouville, tout en déplorant n'avoir que des informations très fragmentaires à propos du couple, Pain (2007: 10-11) s'est hasardé à écrire : "Le 5 juillet 1760 il [François Hippolyte] épouse (en secondes noces ?) Bonne Thérèse Gillain de Bénouville...", confortant ainsi l'hypothèse d'un premier mariage. Quant au nom avec particule de Jossigny, il fut ajouté à un moment indéterminé au patronyme des enfants nés de Françoise de Vallois. La marquise, sans doute au fait de l'origine des Sanguin de Jossigny, des " trois orphelins ", s'y serait attachée et aurait cherché à les aider; sa correspondance montre qu'elle était régulièrement informée de leurs entreprises. Deux lettres de Jossigny à elle adressées montrent une déférence : "Votre très humble et très dévoué serviteur " précède la signature, mais c'était alors la formule habituelle dans toute correspondance (Fig. 2). Apparemment son époux n'intervint pas, sauf peutêtre pour placer les frères Jossigny comme officiers, aides de camp pour les uns et sous-lieutenant pour l'autre... loin de lui, outre-mer. L'attitude de ce père, si cette hypothèse s'avère fondée, est plus que blâmable à nos yeux, mais elle était sans doute conforme à celle d'autres nobles de l'époque. Notons qu'aucune des études généalogiques consultées concernant la famille Sanguin de Livry n'inclut la « lignée » de Jossigny (Badier 1786; Anonyme 2014c-g).

\section{L'isle de France - Le dessinateur de COMMERSON}

Le 4 août 1764 l'Isle de France, de même que Bourbon - future Réunion - avait été rétrocédée par la Compagnie des Indes à la Couronne de France, par application d'un arrêt du 8 avril précédent. À partir de 1767 les Mascareignes étaient effectivement commandées, depuis l'Isle de France, par un officier, le gouverneur général, qui avait l'autorité suprême et commandait les troupes de terre et de mer, et par un intendant, sorte de gouverneur civil, administrateur et gestionnaire; les limites du pouvoir de chacun n'étaient pas toujours précises. À Bourbon, ils étaient représentés respectivement par un commandant particulier et un commissaire général ordonnateur. Paul de Jossigny arriva à Port-Louis, Isle de France, à

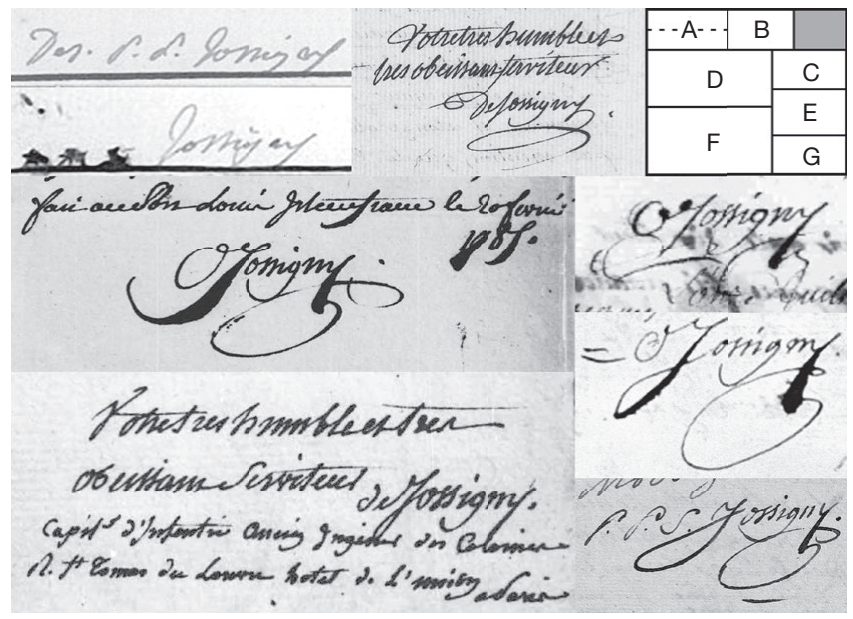

FIG. 2. - Signatures de Paul Philippe Sanguin de Jossigny: A, vers 1770, paternité des dessins (MNHN, manuscrits 282-1, fol. 7 et 14); B, 1776, lettre adressée à la marquise de Bénouville; "Votre tres humble et tres obeissant serviteur » (AOM, E 231: 60); C, 1778, parrain de Rosalie Duparc (NAM, KA 61 : 40); D, 1785, mémoire des activités aux Mascareignes; « fait au Port Louis Isle de France le 20 fevrier 1785 " (AOM, E 231: 82); E, 1787, mariage avec Pétronille Fontaine; (NAM, KA 92: 9); F, 1790, lettre au secrétaire d'État à la Marine La Luzerne; "Votre tres humble et tres obeissant serviteur / Capitne d'Infanterie Ancien Ingenieur des Colonies / R. St Tomas du Louvre hotel de L'Union a Paris " (AOM, E 231: 114); G, 1795, parrain d'Adélaïde Sanguin (Archives du Val-d'Oise, Sarcelles, 3E160 16:85). Abréviations: MNHN, Muséum national d'Histoire naturelle; AOM, Archives nationales d'outre-mer; NAM, National Archives of Mauritius.

bord du vaisseau Le Sphinx, commandé par le comte Charles Jean d'Hector. Sur le premier épisode connu de la vie active de Jossigny les interprétations divergent, mais on peut maintenant clarifier les évènements. On sait qu'il a été d'abord employé comme aide de camp du gouverneur général François Julien du Dresnay, chevalier des Roches, ou Desroches (17191786). Les différentes versions qui relatent cette période ne s'accordent pas sur le point de départ des fonctions de Jossigny, tout en admettant invariablement une arrivée à l'Isle de France en 1768 (e.g., Ly-Tio-Fane 1976: 59; Monnier et al. 1993: 109). Comme Desroches n'est devenu effectivement gouverneur que le 6 juin 1769, jour de son arrivée sur l'île, ce n'est pour certains qu'à ce moment que débuta l'activité d'aide de camp de Jossigny.

En fait, c'est près d'un an plus tôt, le 22 juillet 1768, que Desroches avait été désigné pour remplacer Jean Daniel Dumas (1721-1794), son prédécesseur relevé de ses fonctions en raison de sa mésentente avec l'intendant Pierre Poivre (1719-1786). Après le départ de Dumas, Jean Guillaume de Steinauer, alors brigadier général, futur commandant administrateur de Bourbon (à partir de 1773), assura l'intérim du 27 novembre 1768 jusqu'à l'arrivée du titulaire Desroches, épisode souvent oublié. Dans un mémoire daté de 1781, sorte de curriculum vitae, et dans ceux qui suivirent jusqu'en 1786, Jossigny a bien indiqué, pour 1768 (il a alors 18 ans) : "Ayde de Camp de Mr Le Chevier des Roches gouverneur général des Isles de France \&oc. ", mais sans plus de précision. En 1782 Desroches, complétant l'un de ces mémoires, présenta un témoignage plus circonstancié permettant de préciser sans ambiguïté la genèse de ses relations avec Jossigny : "Je certifie que M. de Jossigny 
qui présente le mémoire cy dessus sest embarqué avec moi en 1768 en qualité de mon aide de camp pour servir dans la colonie que j'allais gouverner. Pendant la traversée qui a duré six mois (y compris une escale à cadiz) il s'est conduit d'une façon à se faire distinguer avantageusement par sa sagesse et par ses talens et dès lors il en donna des preuves dont je fus très satisfait à la côte d'Espagne, à cadiz même, aux côtes dafrique depuis le Cap de bonne Espérance jusqu'aux terres natales et aux atterages de rodrigue et de L'isle de france ". Ce témoignage de Desroches, homme intelligent et cultivé, est tout à fait fiable ; confirmant celui de Jossigny, il nous apprend que lui et son aide de camp se connaissaient dès leur départ de Brest, le 10 décembre 1768; cette date précise est donnée par Desroches lui-même, dans un autre document, une lettre adressée au ministre de la Marine, César Gabriel de Choiseul-Chevigny, duc de Praslin (17121785) (Morel 2011b). En conclusion Desroches et Jossigny ont voyagé ensemble sur Le Sphinx et ont débarqué à l'Isle de France, non pas en 1768, mais le 6 juin de l'année suivante, après un " atterage " [une approche] de l'île Rodrigues. Les biographes intéressés par Jossigny qui ont donné 1768 comme année de son arrivée à l'Isle de France sont donc dans l'erreur, comme ceux qui ont fixé en 1769 le début de ses activités en tant qu'aide de camp du gouverneur Desroches.

Jossigny résuma lui-même, en 1775 , le début de son aventure à l'Isle de France : "[...] il [c'est-à-dire lui-même] s'est embarqué par ordre du Ministre sur le vaisseau du Roy le Sphinx pour passer à l'Isle de France en qualité d'aide de camp de M. le Chevalier des Roches, arrivé à destination il a dessiné par ordre des chefs l'histoire naturelle». En effet Pierre Poivre, l'intendant des Isles de France et de Bourbon, déjà célèbre pour sa recherche des épices, lui-même doué pour le dessin et la peinture, avait très probablement, comme Desroches, remarqué les " talens » de Jossigny, dont ses capacités de dessinateur. Pourtant, ce n'était pas pour Jossigny une vocation, car sa protectrice, la marquise de Bénouville, écrivit en 1774 : "Il a dessiné l'histoire naturelle avec beaucoup de succès il y a eu d'autant plus de mérite qu'il n'avait jamais essayé le genre [...] ». Bien qu'il se brouillât rapidement avec Poivre, le nouveau gouverneur Desroches, qui appréciait déjà Jossigny, partagea le jugement de l'intendant, et l'aide de camp fut présenté au médecin botaniste Philibert Commerson, membre du voyage de circumnavigation de Louis Antoine de Bougainville (1729-1811). Embarqué sur L'Étoile, Commerson avait débarqué à l'Isle de France le 8 novembre 1768, avec de nombreuses caisses d'échantillons récoltés durant l'expédition (pour les détails du voyage de Bougainville, consulter l'ouvrage monumental de Taillemite 1977). Pierre Poivre l'avait accueilli avec les honneurs, décidé à rester à l'Isle de France, et installé dans l'hôtel de l'Intendance à Port-Louis, où il avait lui-même ses appartements (Morel 2011b) - et non pas à la résidence Monplaisir aux Pamplemousses comme il est souvent écrit $\left(^{*}\right)$. De même qu'avec l'accord de Bougainville il avait convaincu Commerson de rester à l'Isle de France, Poivre sut convaincre Jossigny d'être son dessinateur.

Pierre Sonnerat (1748-1814), petit-neveu et filleul de Poivre, débarqué comme Commerson en novembre 1768, officiellement engagé en qualité de secrétaire ou " commis aux écritures » de l'intendant, avait lui aussi été présenté au naturaliste, par son parrain. Comme Jossigny, il dessina pour Commerson plantes et animaux, mais jusqu'en octobre 1770 seulement, puis à partir de juin 1772, à son retour des Moluques; il ne voyagea jamais avec le naturaliste et rapporta au Cabinet du Roi, en 1773, ses propres collections. Cette rencontre fut, pense-t-on, à l'origine de sa vocation : rapidement, Sonnerat montra son indépendance, comme voyageur passionné d'histoire naturelle et comme dessinateur, mais contrairement à ce que suggère le titre de son ouvrage le plus connu (Sonnerat 1776), il n'est pas allé jusqu' en Nouvelle-Guinée. Certains des oiseaux prétendument observés sur cette île n'étaient que des peaux, entre autres celles offertes à Commerson par Joseph Banks; Jossigny a dessiné ces oiseaux, puis Sonnerat a repris et publié les figures en s'en attribuant la paternité (Olsen 2001: 19; pour la biographie de Sonnerat, voir notamment Ly-Tio-Fane 1976 et Morel 2013). Ce qui est certain, c'est que Commerson était satisfait de l'aide apportée par ces deux artistes, au moins pour les figures de poissons, car dès le 6 février 1770 il écrivait à Bernard de Jussieu : "Détourné depuis plusieurs mois par les soins assidus que je donne à deux dessinateurs qui me font la plus belle ichtyographie qui ait encore paru, je ne me suis trouvé rien d'assés pret ni d'assés frais pour vous l'envoyer, mais ce n'est qu'affaire remise " (Cap 1861: 122).

Dans l'intitulé d'un manuscrit de Commerson conservé au Muséum national d'Histoire naturelle de Paris, le Ms 886 (voir Laissus 1978: 155), Secundae lineae ad historiam naturalem insularum Borbonicarum spectantes quibus nempe cursim adumbrantur, tum animalium, tum vegetabilium, tum mineralium species, quae nobis observabantur anno 1769, cette indication de l'observation d'animaux, de plantes et de minéraux de Bourbon (aujourd'hui La Réunion) laisse penser que le botaniste se serait rendu une première fois, en 1769, sur cette île pour y collecter; cependant aucun autre document d'archive, tel le catalogue de son herbier extrait de l'inventaire de ses biens (Anonyme 1871), ne confirme une telle mission; Morel (comm. pers. décembre 2014) n’y croit pas, et je le suis ici. En revanche, un séjour à Madagascar était prévu depuis longtemps, souhaité par le ministre, mais retardé en raison des problèmes de santé du naturaliste. Finalement, accompagné de Jossigny - et non de Sonnerat $\left(^{*}\right)$-, Commerson s'embarqua le 11 octobre 1770 sur L'Ambulante, commandée par le baron Marc Antoine Nicolas Gabriel de Clugny (1741-1792), enseigne des vaisseaux du Roi, futur gouverneur général de la Guadeloupe, qui connaissait bien Madagascar. Cependant, la frégate n'appareilla que le 15 ou le 16 octobre 1770, pour gagner le fort Dauphin, établissement des Français sur la Grande Île, futur Fort-Dauphin (de nos jours Faradofay, puis Tôlagnaro). Jossigny, " chargé de la partie $d u$ dessein ", représenta principalement des plantes, mais aussi divers animaux que lui remettait Commerson. Le naturaliste et ses compagnons ne s'éloignèrent pas du fort Dauphin : "ses plus grandes excursions ont conduit au plus à quatre ou cinq lieux de la ville" (Grandidier 1872: 1082). C'est par erreur que l'on a écrit que l'un et l'autre gagnèrent Foulpointe, aujourd'hui Mahavelona, et la baie d'Antongil, aujourd'hui Helodranon'Antongila $\left(^{*}\right)$. L'Ambulante quitta Madagascar le 3 ou le 4 décembre, et la frégate dut rejoindre 
Bourbon, y accostant vers la fin de décembre 1770 , et non

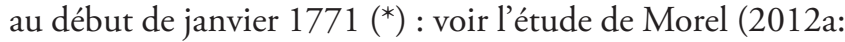
8 ), à laquelle on peut adjoindre le fait que l'herbier de Commerson (Anonyme 1871) inclut des plantes récoltées à Bourbon en décembre 1770. Commerson lui-même écrivit qu'il avait passé trois mois et demi à Madagascar, mais d'après la date de l'appareillage à l'Isle de France on a une estimation de celle de l'arrivée au fort Dauphin, et on connaît celle du départ précipité pour Bourbon : le séjour à Madagascar a en réalité duré moins de deux mois, le voyage depuis l'Isle de France jusqu'à Bourbon à peu près deux mois et demi. Pour Madagascar, Lacroix (1938: 7) donne, par erreur, « août 1770 à janvier 1771 ", soit un séjour de cinq à six mois, mais Morel (2012a) l'estime raisonnablement à une quarantaine de jours.

Commencé par une escale forcée qu’imposaient à la fois la météorologie et la santé du naturaliste, le séjour en partie commun de Commerson et Jossigny sur Bourbon s'étendit sur presque une année : les administrateurs Guillaume Léonard de Bellecombe (1728-1792), commandant, et Cyr Honoré de Cullo de Crémont (1731-vers 1800), ordonnateur (intendant), les invitaient à étudier désormais l'histoire naturelle de Bourbon. La collaboration débuta mal; dès le 18 janvier ces administrateurs écrivirent à Desroches et Poivre : "Le Sr Jossigny qui était employé sous les ordres de $M$. Commerson, docteur en médecine de la faculté de Montpellier, débarqué en cette île de la flùte du Roi l'Ambulante à son retour du Fort Dauphin, et qui se propose de faire ici quelque séjour pour continuer les mêmes recherches pour la botanique qu'il a déjà faites avec tant de succès à l'Isle de France, le Sr Jossigny, disons-nous, ne pouvant résister au travail forcé et pénible auquel il était journellement assujetti par un homme aussi zélé dans sa partie que l'est $M$. de Commerson, a été obligé de le quitter et de porter ses vues d'un autre coté " (relevé par Morel 2014a). Cet autre côté était d'assister l'ingénieur en chef Laurent David de Brüe, ce que Jossigny effectua un temps. Par une lettre datée du 8 février Poivre, conscient de cette tension, et toujours attentif aux travaux de Commerson, enjoignit aussitôt aux administrateurs de raisonner Jossigny : "Mon avis se réduit à vous prier, Messieurs, d'engager le Sr de Jossigny, par toutes sortes de moyens, à continuer le travail commencé auprès de $M$. de Commerson. Ce travail sera bientôt fini, et je lui écris de mon côté de prendre patience jusqu'au bout. Dans le cas où il s'obstinerait, je ne vois aucun moyen de l'employer ailleurs" (Monnier et al. 1993: 129; Morel 2014b). Un peu plus tard, à Bourbon, en juin, Crémont exhortait lui-même Jossigny, sans doute réticent, car un second voyage à Madagascar, cette fois à Foulpointe, était projeté : "M. Poivre m'écrit Monsieur pour vous engager à accompagner $M$. de Commerson au cas qu'il fasse le voyage de Foulepointe sur le batimant la Concorde... vous donneriez à $M$. Poivre une preuve bien satisfaisante du désir que vous avez de lui être agréable et vous devez être persuadé qu'il vous en tiendra grand compte». Le voyage ne se fit pas, sans doute à cause de l'état de santé de Commerson, qui néanmoins remercia son collaborateur peu enthousiaste en lui dédiant un genre de Myrtacée créé pour un arbuste de l'Isle de France, un "Bois de Nèfle ", le nommant Jossinia (dessin reproduit par Monnier et al. 1993: 144).
À partir du 12 novembre 1771 une équipe de plus de quarante personnes (il y avait 32 esclaves, engagés comme porteurs), incluant, outre Commerson et Jossigny, l'ordonnateur de Bourbon Crémont, instigateur de l'expédition, et le jeune Jean Baptiste Lislet Geoffroy (1755-1836), " attaché à $M$. de Commerson en qualité d'herboriste ", et qui plus tard relata cette exploration (publication posthume, Lislet Geoffroy 1871), parcourut durant une dizaine de jours la région du piton de la Fournaise. Commerson, souvent excessif avec les durées, écrivit lui-même : "Un déluge continuel de pluies qui nous ont poursuivis pendant 15 jours ou 20 qu'a duré notre voyage " (Crestey 2010). Jossigny y dessina "des vües du Volcan de cette Isle, duquel on ne sétait jamais tant approché [...] ». À tel point que Crémont, qui s'était hasardé « à s'approcher trop près de ce gouffre ardent " faillit chuter dans le cratère, rattrapé in extremis par "la prompte assistance de quelques noirs généreux", selon Magon de Saint-Elier (1839: 156); cette improbable péripétie n'a été rapportée ni par Commerson, ni par Lislet Geoffroy, ce dernier n'évoquant qu'un Crémont très fatigué et incommodé. Peu après, vers le 12 décembre, à bord du navire Le Dragon, Commerson, probablement accompagné de Jossigny, regagna l'Isle de France, où il débarqua aux environs du 1er janvier 1772 .

Une longue promiscuité avec le naturaliste au caractère ombrageux, dont la santé se dégradait (il souffrait de la goutte, d'un ulcère de jambe et de coliques néphrétiques) fut certainement difficile à supporter par le dessinateur. D'autres désagréments, comme l'odeur dégagée par la préparation des poissons en "herbier ", devaient s'y ajouter. On peut supposer qu'au début de leur relation Commerson " faisait du terrain " tandis que Jossigny restait sur place pour dessiner, mais qu'avec le temps le naturaliste souffrant se déplaçait de moins en moins. Le 23 août 1772 Desroches et Poivre quittèrent l'un et l'autre leurs responsabilités aux Isles de France et de Bourbon : deux jours plus tôt, le 21, avaient débarqué de la Belle Poule leurs remplaçants, respectivement Charles Henri Louis d'Arsac, chevalier de Ternay (1723-1780), et Jacques Maillart Dumesle (vers 1730-1782) (Morel 2014c). Rigoureux, Maillart Dumesle n'avait pas l'ouverture d'esprit de l'ancien intendant vis-à-vis des botanistes et il se montrait jaloux et haineux, tant avec Jossigny et Sonnerat, celui-ci de retour des Moluques, qu'avec Commerson : "C'est le type même du fonctionnaire pointilleux et borné " (Role 1973: 169). Selon La Lande (1775) «M. Maillard [sic], successeur de M. Poivre, faisoit peu de cas des sciences" mais La Lande (1776) modéra rapidement son jugement, admettant que l'intendant n'avait fait qu'obéir aux ordres du ministre. J'ajoute par souci d'équité que selon certains Maillart Dumesle « laissa la réputation d'avoir été le plus habile administrateur qu'aient eu ces colonies" (Amanton 1832: 91), pour d'autres "il arrêta les progrès de l'ouvrage de $M$. Poivre; il semblait envieux du bien que d'autres faisaient auprès de lui, et même du bien qui sétait fait avant lui " (Billiard 1822: 278). Peu après son arrivée le nouvel intendant ordonna à Jossigny de quitter et Commerson et l'Isle de France, et de rejoindre Bourbon pour travailler sous les ordres de Crémont, avec les fonctions d'ingénieur en second; ses appointements étaient de 1800 livres par an (ceux 
de Commerson de 3000). À Commerson, qui avait un temps espéré rentrer en France avec Poivre, l'intendant retira, outre son collaborateur, sa résidence - il dut acheter une maison -, et ses subsides furent fortement réduits. L'intendant lui-même souhaitait que Commerson retournât en France, mais la santé du botaniste ne le lui permettait pas. D'après Monnier et al. (1993: 112), en février de l'année suivante le botaniste récoltait encore des échantillons, au jardin de La Villebague, sis à Flacq selon ces auteurs; cependant, le domaine de La Villebague est situé plus au nord, près des Pamplemousses. Quoi qu'il en soit, un mois plus tard, précisément le 13 mars 1773, Philibert Commerson, souffrant déjà de goutte et de dysenterie, mourut de fatigue, de chagrin ou d'une pleurésie, selon les sources. Allorge \& Ikor (2003: 430) ont mentionné une hépatosplénomégalie, symptôme de diverses pathologies : anémie, infection, parasitose... Il avait 45 ans et 4 mois. Il habitait alors chez Monsieur Bézac à La Retraite, Saint-Julien, district de Flacq (Mauritius Archives KE 5: 40, Anonyme 2014a; Morel 2012b). Ce sieur Bézac, qui assista le naturaliste durant ses derniers jours, écrivit à Maillart Dumesle le lendemain du décès; il nota que Commerson "sétait fait porter chez moi de la Villebague, il y a quinze jours [...] » et précisa " [...] il avait un dépôt formé dans la poitrine qu'il a rendu il y a six jours" (Morel 2012b). Jossigny, alors à Bourbon, n’a pas assisté à sa fin, contrairement à ce qui est parfois écrit $\left(^{*}\right)$. Toujours fielleux, Maillart Dumesle, annonçant cette mort au Ministre de la Marine, s'autorisa à ajouter, peut-être par projection : " Il passait pour très débauché, et on le regardait comme un homme très méchant et capable de la plus noire ingratitude".

Comme il avait travaillé avec le naturaliste, Jossigny fut rapidement (17 avril 1773) désigné par Maillart Dumesle pour rapporter de l'Isle de France à Paris, à " Mrs. les Médecins du Roi », ses collections et manuscrits, qui étaient légués par testament à Sa Majesté (Anonyme 2013c). Rentré de Bourbon avec l'accord de Crémont (juin 1773), Jossigny participa au classement et au rangement de cet héritage qui remplissait 34 caisses, décrites par Maillart Dumesle (Morel 2011a). En novembre 1773 La Victoire, capitaine Louis Dominique de Joannis, quittait l'Isle de France pour Lorient : «Le Sr Jossigny, dessinateur qui a travaillé sous $M$. de Commerson au dessin des plantes, partie dans laquelle il réussit très bien, est aussi embarqué sur ce vaisseau, et comme il a suivi le travail sous les yeux mêmes du médecin naturaliste, il pourra mieux que personne donner en France les renseignements dont on pourroit avoir besoin ". Lorient

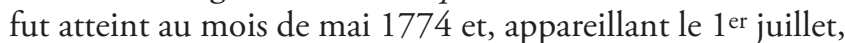
ce fut L'Oiseau, un " chasse-marée ", qui transporta ensuite jusqu'au Havre et à Rouen les 34 caisses d'échantillons et de documents, que finalement Jossigny put remettre, avec ses propres dessins, au "Cabinet du Roy ", le futur Muséum, rencontrant notamment Georges-Louis Leclerc de Buffon et Bernard de Jussieu, âgés respectivement de 67 et 75 ans - lui n'en avait que 24. Aussitôt, " $M$. de Jussieu, le jeune [Antoine Laurent], $M$. d'Aubenton \& $M$. Thoüin, ont commencé à en faire l'examen \& le dépouillement [...] " (La Lande 1775: 113, note). Le 2 août 1774 une lettre adressée à Étienne François Turgot informait le secrétaire d'état à la Marine que la mission de Jossigny était remplie.
L'ISLE DE FrANCE - L'INGÉNIEUR

La tâche étant accomplie, l'administration tarda à la rémunérer, et Jossigny dut patienter plus d'un an et demi à Paris. Il est probable qu'il y rencontra son frère François, revenu pour un temps des Antilles. Un congé de dix-huit mois avait été prévu mais son absence en couvrit trente-trois. En octobre 1775 il obtint finalement une gratification de 1000 livres en complément de ses appointements, grâce au témoignage de satisfaction de Buffon, et suite aux demandes répétées de sa protectrice il fut en même temps breveté ingénieur des Colonies, sous réserve de l'accord de l'intendant. Une gratification exceptionnelle de 400 livres fut de plus attribuée en février 1776 et finalement Jossigny obtint aussi le grade de lieutenant d'infanterie, qu'il avait lui-même sollicité. " A Brest le 22 janvier 1776 [...] le S. de Jossigny sera embarqué sur le vaisseau l'Indien en qualité de passager aux frais du Roi et il lui sera procuré pour l'embarquement de ses effets l'emplacement d'un demi tonneau ». En réalité Jossigny voyagea à bord du Brillant, commandé par François Jean-Baptiste l'Ollivier de Tronjoly, et ce n'est que le 6 juillet 1776 qu'il revint à l'Isle de France. Peu après, le 1er août, Maillart Dumesle, pour des raisons de santé, abandonnait ses fonctions et quittait Port-Louis. Pour Jossigny il n'était plus question de retourner à Bourbon. Il s'installa alors rue du Rempart, à Port-Louis (aujourd'hui rue Edith Cavell; le quartier du Rempart était celui des belles et grandes demeures). Le nouvel ingénieur effectuait des travaux de nivellement, en particulier sur les montagnes de PortLouis et à Grand-Port, ainsi que des sondages du sol, qui lui provoquèrent des maux dont il souffrait encore dix ans plus tard, "une incommodité qu'il conservera le reste de sa vie "; ses appointements étaient de 2400 livres par an, avec une prime annuelle de 1500 livres, notamment pour l'entretien d'un cheval. En 1778 Jossigny assura par intérim les fonctions d'ingénieur en chef, puis il succéda à la Direction des Chemins Royaux à Raphaël Duparc, un autre ingénieur des Colonies.

Ce Raphaël Duparc mérite quelques lignes, car son nom est inscrit sur une table de marbre, jadis appliquée au mur de la cathédrale de Coutances (Manche), derrière le maîtreautel, maintenant conservée dans le Musée de cette ville (Germain 1884; Chennevières 1886) : «ANTOINE DU PARC, ESCUIER ORIGINE / DE LORAINE, NATIF DE MARSEILLE, / SCULPTEUR ET ARCHITECTE. A DON / NE LE DESSEIN, CONSTRUIT ET FAIT / PLACER LAUTEL PRINCIPAL DE CETT ${ }^{\text {E / EGLISE EN }}$ MARBRE. IL EST MORT, LE / I 9 D'AVRIL I755, SANS AVOIR FAIT LES / QUATRE ANGES, QUI SONT PLACES SUR / L'AUTEL. SON FILS RAPHAEL DU PARC / ESCR LES A FAITS : LES DEUX GRANDS / SUR LES MODELES DE SON PERE, LES / DEUX PETITS SUR SES PROPRES / DESSEINS ET MODELES ET LES / A FINIS AU MOIS D'AVRIL I757 / AGE DE VING ET UN AN ». Antoine Duparc (1698-1755) était un artiste renommé, peintre, sculpteur et architecte : voir Achard (1787), Jouin (1886), Billioud (1936, 1937), Sánchez Moreno (1946), Sánchez-Rojas Fenoll (1980), Belda Navarro \& Hernández Albaladejo (2006), Anonyme (2012b). Cet artiste naquit effectivement à Marseille (baptême à La Major le 2 septembre 1698), fils d'Albert Duparc (1661-1721), sculpteur lui-même. Âgé de dix-neuf ans, Antoine émigra en Espagne, à Murcia, où il 
travailla dès 1718 à divers édifices religieux et épousa une espagnole, Gabriele Negrel, probablement d'origine provençale d'après son patronyme; ils eurent plusieurs enfants, et la famille revint à Marseille vers 1730 . C'est là que naquit Raphaël, baptisé à Saint-Ferréol le 7 avril 1736. Antoine partit pour Coutances en 1749, après un séjour en Italie; il aurait transporté à ses frais des statues de Marseille jusqu'à Grandville, par bateau. Après le décès de son père (1755) et l'achèvement de l'autel de Coutances (1757), Raphaël Duparc serait venu à Paris, auprès de sa sœur Françoise (née à Murcia en 1726, décédée à Marseille en 1778), elle aussi artiste reconnue, réputée pour ses toiles. Mais ces évènements déjà exposés au conditionnel se terminent par une étrange contre-vérité : "Londres fut le théatre de sa gloire [celle de Françoise]. On admira ses talents, on y enleva ses productions, et sa fortune s'y accrut en fort peu de temps. Elle revint alors à Paris, où elle ne négligea rien pour rendre heureux le sort d'un frère qu'elle chérissait et qui fut encore enlevé à la fleur de son agge. Cette ligne, c'est toute la vie et la mélancolique épitaphe du pauvre Raphaël» (Chennevières 1886).

En réalité on retrouve le "pauvre Raphaël », bien vivant, en 1761 (il a 25 ans), comme ingénieur volontaire à l'école de mathématique et de dessin de Sedan (ouverte par François Sauvage en 1751, elle disparaitt en 1767), puis à celle du génie de Grenoble, créée en 1764 (dirigée par Pierre Joseph de Bourcet, elle disparait en 1771). C'est le 11 août 1768 qu'il est nommé par le Duc de Praslin, alors ministre de la Marine, «à la place de sous ingénieur aux Isles de France, de Bourbon et Dépendances, avec le brevet de Lieutenant d'infanterie des troupes des Colonies "; il fut ensuite, quelques mois avant sa mort, élevé au grade de capitaine d'infanterie. Le 31 août 1773 Raphaël Duparc épousa Marie Pétronille Fontaine, âgée d'environ 16 ans, originaire de Saint-Pierre (Bourbon). Grâce à l'acte de mariage, dont Patricia Chasteauneuf m'a signalé l'existence (Mauritius Archives KA 59: 104), j'ai pu établir, par celle des parents, l'identité de Raphaël Duparc sculpteur et de Raphaël Duparc ingénieur à l'Isle de France : "Mar. de $m^{r}$. Duparc et de. fontaine - L'an mil sept cent soixante treize le trente et un aoust après la publication de deux bans de mariage, dispense accordée de la troisième, et les fiançailles entre $m$. Raphael Duparc Ingenieur et Lieutenant d'infanterie des troupes des colonies, fils de feu mr. Antoine Duparc ingenieur de sa majesté catholique et de feuë Dame Gabriel Négrel ses père et mère natif de marseil d'une part et demoiselle Petronille fille naturelle de Marie fontainne native de Bourbon et tous deux de cette paroisse, ne s'etant trouvé aucun empechement je soussigné Prefet apostolique les ay mariés et leur ay donné la bénédiction nuptiale selon les formes prescrites par notre mere la Ste Eglise en presence des Srs LeRoux habitant, Patin Bourgeois, Garnier Geographe, Leblanc Employé pour le Roy et autres temoins soussignes avec les conjoints [suivent onze signatures] ». Deux filles naquirent à Port-Louis, Marie Françoise Rosalie Duparc le 18 octobre 1774 et Pétronille Pauline Duparc le 1er juillet 1778 (Mauritius Archives KA 61: 40 et KA 65: 54). Raphaël Duparc n'a pas connu la seconde : il était mort quelques mois plus tôt, le 23 mars 1778, "tombé malade [...] par un excès de fatigue, occasionné par l'activité avec laquelle il remplissoit ses devoirs ", après 11 années de service. L'acte de "sépulture " (Mauritius Archives KA 65: 126) lui a donné 36 ans, alors qu'il en avait 42. Choisi comme parrain de Pétronille Pauline à son baptême, le 11 juillet 1778 , Jossigny était à l'évidence dans les meilleurs termes avec Duparc. Il existe aux Archives des Yvelines (cote 2Fi 70) un plan de Saint-Germain-en-Laye de $40 \times 25 \mathrm{~cm}$ portant la signature des deux ingénieurs : en bas à gauche Duparc f., en bas à droite Par P. P. S. Jossigny. Ce plan sur papier, réalisé à l'encre de Chine et à l'aquarelle, n'a pu être réalisé qu'entre juillet 1776 et mars 1778 , si les deux signataires ont vraiment collaboré à l'Isle de France; le plan est visible sur l'Internet (Anonyme 2013d). Mais Jossigny était aussi en bons termes avec la veuve, Marie Pétronille Fontaine. Le 26 (ou le 27) juin 1780 naquit de leur vie commune une troisième fille, Hélène Sanguin de Jossigny, baptisée le 16 juin 1781 en l'église Saint-François, aux Pamplemousses.

Succédant à Duparc, Jossigny devint par intérim ingénieur en chef, avec un complément de traitement extraordinaire de 1600 livres. Le $1^{\text {er }}$ décembre 1782, appuyé notamment par le fidèle Desroches et par son supérieur direct, le chevalier Desrois, ingénieur en chef depuis 1777, Jossigny était promu capitaine du génie et fut chargé de la direction des Chemins et Corvées (la corvée royale était une prestation en nature imposée aux propriétaires; elle consistait dans l'obligation de fournir gratuitement une main-d'œuvre qui travaillait à l'amélioration du réseau routier par la construction et l'entretien des routes et des chemins) : "Cet officier a des talens, il est le premier des ingénieurs de la colonie et comme il peut être dans le cas de faire les fonctions de chef, il serait convenable de lui donner la Commission de Capitaine; il sert d'ailleurs depuis assez longtemps avec zèle pour obtenir cette grâce. à l'Isle de France le 1er septembre 1781. le Chr Des Roches". Jossigny "sétoit flatté cependant qu'en augmentant en grade son traitement seroit aussy augmenté "; aussi un an plus tard le gouverneur des Isles de France et de Bourbon, le vicomte François de Souillac (1732-1803) sollicita le ministre : «cet officier zélé et instruit et qui est le plus ancien des colonies est dans le cas de joüir d'un traitement audessus de celui quil a».

D’Épinay (1890: 311) a présenté Pierre et Paul Philippe de Jossigny comme étant en 1784 lieutenants dans le régiment dit "de Pondichéry ", le premier dans l'artillerie, le second dans le génie. Le régiment est erroné, de même que le grade de Paul Philippe. Lieutenant depuis 1777 , son frère aîné était nommé capitaine d'artillerie en 1788, incorporé dans le régiment dit "de l'Isle de France ", créé en 1772, dissous en 1791 et reformé en 1792 en devenant le $108^{\mathrm{e}}$ d'infanterie; en 1792 il était aux Indes; on le rencontre encore à Bourbon en 1795, où son esclave Lindor, accusé de recel, est condamné à "être battu de verges et mis à la chaîne de la République pour y servir à perpétuité " (Wanquet 2002). En 1802, toujours capitaine d'artillerie au 108e, il est à Port-Louis (alors Port Nord-Ouest), témoin au mariage de sa nièce par alliance Marie Françoise Rosalie Duparc avec Jean François Bourgain (Mauritius Archives KA 139: 22; orthographe sur l'acte: Bourguain). Il n'est plus recensé dans son régiment en 1806 (Doyen c. 1860). 
Les deux frères Jossigny ont été francs-maçons, mais parmi les quelques renseignements disponibles certains se contredisent. Selon un Index des francs-maçons par loge, en relation avec les Mascareignes (Perret 2003), Pierre de Jossigny, lieutenant d'infanterie, était en 1783 membre de la loge maçonnique de La Parfaite Harmonie, créée en 1777 à Saint-Denis, Bourbon; en 1788, il était membre de la loge Saint Alexandre d'Écosse à Paris. Une partie de ces données ne concorde pas avec celles concernant Paris relevées par Le Bihan (1966: 291) et intégrées dans le fichier Bossu (Bossu 1987) : Pierre de Jossigny, lieutenant puis capitaine d'artillerie, était en 1789 membre du Chapitre Métropolitain, et c'est Paul de Jossigny, capitaine d'infanterie, qui était membre de la loge Saint Alexandre d'Écosse, initié le 26 juillet 1788. Pour Paris cette seconde référence est ici considérée comme la bonne, en raison des grades militaires respectifs comme de la notoriété des auteurs, historiens de la franc-maçonnerie. Pour Saint-Denis (Bourbon) le doute subsiste sur l'identité du frère Jossigny : d'après la date (1783) le membre de la loge de La Parfaite Harmonie pouvait être l'un comme l'autre. La réponse existe probablement dans les archives privées de l'actuelle loge L'Amitié, qui incluent celles de La Parfaite Harmonie (Wanquet 1992: 67).

Le corps des ingénieurs fut supprimé par une ordonnance du 14 mars 1784, appliquée à compter du 31 mars 1785. Paul Philippe, visé par cette décision, espérait la conservation du poste de Grand Voyer (responsable de la construction et de l'entretien des routes) qu'il assurait, mais en vain. Jossigny fut réformé et pensionné le 31 décembre 1786 et il dut quitter l'Isle de France - où il avait passé une quinzaine d'années, dont dix comme ingénieur avec brevet d'officier pour la métropole. Consolation, par l'intervention, une fois encore, de la marquise de Bénouville, il fut proposé pour entrer dans l'ordre royal de Saint-Louis, et admis comme chevalier; cette distinction était accompagnée d'une rente. Son frère Pierre eut le même honneur. Juste avant son départ, le 19 février 1787, dans la paroisse de Port-Louis, Paul Philippe de Jossigny épousa Marie Pétronille Fontaine; en même temps les parents reconnurent et légitimèrent leur fille Hélène, qui avait déjà sept ans et demi (Mauritius Archives KA 92: 8-9; Fig. 3). Le frère du marié, Pierre Sanguin de Jossigny, « lieutenant en premier dans le corps Royal de l'artillerie de l'Isle de France ", était parmi les témoins. Un contrat de mariage avait été établi le 17 février. Les filles de Pétronille Fontaine et de Raphaël Duparc restèrent à l'Isle de France avec leur mère. Elles se marièrent et eurent une importante descendance : Marie Anthoine de la Hausse de la Louvière (1758-1815), capitaine au 108e régiment comme Pierre de Jossigny, épousa successivement les deux sœurs, en 1794 et en 1801 respectivement, l'aînée ayant de lui trois enfants, la cadette six. Marie Pétronille Fontaine mourut à Port-Louis le 12 juin 1811; sa fille cadette, Pétronille Pauline, l'avait précédée le 12 mai 1810, et l'aînée, Marie Françoise Rosalie, les suivit le 23 novembre 1815. Quant à Hélène, il semble qu'elle $\mathrm{a}$, tôt ou tard, rejoint son père en France; restée célibataire, elle mourut à Paris à son domicile, 5 rue Thérèse, le 6 mai 1855 : elle avait presque 75 ans.
RETOUR EN FranCE

Les activités de Paul de Jossigny après son départ de l'Isle de France - il n'avait alors que trente-sept ans - sont à peine connues. En septembre 1787 il était à Versailles et sollicitait auprès du ministre des Affaires étrangères et secrétaire d'État à la Marine par intérim Armand Marc Aurelle, comte de Montmorin Saint-Hérem (1745-1792), d'être nommé ingénieur géographe de l'Isle de France, avec brevet de major. En septembre 1788 le vicomte François de Souillac, successeur de Steinauer comme commandant de Bourbon (de 1776 à 1779) puis, jusqu'en 1787, gouverneur des Isles de France et Bourbon, et finalement des Établissements français au-delà du Cap de Bonne-Espérance, soutenait résolument sa requête, énumérant à nouveau ses mérites et ses qualités : « [...] je lui dois la justice de vous assurer quill a été de la plus grande utilité pour le service du Roy, quil entend parfaitement la bonne construction des ouvrages relatifs au génie, quil a été d'un grand secours aux officiers du corps Royal du génie par la connaissance quil a de l'architecture civile; quil a été particulièrement chargé des chemins qui lui doivent leur perfection; que son zèle enfin, son intelligence et son âge ne devoient pas lui faire craindre la reforme qu'il a éprouvée ". Et l'on reconnaît que c'est sous le gouvernement de Souillac à l'Isle de France (mai 1779avril 1785 , puis jusqu'en novembre 1787) que Port-Louis a véritablement pris l'aspect d'une ville (Toussaint 1972). Manifestement, tous les gouverneurs, intendants, ordonnateurs et autres administrateurs sous l'autorité desquels Jossigny avait travaillé étaient satisfaits de l'homme et de son travail. Mais ce fut sans résultat positif, et Jossigny dut alors abandonner tout espoir de retourner aux Mascareignes.

Apparemment, revenu à Paris, Jossigny ne se risqua guère à mettre de nouveau à profit ses talents de dessinateur naturaliste. Dans le grand ouvrage botanique de L'Héritier (1785: 47, pl. 24), une planche porte la mention « Jossigny del. »; elle représente une espèce mauricienne décrite par Commerson, Ehretia internodis. Jossigny étant alors aux Mascareignes, il est probable que l'auteur et le graveur aient tenu à mentionner le dessinateur de la figure originale, à son insu. Par ailleurs, en 2011, une vente aux enchères a proposé un ensemble de quatre aquarelles figurant des poissons marins de l'Indopacifique, sans date, sans origine, avec l'indication « 4 poissons dessinés par M. Dejossigny d'après nature tirés de la collection qui est au jardin du Roy"; ; je n'ai pu en apprendre davantage auprès du vendeur. De son côté le Muséum ne chercha pas à joindre le collaborateur de Commerson, bien que des scientifiques de premier rang tels que Louis Leclerc de Buffon (1707-1788) ainsi que, selon Cheke (2009a), son collaborateur Philippe Guéneau de Montbeillard (1720-1785), Jean Hermann (1738-1800), Jean Baptiste de Lamarck (1744-1829), Antoine-Laurent de Jussieu (1748-1836), Bernard Étienne de Lacépède (17561825), puis Georges Cuvier (1769-1832), Étienne Geoffroy Saint-Hilaire (1772-1844) et Achille Valenciennes (17941865) aient plus ou moins copieusement utilisé manuscrits et dessins remis par Jossigny. Ce qui n’a pas empêché Cuvier d'être, comme c'était fréquent, critique : «Le second [dessin] est de Jossigny, à la pierre noire. On n'y voit aucunes pointes, et il y a onze épines marquées confusément à la dorsale. Ni l'un ni 


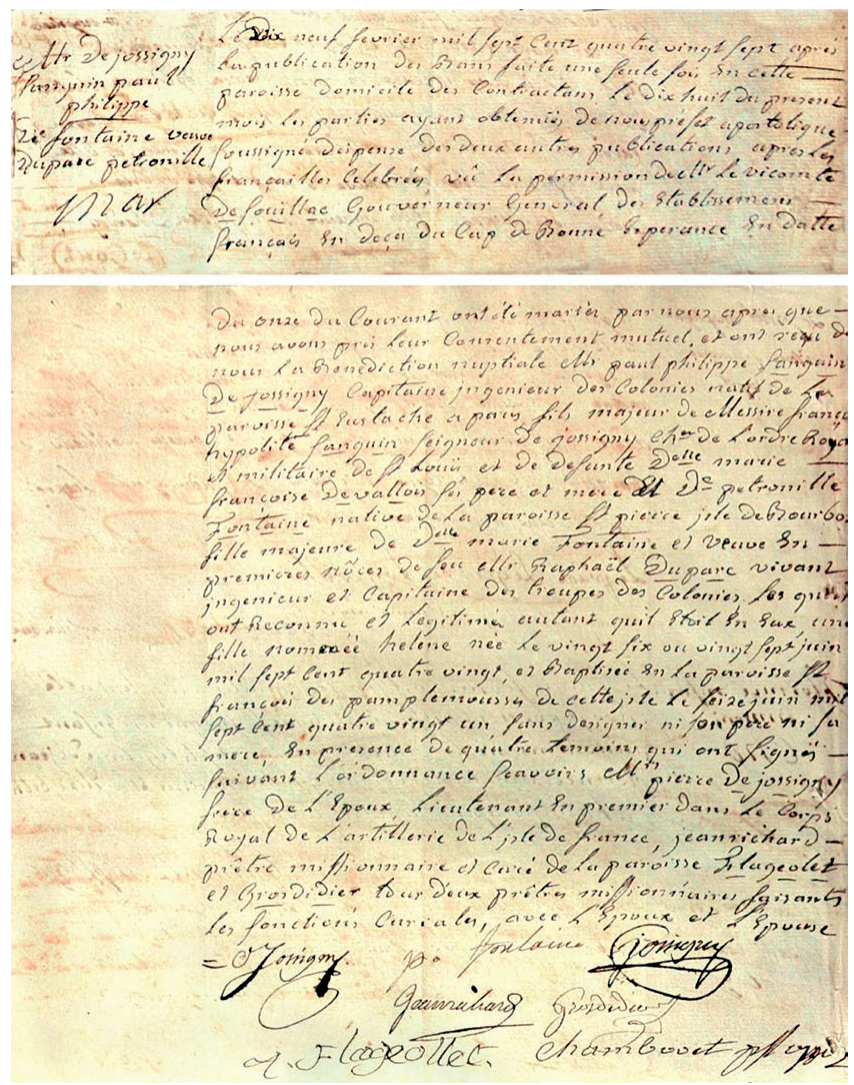

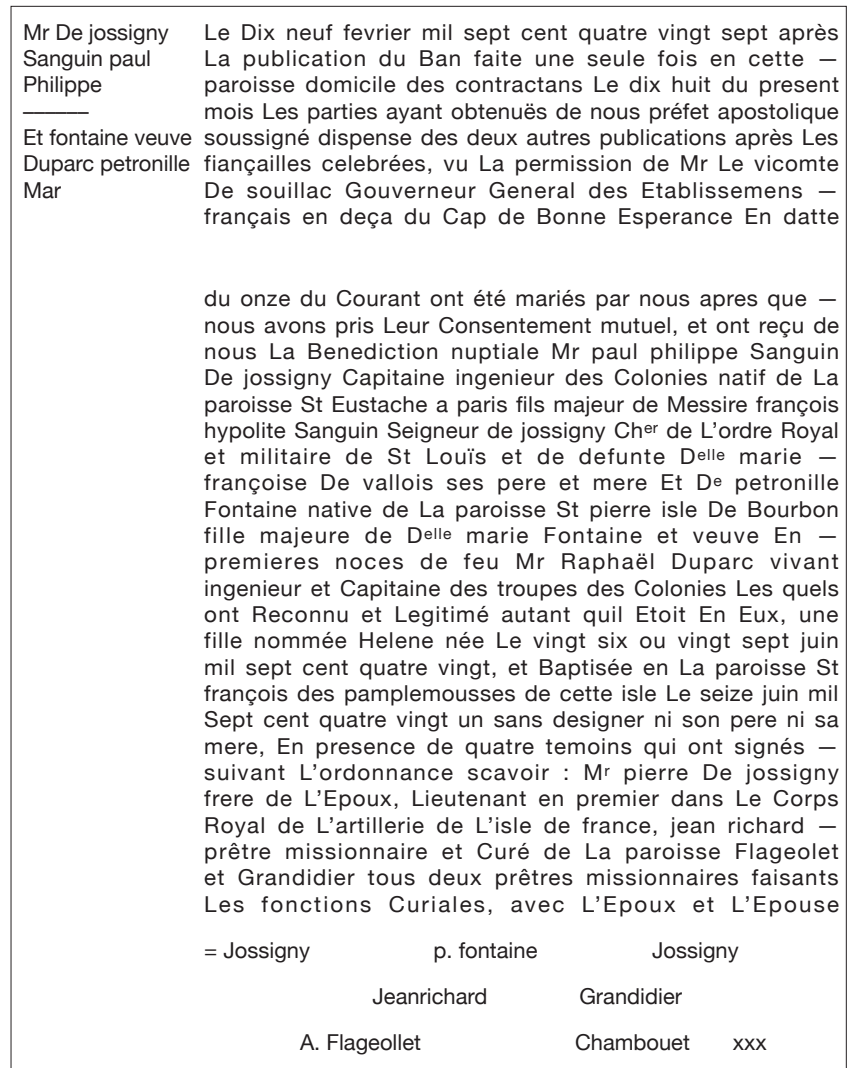

FIG. 3. - Acte de mariage de Paul Philippe Sanguin de Jossigny et de (Marie) Pétronille Fontaine, le 19 février 1787 à Port-Louis. Les parents ont reconnu leur fille Hélène, née le 26 ou 27 juin 1780. Pour de Souillac le prêtre a écrit par erreur « Gouverneur General des Etablissemens français en deça du Cap de Bonne Esperance ", la formule correcte étant bien sûr " au-delà ", ce qu'il était depuis le 15 août 1784. Document original des National Archives of Mauritius, référence KA 92, 8-9.

l'autre n'est étiqueté par Commerson, et il ne parait pas les avoir revus; ce qui explique les inexactitudes de détail qu'ils présentent: inexactitudes auxquelles d'ailleurs Jossigny était fort sujet, comme on peut s'en assurer par plusieurs de ses autres dessins, qui sont plus d'un artiste que d'un naturaliste " (Cuvier \& Valenciennes 1828: 292). En revanche, bien qu'ils aient eu connaissance de ces documents, Constant Duméril et Gabriel Bibron s'en sont à peine servis, mentionnant uniquement " Testudo madagascariensis " (voir plus bas) et la confirmation par Commerson de l'association du poisson Rémora avec les tortues marines (Duméril \& Bibron 1835: 85, 524).

"A partir de cette date [1790], on perd sa trace. Peut-être fut-il entraîné dans la tourmente révolutionnaire " (PinaultSørensen 1989: 152). En 1790, à Paris, Jossigny était logé à l'hôtel L'Union, 3 rue Saint-Thomas-du-Louvre (rue qui menait du Palais-Royal à la Seine et disparut vers 1850 : aujourd'hui elle borderait la Pyramide du Louvre); il demanda à l'administration des accommodements financiers pour son épouse, veuve Duparc, et ses deux filles, âgées de 12 et 16 ans. Ensuite celles-ci semblent disparaître de son existence, la réciproque n'étant pas vraie : à l'Isle de France, en 1801, sur l'acte de mariage de Pétronille Pauline Duparc il est précisé, à propos de sa mère, "citoyenne marie Petronille fontaine actuellement Epouse du citoyen Jossigny » (Mauritius Archives KC 118: 2), et l'année suivante l'épouse signa elle-même, comme témoin, Fontaine Jossigny (Mauritius Archives KA 139: 22). Désormais installé à Paris, Jossigny épousa Marie Lecler (à une date inconnue, peut-être après le décès en 1811 de Marie Pétronille; au moins deux actes d'état civils, postérieurs, précisent bien épouse); il eut avec elle un fils, Paul Henry Sanguin Jossigny (la particule est supprimée vu le moment), né le 18 juillet 1792, baptisé le lendemain à Saint-André-des-Arts; sa propre fille, Hélène, avait alors 12 ans. Sur l'acte de naissance de ce fils Paul Philippe est signalé comme étant "Bourgeois de Paris »; le couple habitait alors rue de l'Hirondelle (tout près de la place Saint-Michel). Le 31 mai 1793, sous la Terreur, Jossigny fut arrêté comme suspect, en même temps que les frères Antoine Aglaé Hippolyte Sanguin de Livry (1762-1828) et Hippolyte Sanguin de Livry (1765-1834), fils de son ancienne protectrice, la marquise de Bénouville - probablement ses demi-frères (Tuetey 1908: 430, 443). Cette arrestation n'eut apparemment pas de conséquences pour lui, mais les deux frères furent emprisonnés et échappèrent de peu à l'échafaud. Dans ce groupe de suspects en réunion interpellés figuraient également Jacques-Dominique Hermann (1764-1852), " musicien de la ci-devant Reine " et Hue de Miromesnil, probablement Bernard François Thomas (1768-1822), officier au régiment des Gardes françaises qui avait été dissous le $1^{\text {er }}$ septembre 1789. En 1795 Jossigny demeurait rue Mazarine; le 10 prairial an III (29 mai) il se rendit à Sarcelles, étant témoin à la déclaration de naissance d'Adélaïde Madeleine Aglaé Sanguin de Livry, fille d'Antoine 


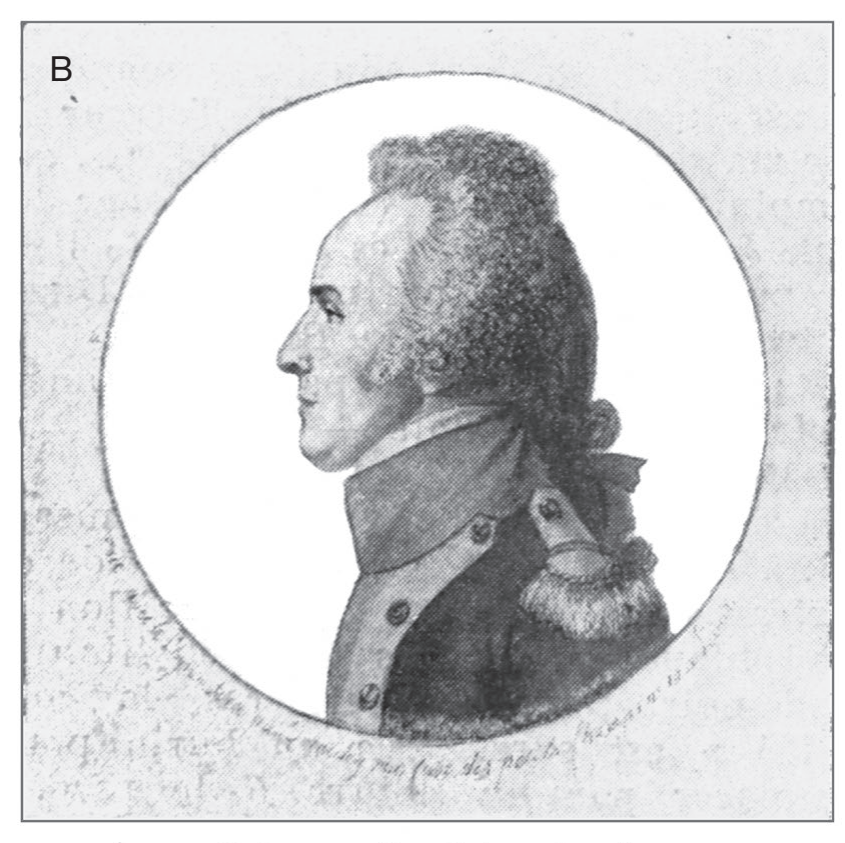

A

« K 1 »- Capitaine Jossigny.

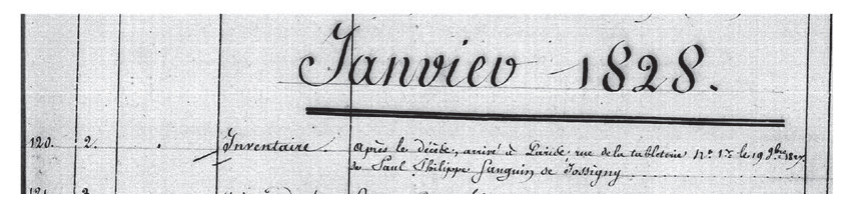

FIG. 4. - A, Acte notarial (inventaire) reportant le décès de Paul Philippe Sanguin de Jossigny à Paris rue de la tablet[t]erie, $n^{\circ} 1$, le 19 novembre 1827 (Archives nationales, répertoire du notaire Jean Eustache Montaud); B, portrait dessiné au physionotrace et gravé par Edme Quenedey à Paris dans les premiers mois de 1790. Sous le portrait l'artiste a écrit « [Dessiné et gravé] avec le Physionotrace par Quenedey rue Croix des petits champs $n^{\circ} 10$ à Paris ". Quenedey l'avait catalogué «K1 - de Jossigny ». Hennequin $(1931,1932)$ a estimé avec doute qu'il s'agissait du capitaine Pierre de Jossigny, mais d'après la date et le lieu de l'exécution le portrait peut tout aussi bien être celui de son frère cadet Paul Philippe, lui aussi capitaine. D'après une reproduction de $5 \times 5 \mathrm{~cm}$ dans Hennequin (1932 : 203) qui l'a intitulée « Capitaine Jossigny »; l'original n'est pas localisé actuellement.

Aglaé Hippolyte, petite fille de François Hippolyte Sanguin de Livry et de la marquise Bonne Anne Thérèse Gillain de Bénouville; celle-ci n'était pas présente. Un mois plus tard, le 8 messidor an III (26 juin 1795) naquit à Paris chez sa mère, rue des Moulins, Paul Philippe Sanguin Jossigny, fils de Paul Philippe (présenté cette fois comme "rentier ") et d'Anne Moran (ou Morand, dont nous ne savons rien). L'enfant mourut sept jours plus tard, le 15 messidor, au Mesnil en France (aujourd'hui Le Mesnil-Amelot, en Seine-et-Marne), rue du Bonnier ou Bosnier. Il devait y avoir des raisons impérieuses pour qu'un enfant de moins d'une semaine soit ainsi déplacé de plus de 30 kilomètres.

Vingt-cinq ans s'écoulèrent, qui virent la grandeur et la décadence de Napoléon 1 er puis la restauration de la royauté. En 1819, déclarant à l'état civil la mort le 21 janvier de son frère aîné Pierre, Paul Philippe de Jossigny fut inscrit sur l'acte comme «Ancien Capitaine au corps du Génie [...] Pensionnaire du Roi "; il habitait alors rue de la Tabletterie (donnant rue SaintDenis et place Sainte-Opportune, elle disparut vers 1853 lors de l'ouverture de la rue des Halles). Comme nous l'avons vu plus haut, vers la fin de sa vie Jossigny demanda le rattachement officiel de « de Jossigny " (avec la particule) à son patronyme Sanguin, ce qui fut accordé le 7 novembre 1821 par une ordonnance royale (Anonyme 1822a). Cette requête avait certainement pour but de mettre un terme aux "Sanguin dit Jossigny ", encore présents dans l'acte d'état civil mentionné ci-dessus. C'est la dernière mention de Paul Philippe de son vivant dont j'ai connaissance : il avait alors 71 ans et demi. Dans un acte notarié conservé aux Archives nationales (Anonyme 2015), un inventaire après décès (répertoire du notaire Jean Eustache Montaud), il apparaît que Paul Philippe Sanguin de Jossigny ne quitta plus la rue de la Tabletterie, habitant au $\mathrm{n}^{\circ} 1$; il mourut chez lui, âgé de 77 ans et demi, le 19 novembre 1827 (Fig. 4A). Au jour près, Commerson était né un siècle plus tôt.

Il existe peut-être un portrait de Paul de Jossigny. Dans les premiers mois de 1790, l'artiste Edme Quenedey (17561830) a tracé, à l'aide du physionotrace, puis gravé le visage d'un de Jossigny. Dans une liste directement fondée sur des notes manuscrites de Quenedey, L'Intermédiaire des Chercheurs et des Curieux (Anonyme 1892: 200) mentionne le premier un portrait de de Jossigny, réalisé en utilisant ce grand pantographe vertical qu'était le physionotrace. Plus tard, le spécialiste Hennequin $(1931: 85,155)$ tenta sans certitude d'y reconnaître le frère aîné Pierre : "JOSSIGNY [K1, à g. ; 45 à 50 ans, en uniforme (épaulette; ancre sur les boutons, semble-t-il)] Vraisemblablt le capitaine J., mentionné à lEtat milit. de 1793 dans les cadres du 108e rég. d'infie, régiment colonial remplaçant l'ancien régt (colonial aussi) dit de l'île de France [...]". Bien que méticuleux, Hennequin s'est uniquement fondé sur ce document (Hennet 1903: 175), parce que c'était le seul à sa disposition mentionnant un Jossigny. Cependant, depuis 1787, c'est Paul Philippe qui était à Paris, Pierre n'ayant définitivement quitté les Mascareignes qu'au début du XIXe siècle. Aucun document n'atteste une longue permission de ce dernier en 1789 et 1790 , le voyage aller vers la France comme le retour vers l'Isle de France pouvant durer six mois; un séjour avéré aurait inclus l'agrégation à la loge du Chapitre Métropolitain et la rencontre avec Quenedey. Il est donc tout aussi vraisemblable que ce portrait soit celui de Paul Philippe Sanguin de Jossigny; notons que les frères avaient alors respectivement 41 et 40 ans, et non 45 à 50 . La Bibliothèque nationale de France ne possède pas cette gravure; la Fig. 4B est fondée sur la figure K1 dans Hennequin (1932: 203), qui reproduit l'estampe originale.

Le fils de Paul Philippe suivit lui aussi une carrière militaire. Nommé sous-lieutenant en 1821 (il a 29 ans) et lieutenant en 1826, Paul Henry Jossigny fut officier à la Maison militaire du Roi, dans les gardes du corps de Monsieur (le futur Charles X) jusqu'en 1824, ensuite dans les gardes du corps du Roi (Régiment de Rivière, puis Grammont) jusqu'en 1829 (Anonyme 1822b-1829). Ex-officier de cavalerie, il épousa à Paris, à Saint-Eustache, le 1er octobre 1831, Henriette Sarda, " rentière ». À cette date, selon l'acte de mariage, ses parents Paul Philippe Sanguin de Jossigny et Marie Lecler, son épouse, étaient décédés. Veuf, Paul Henry se remaria 

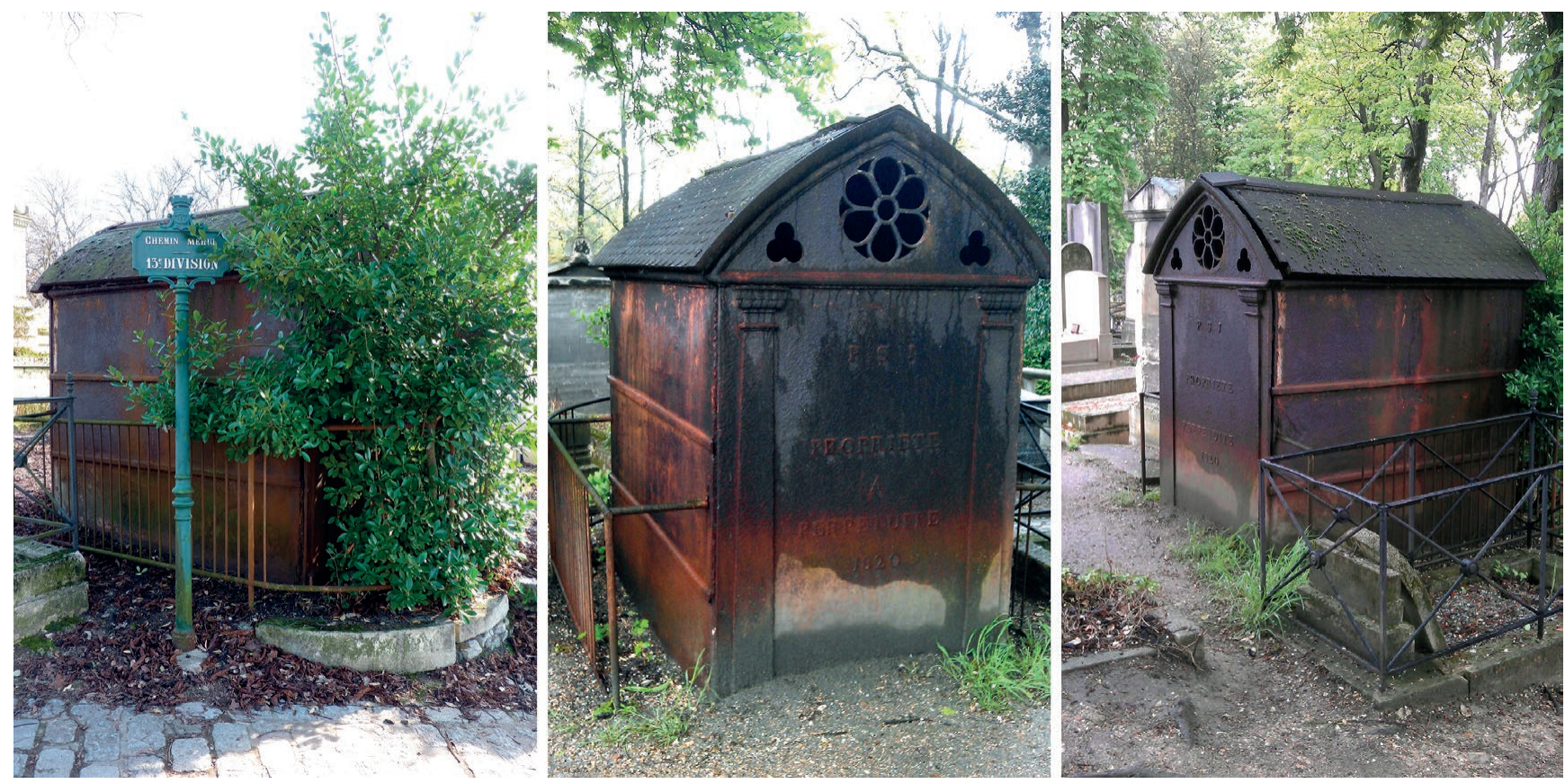

FIG. 5. - Sépulture Sanguin de Jossigny au cimetière du Père-Lachaise, à Paris (20e arrondissement), vue le 24 avril 2012 , revue le 4 février 2015. Cet étrange tombeau est en fonte, maintenant recouverte de rouille: il est situé dans la 13e division, au bord du chemin Méhul. Les lettres P S J correspondent à Pierre Sanguin de Jossigny (1749-1819), frère de Paul Philippe. II est accompagné de quatre autres défunts, dont sa compagne Marie Cler (1771-1826) et sa nièce, Hélène Sanguin de Jossigny (1780-1855). Les deux autres pourraient être Paul Philippe (1750-1827) et son épouse Marie Lecler (dates inconnues).

le 13 septembre 1856 (il a alors 64 ans) avec Eugénie Sophie Pichon, née le 29 mars 1817 à Arras. C'était elle-même une veuve, son premier époux étant mort après seulement trois ans de vie commune; par la suite elle vit disparaître trois Sanguin Jossigny, ses deux fils et son second époux. Paul Henry mourut à Meudon le 21 juin 1860 : il avait presque 68 ans. Le premier fils, Henri Paul, né en décembre 1856, le suivit de près : il mourut le 29 septembre 1860 . Eugénie Sophie Pichon, veuve Jossigny (et non Sanguin), partit s'installer dans l'Oise, à Trie-Château, avec leur second fils, Eugène Charles, né le 11 juillet 1859. Eugène Charles Sanguin Jossigny "âgé de vingt-cinq ans, rentier " se maria le 13 août 1884 à Flavacourt (Oise) avec Marie Octavie Léontine Compiègne; il y mourut le 19 octobre 1891. Deux enfants, arrière-petits-fils de Paul Philippe, Eugène Henri Théophile et Marie François Pierre, naquirent respectivement le 26 mars 1885 et le 28 avril 1888. Le premier se maria à Monsures (Somme) le 17 mai 1909 avec Héloïse Marie Descoutures; le second, adjudant, fut "tué à l'ennemi " le 13 avril 1915 à Marchéville-en-Woëvre (Meuse), à l'endroit même où l'écrivain Louis Pergaud, cinq jours plus tôt, était lui aussi "mort pour la France » : son nom est inscrit sur le monument aux morts de Beauvais.

Dans un curieux tombeau en fonte, sans autre inscription que " P S J PROPRIETE A PERPETUITE 1820 ", sont inhumées à Paris, au cimetière du Père-Lachaise, cinq personnes, dont le frère aîné de Paul Philippe, Pierre Sanguin de Jossigny (P S J), décédé le 21 janvier 1819 (Fig. 5). La concession est située dans la 13 e division, section X (= sud), bordant le chemin Méhul. Les noms de Sanguin (ou
Janguin) et Jossigny, pas plus que les initiales P S J, ne sont mentionnés dans le Recueil général alphabétique des concessions perpétuelles... de Salomon (1855). Cependant, après étude sur place des tombes avoisinantes, il est apparu que Salomon avait bien enregistré la sépulture de Jossigny, mais au chapitre "sans indication de famille ", sous le $n^{\circ} 93$ de sa propre division X. Son plan est schématique, et en réalité la concession recouvre aussi une partie des $n^{\circ} 242$ et 243 de cette même division (Salomon 1855: 305 et plan). Une page de l'Internet tenue par l'Association des Amis et Passionnés du Père-Lachaise (AAPL, Anonyme 2009) figure cette sépulture, mais elle contient plusieurs inexactitudes, notamment à propos de deux personnes qui sont inhumées à ses côtés : Sanguin est orthographié Janguin, Marie Cler (née à Dijon le 12 février 1771, décédée à Paris le 5 septembre 1826) n'était pas l'épouse mais la compagne de Pierre, et Hélène Sanguin de Jossigny (décédée le 6 mai 1855, et non en 1857) n'était pas leur fille, mais leur nièce, fille de Paul Philippe. Les actes d'état civil respectifs précisent que la première était célibataire et "dame de confiance ", que la seconde était née à l'Isle de France et décédée à l'âge de 74 ans et 10 mois, elle aussi célibataire. Pour ajouter au mystère la même notice indique que "Suite à une exhumation, deux corps de membres de la famille reposent également dans ce tombeau, mais sans inscription de leurs noms dans les registres, ni sur le tombeau "; il se peut que l'un de ces corps soit celui de Paul Philippe, qui, exhumé, serait venu rejoindre celui de sa fille Hélène. Je n'ai pu en apprendre davantage, ni auprès de l'AAPL, ni auprès de la conservation du cimetière, mes questions sont restées sans réponses. 
TAbleau 1. - Liste des taxons cités (genres et espèces).

Aldabrachelys Loveridge \& Williams, 1957

Amphiesma Duméril, Bibron \& Duméril, 1854

Amphiesma stolatum (Linnaeus, 1758)

Archaius Gray, 1865

Archaius tigris (Kuhl, 1820)

Astrochelys Gray, 1873

Astrochelys radiata (Shaw, 1802)

Boiga Fitzinger, 1826

Boiga irregularis (Bechstein, 1802)

Calotes Cuvier, 1817

Calotes versicolor (Daudin, 1802)

Calumna Gray, 1865

Calumna tigris (Kuhl, 1820)

Chelonia Brongniart, 1800

Chelonia mydas (Linnaeus, 1758)

Cylindraspis Fitzinger, 1835

Cylindraspis indica (Schneider, 1783)

Cylindraspis vosmaeri (Suckow, 1798)

Emoia Gray, 1845

Furcifer Fitzinger, 1843

Furcifer pardalis (Cuvier, 1829)

Hemidactylus Oken, 1817

Hemidactylus frenatus Duméril \& Bibron, 1836

Lamprolepis Fitzinger, 1843

Lamprophis geometricus (Schlegel, 1837)

Lycognathophis Boulenger, 1893

Lycognathophis seychellensis (Schlegel, 1837)

Pelomedusa Wagler, 1830

Pelomedusa subrufa (Lacépède, 1788)

Pelusios Wagler, 1830

Pelusios subniger (Lacépède, 1788)

Phelsuma Gray, 1825

Phelsuma lineata Gray, 1842

Phelsuma ornata Gray, 1825

Stegonotus Duméril, Bibron \& Duméril, 1854

Stegonotus batjanensis (Günther, 1865)

Testudo Linnaeus, 1758

Testudo commersoni Vaillant, 1898

Testudo indica Schneider, 1783

Testudo madagascariensis Schweigger, 1812

Testudo radiata Shaw, 1802

Testudo rodericensis Günther, 1873

Testudo subnigra Lacépède, 1788

Testudo subrufa Lacépède, 1788

Testudo vosmaeri Suckow, 1798

Zonosaurus Boulenger, 1887

Zonosaurus madagascariensis (Gray, 1831)

\section{L'CEUVRE}

\section{LES DESSINS DE JOSSIGNY}

C'est son œuvre de dessinateur qui assura, mais tardivement, la renommée de Paul Philippe Sanguin de Jossigny. Voici ce qu'a écrit Antoine Cap (1861: 39) à ce propos : "Les dessins, au nombre de 1,500 environ, sont contenus dans cinq portefeuilles, dont trois de botanique et deux de zoologie. Ils portent tous sa signature [celle de Commerson] ou celle de Jossigny. Ces dessins à la plume ou au crayon, réunissent tous les détails de chaque plante et sont, avec ceux de Plumier, les plus beaux que possède le Muséum de Paris". Je dois ajouter qu'au moins un auteur (Zirnstein 2015: 203) a évoqué, par erreur, des cuivres gravés par Jossigny ("die Paul Jossigny angefertigten Kupferplatten») rapportés à Paris. Cette œuvre comprend des documents de grande valeur sur des espèces végétales ou animales aujourd'hui disparues, les plus spectaculaires parmi les animaux étant la huppe de Bourbon, le petit-duc de l'Isle de France (ou de Commerson), la perruche et la grande tortue de Rodrigues. Mais l'auteur en fut mal récompensé : "En 1775. je remis au Cabinet du Roy neuf cent desseins d'histoire naturelle des Isles de France, Bourbon et Madagascar; le fruit denviron cinq années de Travail le plus assidu. On me promis Six mil Livres de Gratification, qui ce reduisit à huit cent livres [nous l'avons vu plus haut, 1000 livres selon le courrier du ministre de la Marine], MMrs de Jussieux et de Bougainville ont une entiere connoissance de ce fait [...] A Paris le 30 juillet 1790 ». L'administration justifia ainsi sa lésinerie: "Pour ce qui est de son travaille qu'il à remis de même au Cabinet du Roy on lui a dit qu'il ne pouvoit en être récompensé que par le Ministre de la Marine; n'ayant point été comme M. de Comerson envoyé dire(c)tement par la cour mais employé à ces objets par les administrateurs des Colonies dans l'Inde». Jossigny ne pouvait appréhender l'importance scientifique, aujourd'hui considérable, de son travail : il espérait tout juste en tirer quelques milliers de livres.

On a écrit que le successeur de Bernard de Jussieu, son neveu Antoine Laurent de Jussieu était le premier responsable de ces collections, puis, négligent, de leur abandon : "Il eut la charge de recevoir, de dénombrer et d'étudier les immenses collections de Commerson adressées au Muséum après la mort de celui-ci» (Monnier et al. 1993: 10); "Celui-ci devait mettre en ordre et publier les travaux de Commerson, mais il ne s'acquitta jamais de cette tâche et les papiers conservés aujourd'hui à la Bibliothèque du muséum d'histoire naturelle sont demeurés en l'état " (Taillemite 1977: 135). En fait cette négligence fut collective, chaque savant prenant à l'occasion, comme nous l'avons vu plus haut, le matériel qui pouvait l'intéresser. Dès 1791, Alexis Marie [de] Rochon (1741-1814), dit l'abbé Rochon, astronome, ami de Poivre, arrivé à l'Isle de France en juillet 1768, désapprouvait le peu d'intérêt apporté au travail de Commerson : "Combien ne doit-on pas regretter que des travaux aussi précieux ayent été perdus ou dispersés après la mort de cet homme infatiguable, qui a été enlevé aux sciences dans le moment où il alloit jouir en paix $d u$ fruit de ses utiles recherches! [...] Mais que nous reste $t$-il aujourd'hui de cette immense collection qu'il nous montroit à l'île de France, avec dautant plus de satisfaction quelle lui avoit plus coûté de peine? rien, ou presque rien, J'en appelle au témoignage de M. de Jussieu qui a eu la bonté de me communiquer ce qu'on a pu se procurer des débris de ces immenses recherches. Ces tristes restes des pénibles travaux d'un Savant disti(n)gué ne renferment que des commentaires de peu d'importance, sur quelques plantes décrites par Flacourt, dans son Histoire de Madagascar" (Rochon 1791: 126-127). Georges Cuvier - qui avait mis de côté pour ses études les dessins de poissons - confirmait : «[...] ceux à qui ses manuscrits et son herbier ont été confiés les ont négligés d'une manière coupable ", et dans la même publication, posthume, Cuvier paraît avoir complètement oublié Jossigny : les descriptions "[...] sont accompagnées de dessins faits, les uns par Commerson, les autres par Sonnerat, d'autres encore par des artistes qui étaient partis avec Bougainville», en concluant " Parmi ceux qui avaient aidé Commerson, on doit citer Poivre et Sonnerat » (Cuvier \& de Saint-Agy 1845: 93-97). 
Au XXe siècle rien ne semble avoir changé : on a continué à ignorer ces dessins, au mieux à se lamenter sur leur sort. La seule avancée notable a été le catalogage de l'ensemble des manuscrits de Commerson par Yves Laissus (1974), conservateur de la Bibliothèque centrale du Muséum. Dix ans plus tôt, son prédécesseur à ce poste, Gabrielle Duprat (1964), avait déploré : "D'autres dessinateurs, comme Pierre [sic] Jossigny [...] ont rapporté des liasses de dessins qui n’ont jamais été publiés et c'est ainsi que l'oenvre de Jossigny dort, ignorée, dans la Bibliothèque du Muséum ». Pour Madeleine Ly-Tio-Fane (1976: 67) : « Together with Commerson's collections and manuscripts, they [Jossigny's drawings] constitute a treasure which even to this day has not been critically inventoried and evaluated". Anthony Cheke et Julian Hume (2008: 100), en rappelant les remarques de Rochon, se sont montrés tout aussi sévères: "His collections [Commerson's] of plants, fishes and birds were shipped to Paris, together with many incomplete manuscripts, only to disappear into the depths of the Paris Natural History Museum [...] Although Commerson's qualities as a naturalist and collector are now fully recognised, his manuscripts have still not been properly used. The manuscripts include Jossigny's animal drawings (birds, bats, tortoises, insects etc.), some of which are extremely important to Mascarene wildlife history ". Il faut reconnaître que ces documents ont été maintenant examinés et exploités par un petit nombre de chercheurs, certaines illustrations reproduites; ils sont classés, prêts pour un travail global et exhaustif... qui reste à faire. La plus récente publication fondée sur ces dessins, prouvant leur intérêt toujours actuel, est une note d'ordre nomenclatural de Cheke (2009b), qui montre que le type d'une chauve-souris endémique de l'île Maurice, Mormopterus acetabulosus (Hermann, 1804), est le spécimen représenté par Jossigny il y a presque deux siècles et demi.

L'ensemble des manuscrits de Commerson a donc été minutieusement catalogué par Laissus (1974; 1978), dont le classement est suivi ici; pour les dessins d'histoire naturelle Laissus s'est fondé sur les cinq portefeuilles mentionnés par Cap (1861). La plupart des planches de botanique (trois portefeuilles, Ms 279, 280, 281; total : environ 585 pièces) sont signées P. S. Jossigny, P. Jossigny ou Jossigny, quelques-unes Sonnerat, Morlaix, ou Pecquet. Les planches de zoologie (deux portefeuilles, Ms 282-1 et 2, plus les poissons classés parmi les vélins, tomes 89 à 94 ; total : environ 651 pièces), "généralement moins soignées ", sont de même identifiées Jossigny, plus rarement Sonnerat, sauf pour les oiseaux représentés par un grand nombre d'aquarelles de Sonnerat. Selon Oustalet (1896b: 7), "Les dessins de Sonnerat sont souvent coloriés, mais en général moins bons, moins artistiques que ceux de Jossigny, qui sont, pour la plupart, à la mine de plomb [...] ». Les relevés de Laissus donnent un ensemble de 1236 planches; nous avons vu que Cap, en 1861, en avait compté 1500 environ, mais Jossigny lui-même, en 1790, dénombrait seulement "neuf cent desseins"; il ne reconnaissait peut-être là que les siens, car en 1787, dans une autre lettre, Jossigny écrivait : "Il [lui-même] a remis en 1775 par ordre de Mr. De Boynes [ministre de la Marine] au Cabinet du Jardin du Roy entre les mains de Mr de Buffon plus de trois mil desseins à la plume ou au Crayon ». Ce dernier total est repris par Morel (2012a).

\section{À PROPOS DES ILLUSTRATIONS}

Échelle : sur toutes les reproductions des planches, le cachet de la Bibliothèque du Muséum national d'Histoire naturelle est large hors-tout de $16 \mathrm{~mm}$; l'expérience montre que les indications portées sur les dessins donnent des dimensions parfois fantaisistes; les dimensions des planches sont celles des cadres, données en millimètres, mais elles sont parfois approximatives, certains cadres n'étant pas tout à fait rectangulaires.

\section{LES TORTUES}

Le premier portefeuille de l'ensemble Ms 282 est intitulé de la main de Commerson "De Reptilibus Amphibiis \& Insectis Pars $V . a »$. Une quinzaine d'espèces de reptiles ont été dessinées, couvrant un ensemble de 22 planches (soit seulement 3,4\% des illustrations d'animaux), certaines sont l'œuvre de Pierre Sonnerat, d'autres n'ont pas d'auteur formellement identifié. Les annotations au recto sont de la main de Commerson; la signature de Jossigny, le plus souvent au crayon, est fréquemment accompagnée de trois astérisques ou étoiles, à l'encre, dont on ignore l'auteur et la signification. Quelques annotations à l'encre, ajoutées au verso, sont signées par Philibert Commerson. Quatre planches représentent des spécimens qui ne sont pas originaires de la zone qui nous intéresse, précisément un lézard et un serpent récoltés à Pondichéry, en Inde, dessinés par Jossigny, et un lézard et un serpent récoltés sur l'île Bouro (aujourd'hui Buru, aux Moluques) selon les annotations, dessins non signés, et dont la détermination est problématique; je les inclus néanmoins, traitant ainsi l'ensemble des planches de reptiles. Le Tableau 1 donne la liste des taxons nominaux utilisés dans ce travail.

Dix planches, toutes de dessins au crayon exécutés (d'après l'indication portée) par Jossigny, figurent des tortues (Vaillant 1898). Leur contenu est présenté dans l'ordre de numérotation des folios, de 4 à 13 (les trois premières planches figurent des crabes) :

\section{Planche 4 (Fig. 6)}

Une tortue d'eau douce de Madagascar (Pelusios subniger), sur une planche, vues dorsale et ventrale, déjà commentées et reproduites par Bour (1982: pl. 2) - Annotation : «Species communicata. Ad naturae Typum ". Cette tortue est le type de «La noirâtre » ou Testudo subnigra décrite par Lacépède (1788: 175 et pl. 13), qui en ignorait l'origine. La carapace, longue selon sa courbure de «cinq pouces quatre lignes " $(144 \mathrm{~mm})$, est conservée dans les collections du Muséum, $\mathrm{n}^{\circ} \mathrm{MNHN}$ -RA-0.8366. Il s'agit probablement de l'une des " quelques écailles de tortues " contenues dans la caisse $\mathrm{n}^{\circ} 14$ de Commerson, mentionnées par Maillart Dumesle (Morel 2011a). L'espèce est africaine et habite aussi Madagascar (côte orientale uniquement), ainsi que plusieurs îles des Seychelles granitiques.

\section{Planches 5 et 8 (Figs 8 \& 9)}

Une tortue franche, de Rodrigues (Chelonia mydas), sur deux planches - Annotations : "Tortue de mer de Rodrigue vue de costé et par dessus. Dessin pris sur un sujet médiocre et d'après nature " et "Tortue de mer de Rodrigue vue par-dessous. D'après nature». La tortue franche, ou tortue verte, est cosmopolite; 

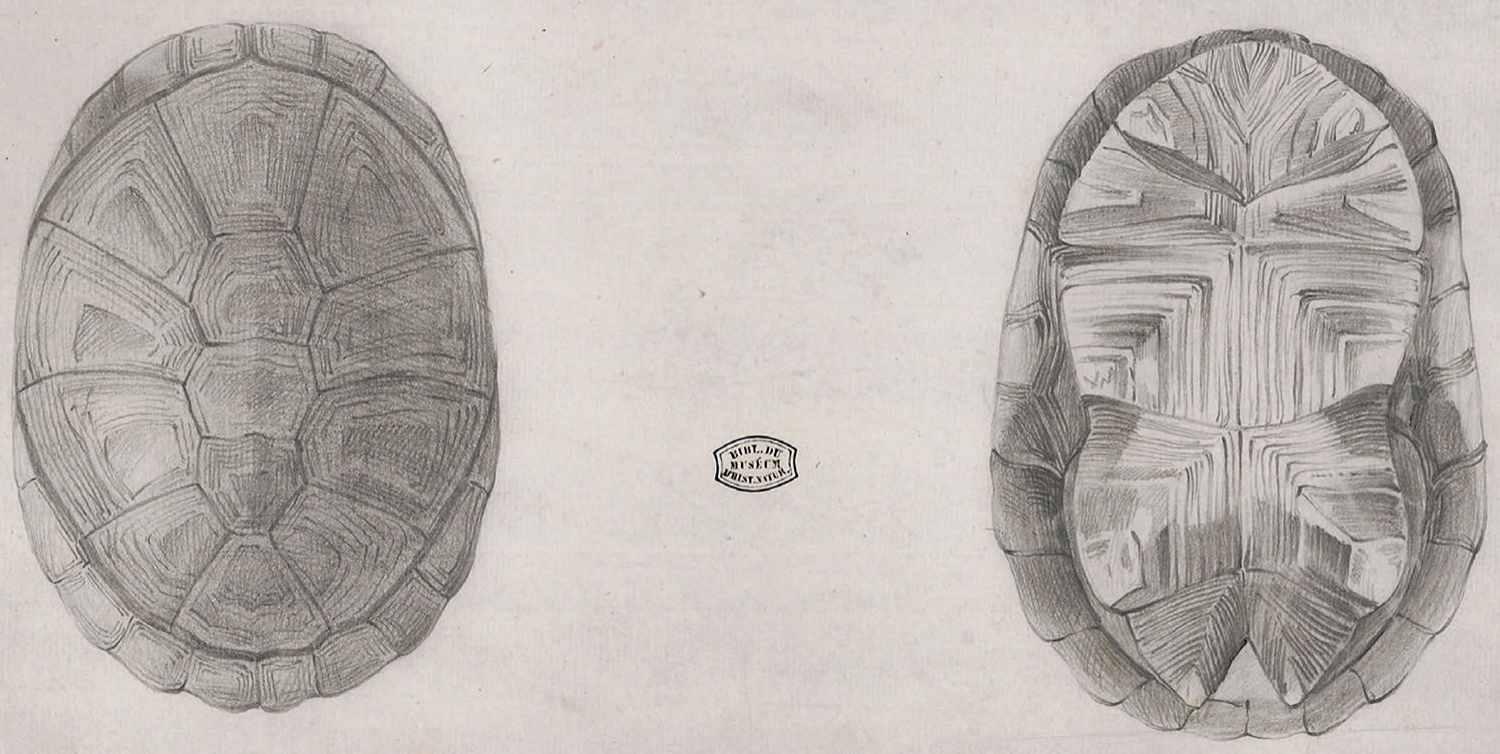

FIG. 6. - Tortue d'eau douce (carapace, Pelusios). Annotations : « Species Communicata. ad Naturae Typum ». Identification : Pelusios subniger (Lacépède, 1788), probablement de Madagascar. Type de «La noirâtre " de Lacépède (1788). Cette carapace, longue de $130 \mathrm{~mm}$, est dans les collections du Muséum, ${ }^{\circ}$ MNHNRA-0.8366. Dessin de Jossigny, $340 \times 212$ mm. MNHN, Bibliothèque centrale, Ms 282-1, 4 .

elle est devenue rare aux Mascareignes : son dernier grand refuge régional se situe sur l'îlot de Tromelin, plus au nord. À Rodrigues la tortue franche se rencontre encore aux alentours de l'île, et vient, occasionnellement, pondre sur le littoral (Cheke 1987: 54). Bien qu'originaire de Rodrigues, celle-ci, comme les tortues terrestres prélevées sur cette île, a été vraisemblablement parquée à Port-Louis avant d'être consommée.

\section{Planche 6 (Figs 10 \& 11)}

Une tortue rayonnée de Madagascar, du fort Dauphin (Astrochelys radiata), une planche, reproduite par Cheke \& Bour (2014: 38) - Annotation au recto : "La belle tortue terrestre du fort Dauphin, prise d'un sujet de moyenne grandeur ". Annotation au verso : une description signée par Commerson de «La Belle Tortue Malgache». Le texte en latin inclut trois diagnoses distinctes mais redondantes que l'on peut ainsi traduire : "Tortue [...] Voyez la Descr[iption]. Fortement voûtée; pieds sans doigts; ceux de l'avant à cinq ongles; ceux de l'arrière à quatre; écailles du dos subpentagonales striées noires, au centre pointillé et aux rayons jaunes. Par nous - Tortue aux pieds tronqués, sans doigts; à cinq ongles; carapace fortement voûtée; aux écailles dorsales à bordure à cinq angles rayées de triangles presque isocèles, et décorées de jaune. Par nous - Tortue fortement convexe, dont toutes les écailles sont rayées de noir et rayées de jaune; celles $d u$ dos pointillées au centre, à pourtour subpentagonal; mains à 5 ongles, pieds à 4 ongles, sans doigts, avec autant d'excroissances sur le bord opposé, à l'arrière. Commerson D [octeur en] M[édecine] Nat[uraliste] du Roi ». Ni Lacépède (1788) ni Daudin (1801) n'ont remarqué ce joli dessin, représentant une tortue de Madagascar subadulte : c'est Schweigger (1809; 1812: 457) qui, le premier, a identifié l'espèce comme étant la Testudo radiata décrite par Shaw en 1802 et il a crée, à partir de cette planche et des notes manuscrites de Commerson, une Testudo madagascariensis, mais en synonymie de Testudo radiata. Le nom n’a pas été utilisé par la suite de façon valide, et il n'a donc pas de statut nomenclatural. Aujourd'hui cette espèce, endémique de Madagascar, est en forte régression : on ne la rencontre plus que sporadiquement dans le sud de la Grande Île. Planche reproduite Fig. 10, les diagnoses par Commerson Fig. 11.

\section{Planche 7 (Fig. 7)}

Une tortue d'eau douce de Madagascar (Pelomedusa subrufa), sur une planche, vues ventrale et dorsale, déjà commentées et reproduites par Bour (1982: pl. 3) - Annotation : «Vue pardessous. Petite tortue de terre du fort Dauphin (à Madagascar). Vue par-dessus. En grandeur naturelle». Cette tortue est probablement celle du type de "La roussâtre " ou Testudo subrufa, autre tortue décrite par Lacépède (1788: 173, pl. 12). Lacépède 


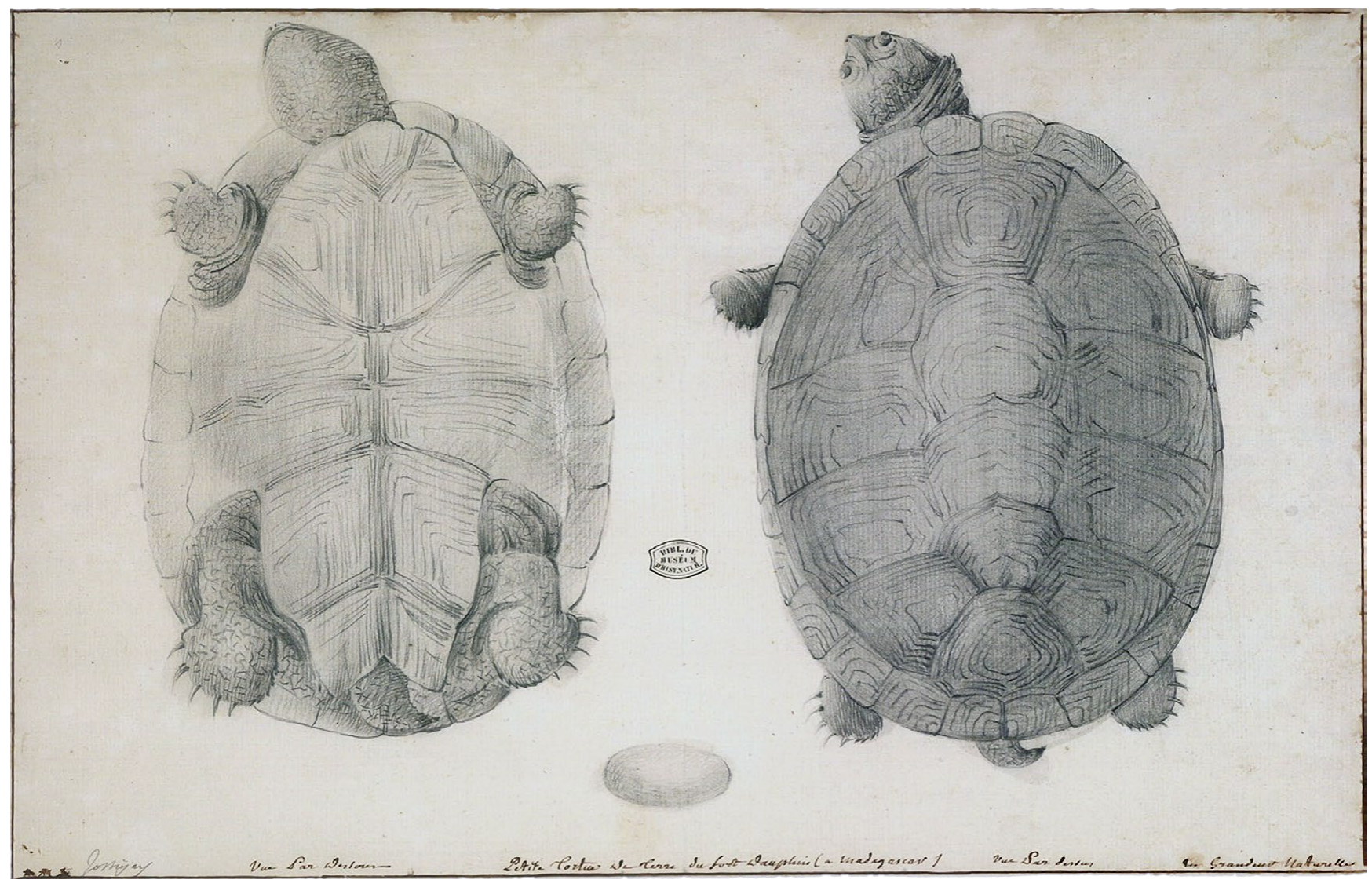

FIG. 7. - Tortue d'eau douce de Madagascar (Pelomedusa). Annotation : « Vue Par Dessous. Petite Tortue De Terre du fort Dauphin (a Madagascar). Vue Par dessus. En Grandeur Naturelle ». Identification : Pelomedusa subrufa subrufa (Lacépède, 1788), de Madagascar. Probablement le type de "La roussâtre » de Lacépède (1788). La carapace est dans les collections du Muséum, $n^{\circ}$ MNHN-RA-0.7970. Dessin de Jossigny, $376 \times 240$ mm. MNHN, Bibliothèque centrale, Ms 282-1, 8 .

pensait qu'elle avait été rapportée par Sonnerat, « des Indes ». La carapace, longue de "cinq pouces six lignes " $(148 \mathrm{~mm})$, est conservée dans les collections du Muséum, $\mathrm{n}^{\circ} \mathrm{MNHN}$ RA-0.7970. Peut-être était-ce aussi une des "quelques écailles de tortues " contenues dans la caisse $\mathrm{n}^{\circ} 14$ de Commerson (Morel 2011a). L'espèce occupe une vaste aire de répartition en Afrique; elle habite aussi Madagascar, sur une grande partie du territoire, mais est absente des Seychelles, ainsi que « des Indes ». Planche reproduite Fig. 7.

\section{Planche 9 (Fig. 12)}

Une tortue terrestre juvénile, vues latérale et ventrale sur une planche, reproduites par Bour (1984: 283) et Cheke \& Bour (2014: 75) - Annotation : "Communicata. Sub magnitudine naturali". Il s'agit d'un juvénile d'une tortue géante insulaire, comme le montre le plastron aux lobes antérieurs et postérieurs réduits : cette tortue peut appartenir soit au genre Aldabrachelys et plutôt à une espèce des Seychelles granitiques, soit au genre Cylindraspis des Mascareignes et alors représenter vraisemblablement une espèce de Rodrigues. L'illustration fait penser de prime abord à une tortue des Seychelles (Vaillant 1898; Bour 1984) : lorsque Jossigny l'a dessinée, de telles tortues vivaient encore sur la plupart des îles Seychelles centrales, d'où elles ont été exterminées, tandis que celles des atolls - essentiellement d'Aldabra - n'étaient pas encore exploitées. La qualité du dessin est moyenne, tout au moins pour certains éléments (stries des écailles de la carapace); cependant plusieurs particularités, complémentaires, laissent à penser qu'il s'agirait plutôt d'une espèce du genre maintenant éteint des Mascareignes, Cylindraspis, plus précisément, comme celle figurée sur les planches suivantes, d'une tortue de Rodrigues. Ainsi la tête n'est pas spécialement bombée et elle ne montre pas de grandes écailles préfrontales; le bord libre de la mâchoire supérieure est dentelé et terminé par un bec crochu; les écailles des avant-bras sont polygonales et juxtaposées; les gulaires sont petites, triangulaires, en coin dans les humérales (le sillon médian peut disparaître avec l'âge) : tous ces caractères sont ceux des tortues des Mascareignes, quand on les compare à celles des Seychelles. Néanmoins, le dessin insuffisamment précis et une quasi absence de matériel de comparaison interdisent toute certitude dans l'identification.

\section{Planches 10 à 13 (Figs 13 à 16)}

Une tortue de Rodrigues (Cylindraspis vosmaeri), sur quatre planches (vues latérale, dorsale et ventrale; anatomie du crâne) en partie reproduites par Cheke \& Bour (2014: 68), Bour et al. (2014b: 149), un peu modifiées par Vaillant (1898), et très modifiées par North-Coombes (1986) - Annotations : "Tortue de terre de Rodrigue vue de profil "; "Tortue de terre 


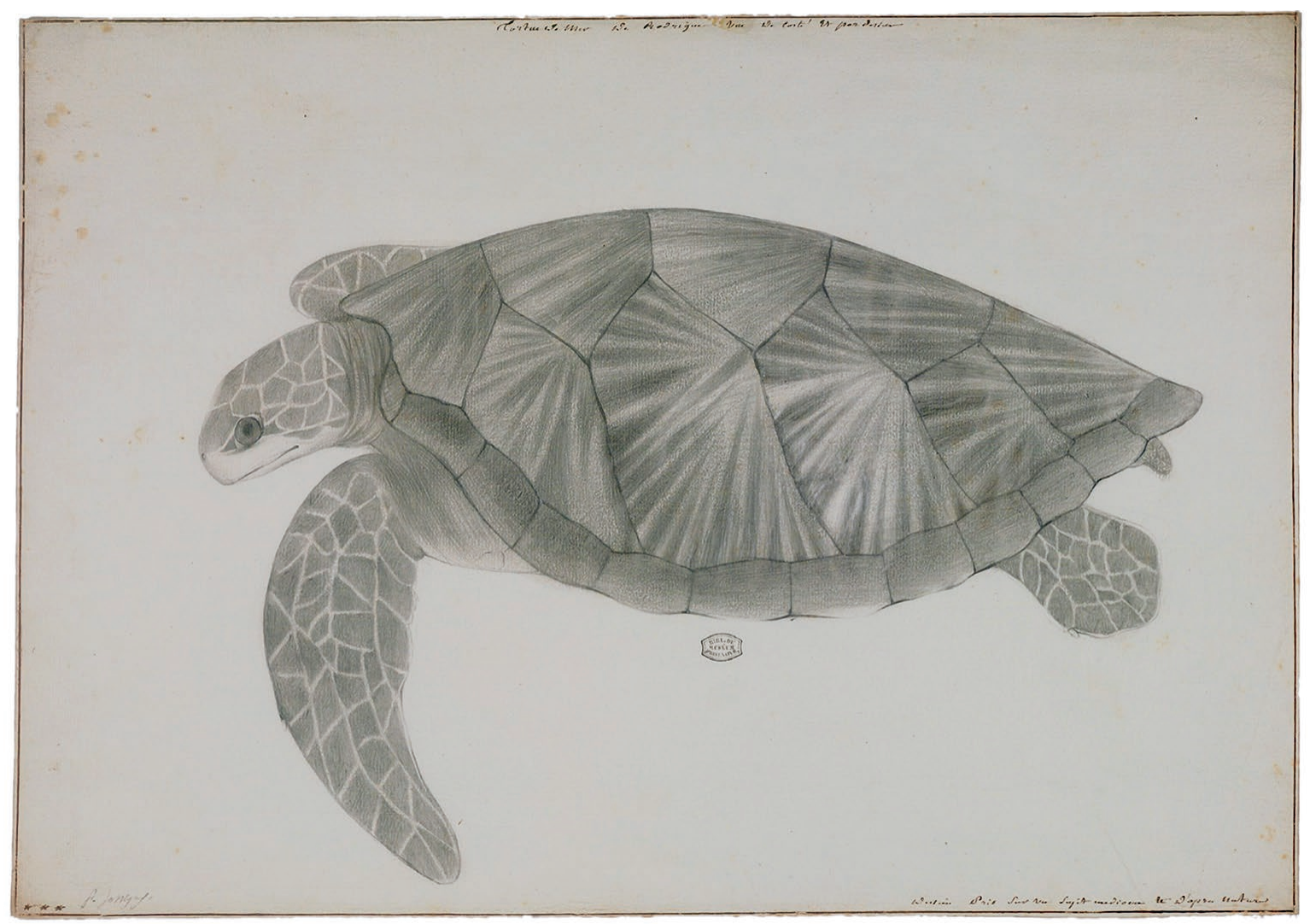

FIG. 8. - Tortue marine de Rodrigues (Chelonia). Annotations : "Tortue de Mer De Rodrigue Vue De Costé Et par dessus. Dessin Pris Sur un Sujet médiocre et D'après Nature ». Identification: Chelonia mydas (Linnaeus, 1758), de Rodrigues. Vue latérale. Dessin de Jossigny, $510 \times 360$ mm. MNHN, Bibliothèque centrale, Ms 282-1, 5.

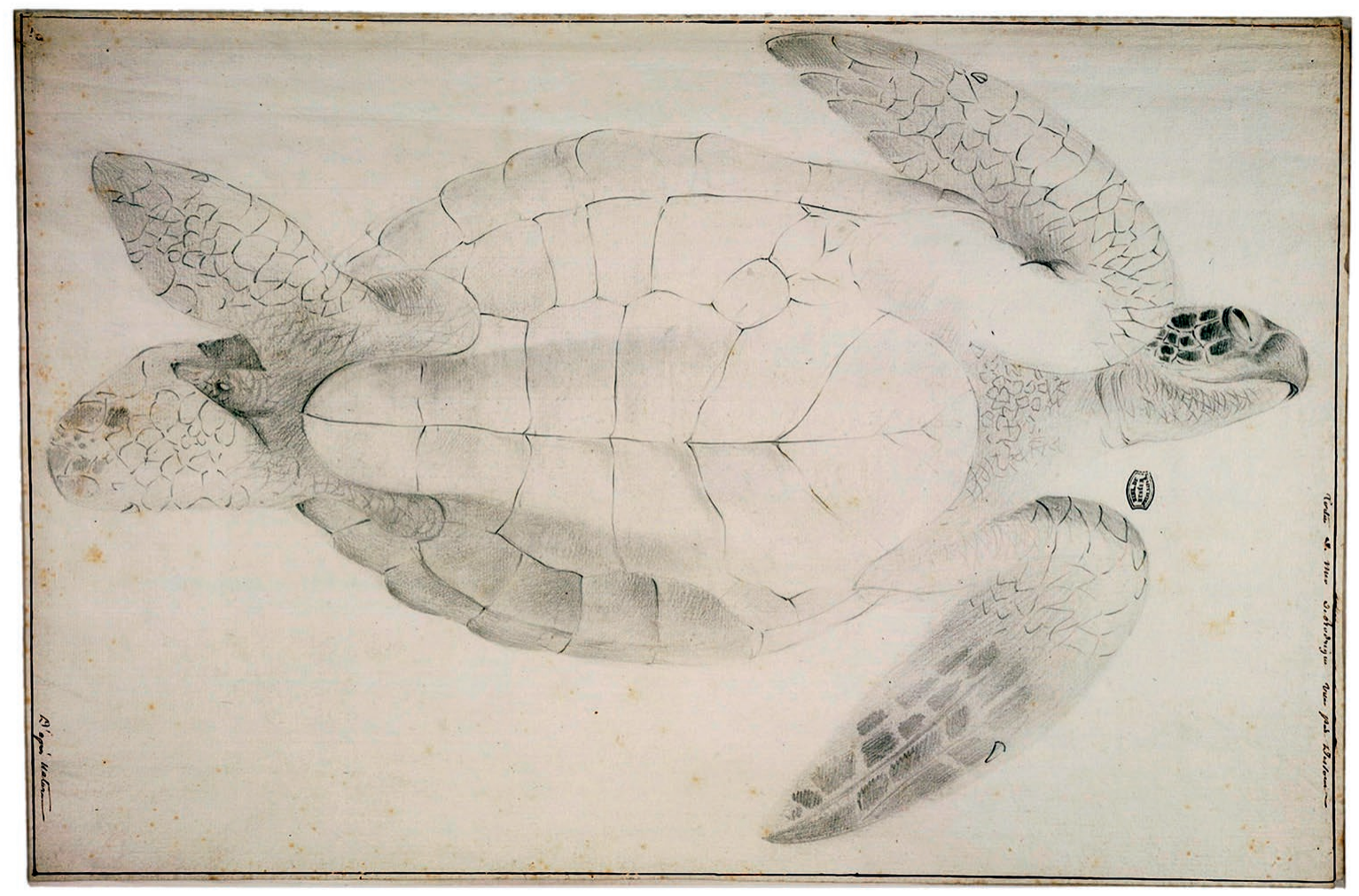

FIG. 9. - Tortue marine de Rodrigues (Chelonia). Annotation : "Tortue de Mer de Rodrigue vue par Dessous. D'après nature ». Identification : Chelonia mydas (Linnaeus, 1758), de Rodrigues. Dessin de Jossigny, vue ventrale, $515 \times 360 \mathrm{~mm}$. MNHN, Bibliothèque centrale, Ms $282-1,8$. 


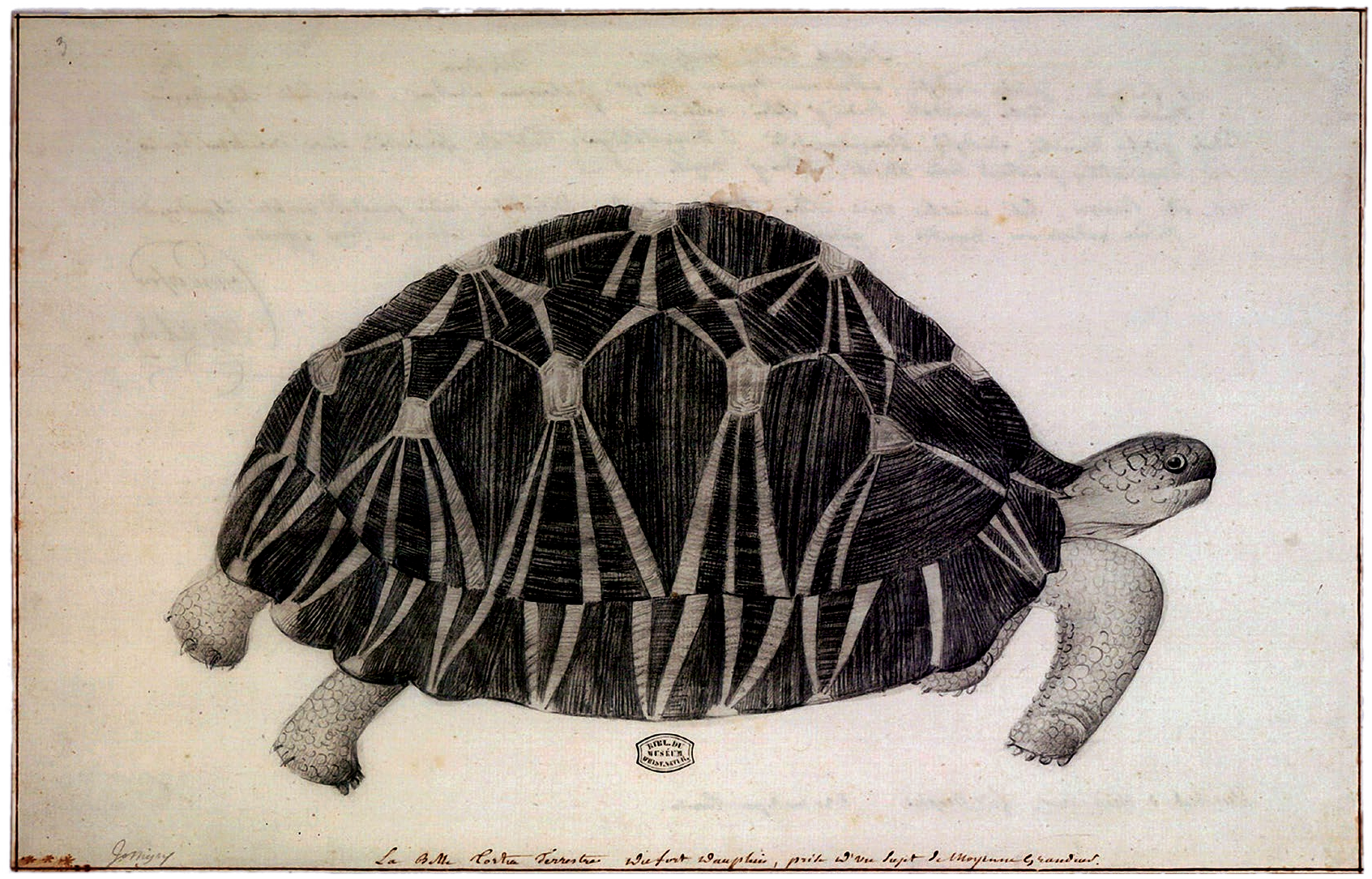

FIG. 10. - Tortue terrestre de Madagascar (Astrochelys). Annotation : «La Belle Tortue Terrestre Du fort Dauphin, prise D'un sujet de Moyenne Grandeur ». Identification : Astrochelys radiata (Shaw, 1802), environs de Fort-Dauphin, Madagascar. Dessin de Jossigny, $380 \times 242$ cm. MNHN, Bibliothèque centrale, Ms $282-1,6$.

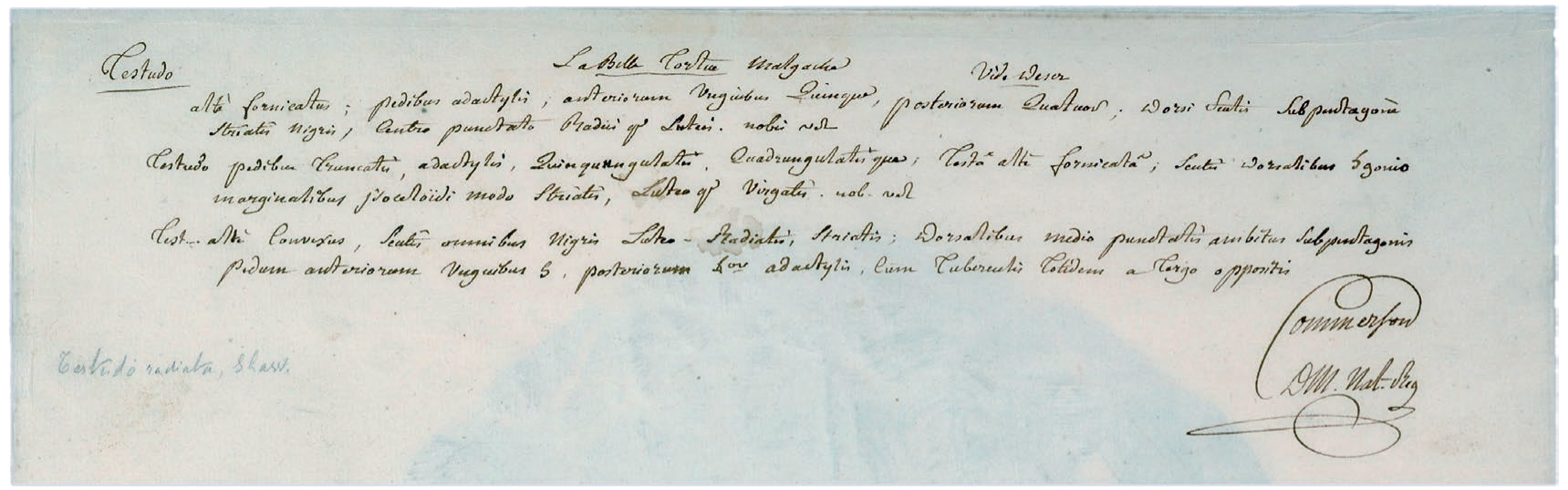

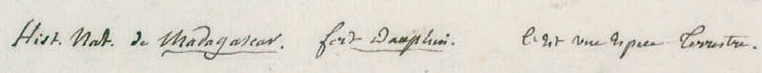

FIG. 11. - Essais de diagnoses manuscrites de «La Belle Tortue Malgache » par Commerson, au verso de la planche. Une traduction est proposée dans le texte. MNHN, Bibliothèque centrale, Ms 282-1, 6 .

Testudo

La Belle Tortue Malgache

alte fornicatus; pedibus adactylis; anteriorum Unguibus Quinque, posteriorum Quatuor; Dorsi Scutis Subpentagone striatis nigris, Centro punctato Radiisque Luteis. nobis vel

Testudo pedibus Truncatis, adactylis, Quinqueungulatis Quadrungulatisque; Testa alte fornicata; Scutis Dorsalibus $5 \mathrm{gonio}$ marginalibus isoceloïdi modo Striatis, Luteoque Virgatis. nob. vel

Test. alte Convexus, Scutis omnibus Nigris Luteo-Striatis, Striatis; Dorsalibus medio punctatis ambitus Subpentagonis pedum anteriorum Unguibus 5, posteriorum 4or adactylis, Cum Tuberculis Totidem a Tergo oppositis 


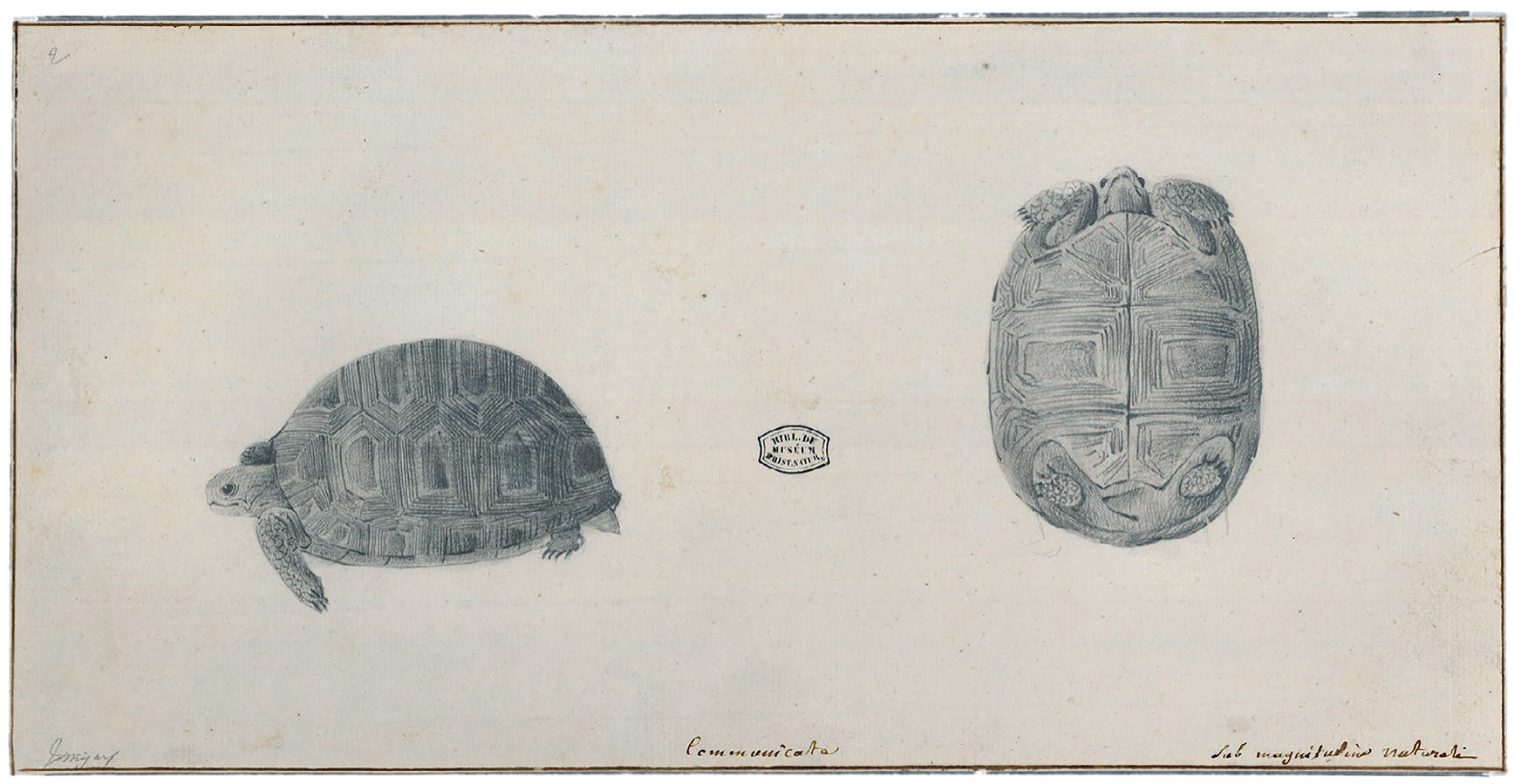

FIG. 12. - Tortue terrestre (Aldabrachelys ou Cylindraspis). Annotation : “ Communicata. Sub magnitudine naturali ». Vue latérale et vue ventrale du juvénile d'une tortue géante insulaire. Identification : cette tortue peut appartenir soit au genre Aldabrachelys, des Seychelles, soit, plus vraisemblablement, au genre Cylindraspis des Mascareignes. La mention (en latin) « de grandeur naturelle » indique une carapace longue de $80 \mathrm{~mm}$. Le dessin n'est pas suffisamment précis pour permettre une identification certaine (voir le texte). Dessin de Jossigny, $343 \times 170 \mathrm{~mm}$. MNHN, Bibliothèque centrale, Ms $282-1,9$.

de Rodrigue. Vue de dessus et réduite de moitié"; "Tortue de terre. Vuë par-dessous. de Rodrigue. Réduite à moitié"; "Os de la teste d'une tortue de terre (de Rodrigue) A. L'ensemble de la teste. B. id. vu de face sans la mâchoire inférieure. C. La mâchoire inférieure. D. E. Pièces de corne qui chaussent ou revêtissent les mâchoires [D] supérieure \& inférieure [E]. Dans la Fig. A. Les deux mâchoires sont vues avec le revêtement. Et dans les Fig. B. \& C. sans yceluy ». Ces dessins sont évidemment les plus intéressants, car ils représentent une espèce aujourd'hui disparue, éteinte vers 1800 , et on peut ici leur accorder davantage d'attention. La représentation du crâne est particulièrement réussie, et sa qualité est comparable à celle des figures de botanique.

Rappelons qu'à partir de 1735, date à laquelle celles de l'île Maurice étaient déjà exterminées, les tortues terrestres de Rodrigues furent méthodiquement exploitées : emploi de ramasseurs spécialisés, "une douzaine de noirs sous le commandement d'un officier blanc ", création de parcs à tortues où s'accumulaient plusieurs milliers d'individus, utilisation de navires spécialement affrétés, les «bateaux-tortues » selon North-Coombes (1986). Les tortues étaient embarquées pour alimenter, entre autres, les malades de l'hôpital de PortLouis, "mais, dit-on, les chefs de cette isle sont toujours malades à l'arrivée de la corvette ", comme l'a malicieusement noté le chanoine Guy Alexandre Pingré (1761). La Compagnie des Indes avait fait construire à Port-Louis un parc pour les tortues de terre et un bassin clos pour les tortues marines. Des comptes précis ont révélé qu'en une trentaine d'années près de 300000 tortues de terre avaient été prélevées, dont beaucoup n'avaient pas survécu au transport en raison de leur carapace fragile (North-Coombes 1986; Cheke \& Bour 2014). L'Étoile, avec à son bord Philibert Commerson, passa au large de Rodrigues le 5 novembre 1768. Point important, elle n'y fit pas escale $\left(^{*}\right)$, ne serait-ce qu'une journée, selon les divers livres de bord et journaux (voir notamment Taillemite 1977). Néanmoins Lamarck (1808: 720) rapportait déjà, par erreur : "Pendant les deux premières années, Commerson parcourut les côtes du Brésil, Buenos-Ayres, les terres magellaniques, la Nouvelle-Angleterre, les îles d'Otaitti, de Bouro, de Java, de Roderic [sic], \& beaucoup d'autres; il vécut ensuite, pendant l'espace d'environ cinq ans, dans les îles Maurice et Bourbon, visita deux fois [sic] celle de Madagascar; il avoit entrepris de dessiner et de décrire les plantes et les animaux de ces trois îles [...]", et beaucoup plus récemment Role (1973: 166) précisa même: "Après la longue traversée que nous avons évoquée, semée de fécondes escales, "La Boudeuse" et "L'Étoile", après une dernière et brève relâche à Rodrigue où Commerson put faire de nouvelles récoltes, parvinrent à Port-Louis le 8 septembre $1768 »$. La tortue de Rodrigues dessinée n'avait donc pas été prélevée par l'expédition de Bougainville. L'espèce était déjà considérée comme rare et la tortue représentée était probablement une rescapée de l'un de ces derniers arrivages : " 16 janvier [1768, depuis Rodrigues] - Le both L'Heureux transporte à l'Isle de France un lot de 1215 tortues de grande taille (carosses) [...]»; L'Heureux était suivi de L'Étoile du matin en mars, avec 690 tortues, et du Désir en juillet de la même année, avec 980 tortues (North-Coombes 1986: 39; Berthelot 2002: 147). Jossigny a figuré une femelle; il serait plus juste de dire esquissé, car les dessins manquent de détails et comportent des erreurs : bord du bec non dentelé, 


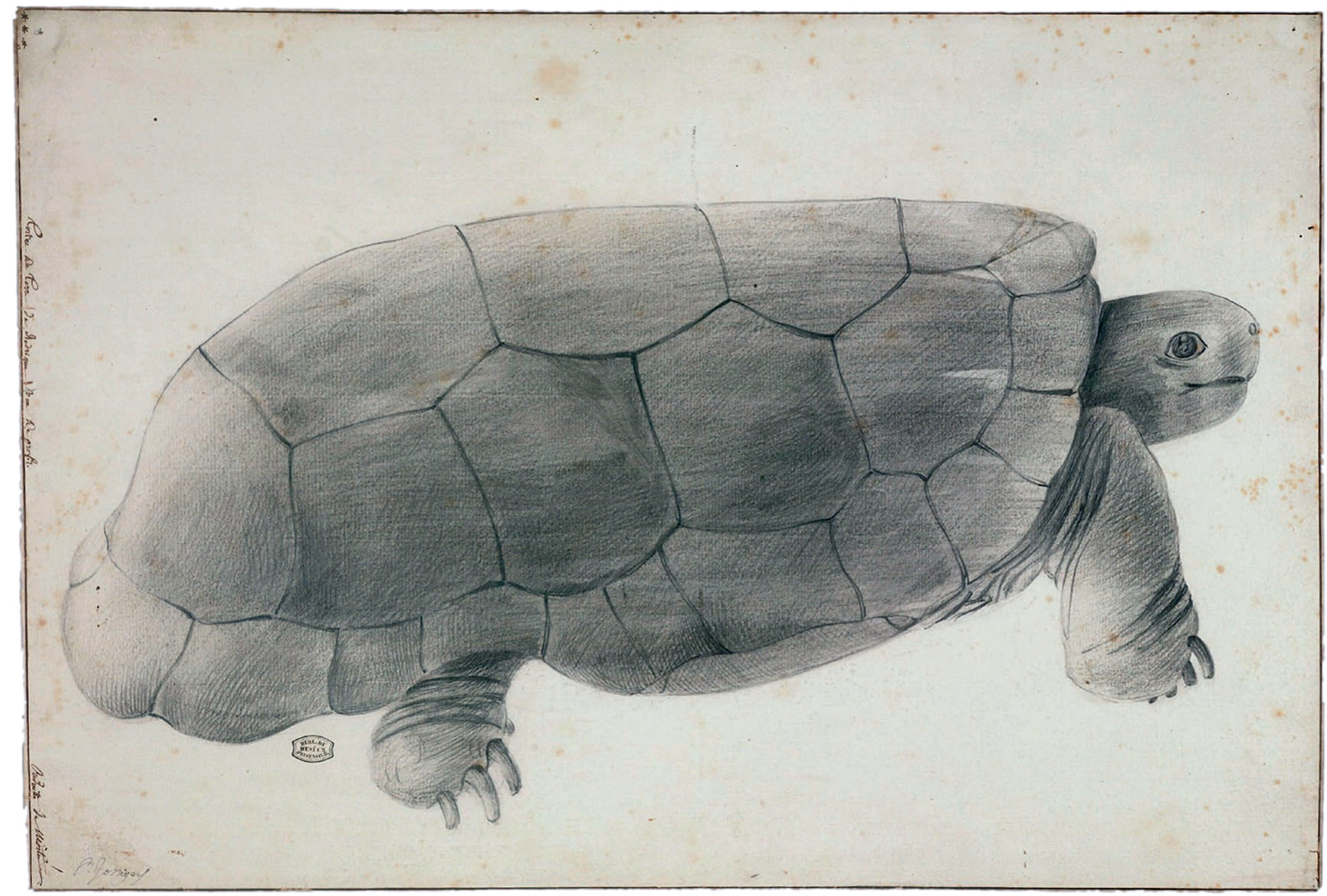

FIG. 13. - Tortue terrestre de l'île Rodrigues (Cylindraspis). Annotation : "Tortue De Terre De Rodrigue Vue De profil. Reduite de Moitié ». Identification : Cylindraspis vosmaeri (Suckow, 1798), de Rodrigues. Dessin de Jossigny, vue latérale, $510 \times 355 \mathrm{~cm}$. Type de Testudo commersoni Vaillant, 1898 . MNHN, Bibliothèque centrale, Ms 282-1, 12.

sur le plastron ni intergulaire impaire ni inguinales, pas de grandes écailles arrondies sur les avant-bras, écaillure frontale inachevée... De plus, selon Vaillant (1898), relevant les annotations de Commerson, "la carapace y mesure 420 millimètres de long, 200 millimètres de haut, 240 à 250 millimètres de large; l'indication "réduite de moitié", qu'elles [les planches] portent, fait voir que l'individu était de grande taille [...]"; or les proportions encore juvéniles de cet individu laissent un doute sur cette estimation de plus de $80 \mathrm{~cm}$ de longueur de carapace. En revanche Jossigny a plus fidèlement figuré un crâne et sa mandibule, encore munis des ramphothèques (étuis cornés qui recouvrent les mâchoires); la crête supraoccipitale est brisée. Plusieurs particularités diagnostiques du genre Cylindraspis telles que bordure maxillaire labiale fortement découpée en dents de scie, tubercules odontö̈des sur les surfaces triturantes maxillaires et mandibulaires, crête pariétale latérale ou cylindraspidienne dans la fosse temporale sont bien visibles. Il est vraisemblable que ce soit le crâne auquel Lacépède (1788: 156) a fait allusion : "Le Cabinet du Roi renferme aussi une tête de tortue de terre apportée de l'Isle Rodrigue, et qui a près de cinq pouces de longueur" (moins de $135 \mathrm{~mm}$ ), car il a eu en mains plusieurs objets dessinés par Jossigny, comme la carapace du type de la tortue noirâtre (Pelusios subniger) qu'il a décrite.
Avant la fin du XVIIIe siècle, date à laquelle on situe l'extinction des tortues de Rodrigues (North-Coombes 1986; Bour et al. 2014a), la plus grande des deux espèces de cette île était déjà représentée sur quatre documents distincts (I à IV); un seul fut publié (les tortues grossièrement dessinées sur le frontispice du Voyage... de François Leguat, publié en 1707, ne sont pas identifiables). La plus ancienne illustration, la seule en couleur, figure une femelle adulte (I) : c'est une gouache du peintre Claude Aubriet (1651-1743), rangée parmi les vélins, qui doit être datée de 1730 environ. Le squelette de cette tortue a été préparé et est conservé au Muséum de Paris ( $\mathrm{N}^{\circ}$ MNHN-AC-A.5222). Nous venons de mentionner les dessins de Jossigny pour Commerson (II), exécutés vers 1770. Le Muséum d'Histoire naturelle de Vienne possède dans ses collections l'une des quelques carapaces des tortues rapportées des "Indes ", aujourd'hui identifiées; de par sa forme unique on sait maintenant qu'elle appartient à cette même espèce ( $\left.\mathrm{N}^{\circ} \mathrm{NMW} 1461\right)$. Le genre Cylindraspis a été créé en 1835 par Leopold Fitzinger (18021884), alors directeur du Muséum de Vienne, à partir de cette carapace, le nom choisi soulignant sa forme singulière, cylindroïde, créée par des flancs arrondis et sans carène. Auparavant, en novembre 1783, cette carapace avait été dessinée par J. Robert (III), accompagnée de cette légende : 


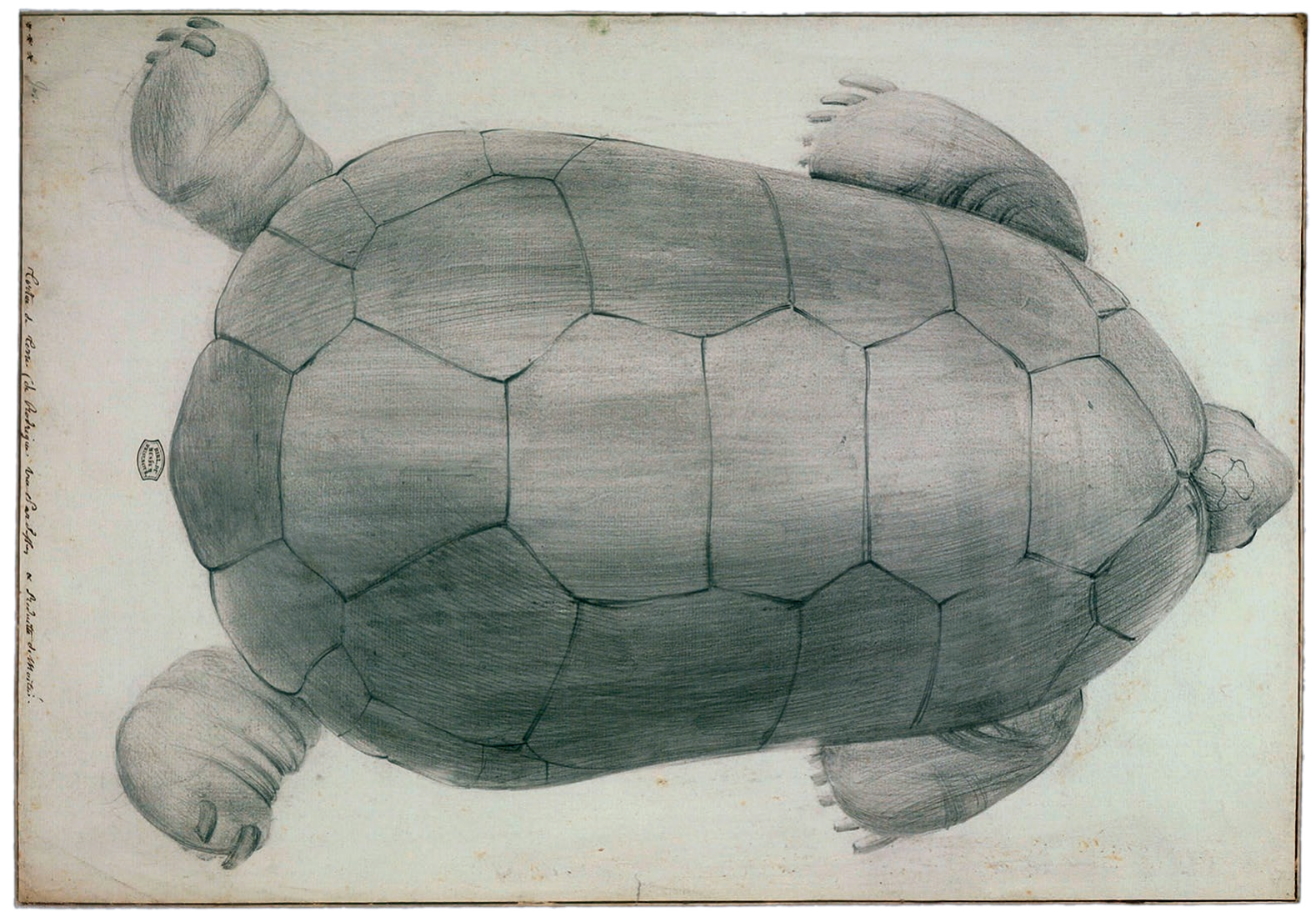

FIG. 14. - Tortue terrestre de l'île Rodrigues (Cylindraspis). Annotation : "Tortue de Terre de Rodrigue. Vue Par Dessus et Reduite de moitié ». Identification : Cylindraspis vosmaeri (Suckow, 1798), de Rodrigues. Dessin de Jossigny, vue dorsale, 512 × 355 mm. MNHN, Bibliothèque centrale, Ms $282-1,13$.

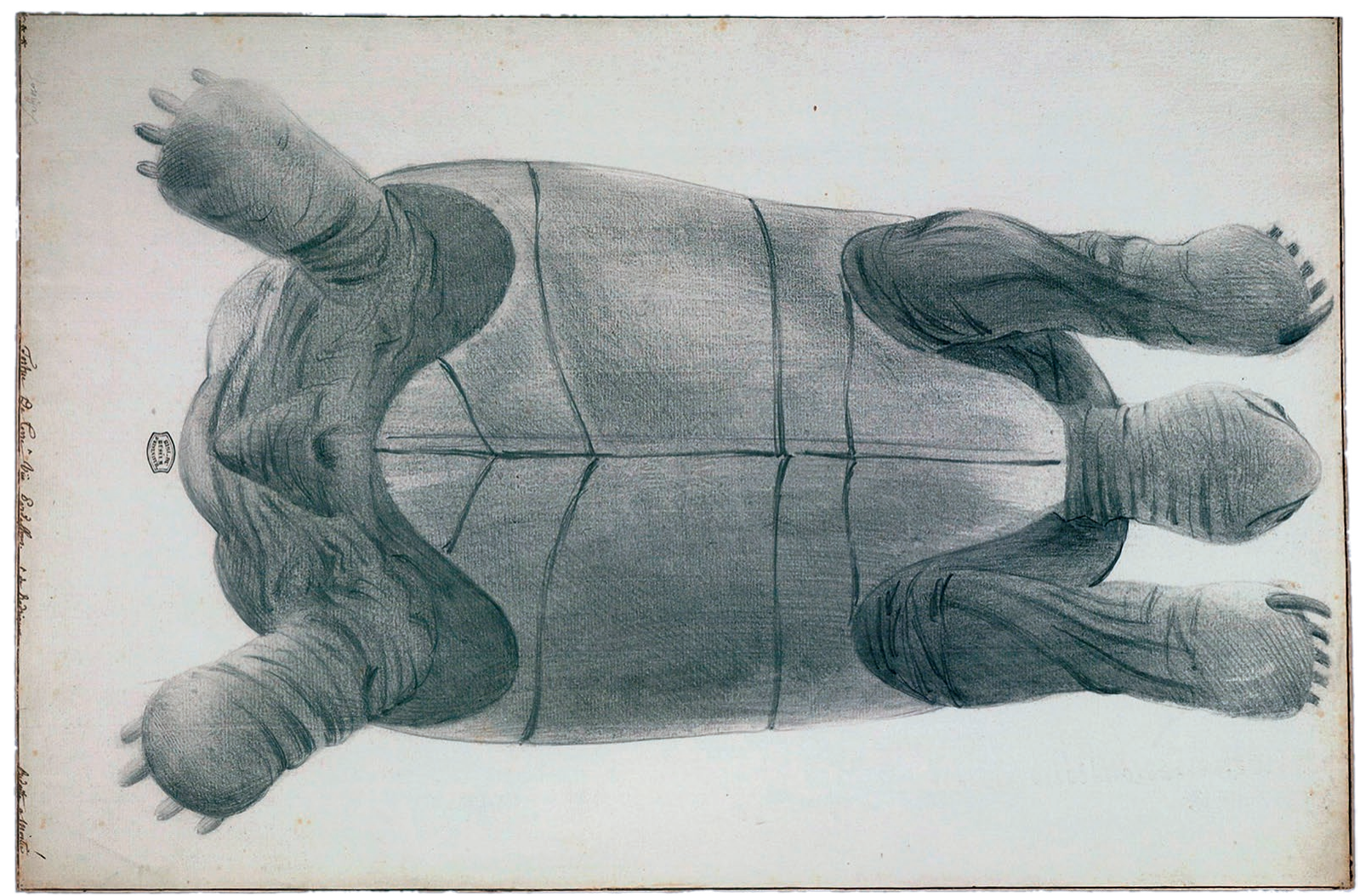

FIG. 15. - Tortue terrestre de l'île Rodrigues (Cylindraspis). Annotation : «Tortue de Terre. Vuë Par Dessous. de Rodrigue. Reduite a moitié ». Identification : Cylindraspis vosmaeri (Suckow, 1798), de Rodrigues. Dessin de Jossigny, vue ventrale, $520 \times 353 \mathrm{~mm}$. MNHN, Bibliothèque centrale, Ms $282-1$, 10 . 


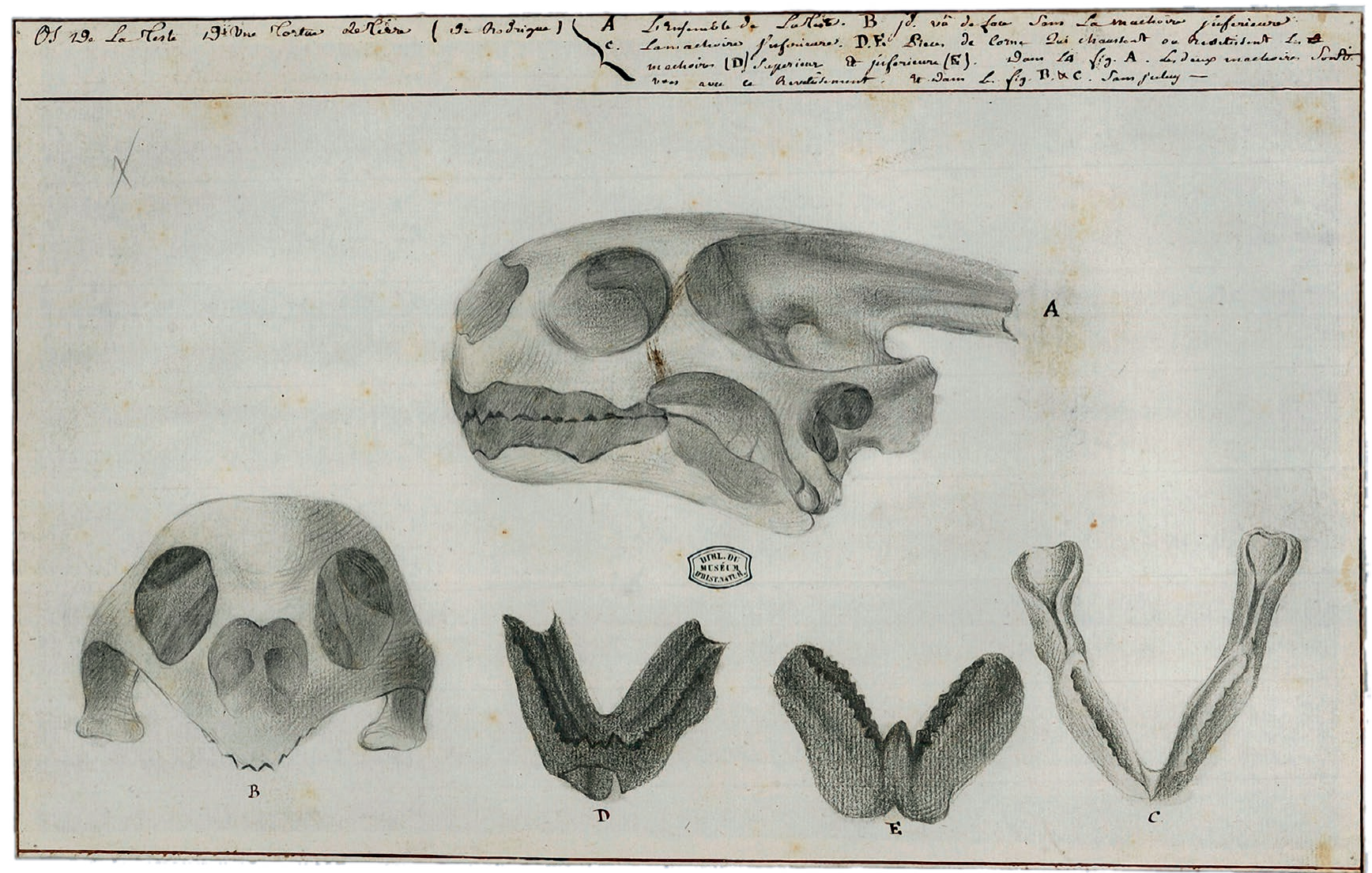

FIG. 16. - Tortue terrestre (crâne et mandibule) de l'île Rodrigues (Cylindraspis). Annotation : « Os De La Teste D’Une Tortue de Terre (De Rodrigue) A. L'Ensemble de La Teste. B. id. vu de face Sans La machoire inferieure. C. La machoire inferieure. D. E. Pieces de Corne Qui chaussent ou revetissent Les machoires [D] superieur \& inferieure [E]. Dans La Fig. A. Les deux machoires Sont vues avec le Revetissement. Et Dans Les Fig. B. \& C. Sans iceluy ". Identification : Cylindraspis vosmaeri (Suckow, 1798), de Rodrigues. Dessin de Jossigny, $347 \times 215 \mathrm{~mm}$. MNHN, Bibliothèque centrale, Ms 282-1, 11.

"Tortue presque cylindrique à écailles particulièrement lisses, et noires. Cette tortue est terrestre. Elle est singulière en ce qu'elle est bombée, ce qui lui donne une figure presque cylindrique. Les écailles partielles sont entièrement lisses, sans cannelures et sans stries. Elle est noire. Elle est conservée dans le cabinet de M. le Duc d'Orléans ". Le document est resté manuscrit (MNHN, Bibliothèque centrale, Ms 2189 folio 198). On ne connaît pas les modalités du transfert de la carapace au Muséum autrichien : elle a été probablement donnée, soit comme double, soit en tant que " réparation " en 1815. Curieusement, elle faillit disparaître des collections de Vienne il y a quelques dizaines d'années : en mauvais état, elle avait été récupérée in extremis sur un tas d'ordures! Une étiquette jointe au spécimen NMW 1461 rappelle ce haut fait. Néanmoins c'est Johann David Schoepff (1752-1800) qui le premier, en 1795, a publié une description et une illustration (IV) de cette espèce de tortue, à partir de documents communiqués par Vosmaer (Schoepff 1795, in 1792-1801a: 103 et 17921801b: 120). Arnout Vosmaer (1720-1799), directeur du Cabinet d'histoire naturelle du Stathouder à La Haye, avait eu sous les yeux une carapace, qu'il pensait provenir du Cap, et qui existe toujours dans les collections du Muséum d'histoire naturelle de Leiden ( $\mathrm{N}^{\circ} \mathrm{RMNH}$ 6001). Schoepff a nommé la tortue "Testudo indica. Vosmaeri ", c'est-à-dire Testudo indica, d'après Vosmaer, pour la différencier de "Testudo indica. Perrault ", celle décrite et figurée par Claude Perrault (1676) - aujourd'hui Cylindraspis indica (Schneider, 1783), originaire de La Réunion. D’un point de vue nomenclatural, Schoepff n'a pas créé de nouveau taxon nominal, autrement dit il n'est pas l'auteur de Testudo vosmaeri. C'est Suckow (1798: 57) qui, en proposant, trois ans plus tard, le trinôme Testudo indica vosmaeri, est l'auteur du nom, l'holotype étant la carapace mentionnée par Schoepff. Plus tard, Fitzinger (1826: 44) utilisa, le premier semble-t-il, la combinaison Testudo vosmaeri. Par la suite, l'espèce fut attribuée soit à Fitzinger (e.g., Siebenrock 1909: 537), soit à Schoepff (e.g., Lindholm 1929: 286). Ce n'est que récemment que Suckow a été correctement reconnu comme son auteur (cf. e.g., Bour 1987, 1988, 1994; Fritz \& Havaš 2007; Rhodin \& Carr 2009; Turtles and Tortoises Taxonomic Group 2014). Deux autres noms sont considérés comme étant des synonymes subjectifs de Cylindraspis vosmaeri (Suckow, 1798) : Testudo rodericensis Günther, 1873 est fondée sur des os subfossiles exhumés des cavernes de Rodrigues, dont une vertèbre cervicale C6 (lectotype), et Testudo commersoni Vaillant, 1898 a pour holotype la grande tortue de Rodrigues évoquée plus haut, celle dessinée par Jossigny (Bour 1985). Tout ce matériel a récemment été figuré par Bour et al. (2014b). 


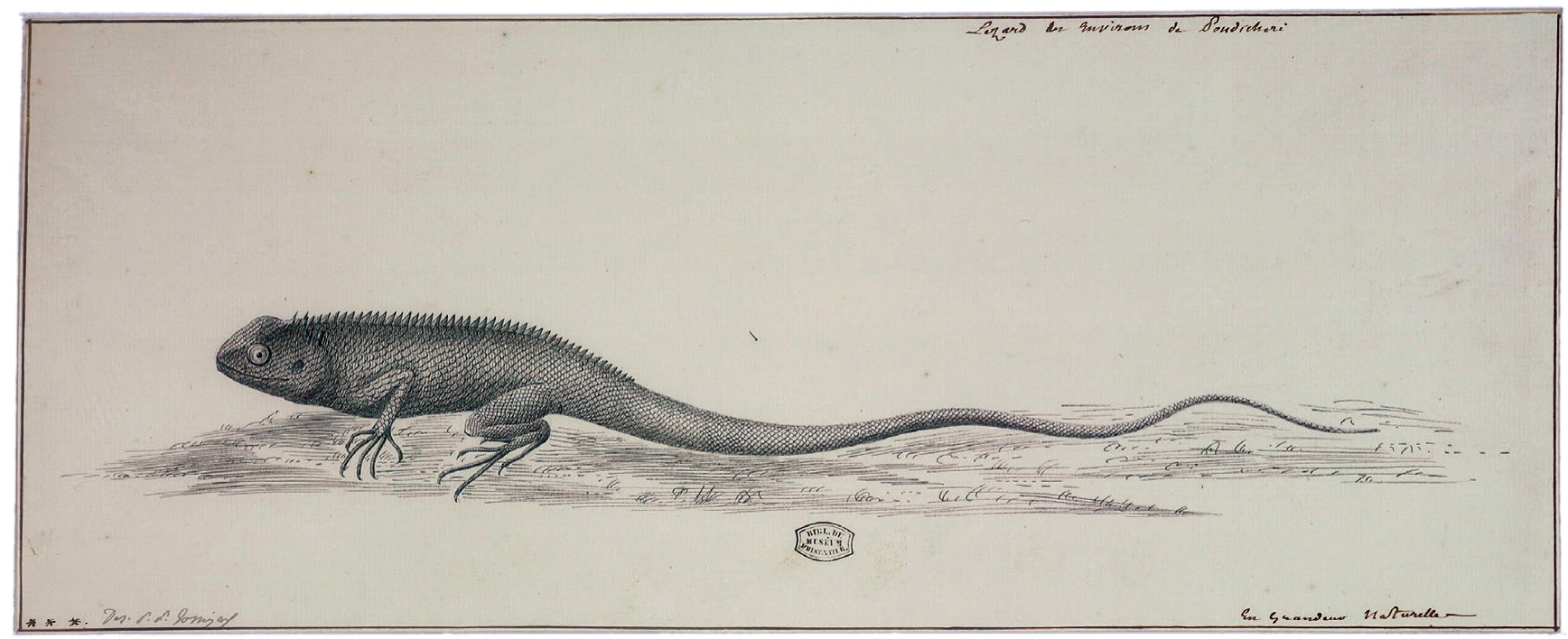

FIG. 17. - Un lézard, agame, des environs de Pondichéry, Inde (Calotes). Annotation : « Lezard des Environs de Pondicheri [...] En Grandeur Naturelle ». Longueur estimée : $35 \mathrm{~cm}$. Identification : Calotes versicolor (Daudin, 1802). Dessin de Jossigny, $425 \times 170$ mm. MNHN, Bibliothèque centrale, Ms $282-1,14$.

\section{LES LÉZARDS ET LES SERPENTS}

Les douze autres planches de reptiles représentent huit lézards et quatre couleuvres. Il faut reconnaître que la plupart de ces planches sont surtout intéressantes par leur valeur historique, car ce sont les premières illustrations « scientifiques " des espèces représentées. Comme nous l'avons déjà relevé, en dehors de Vaillant (1898) qui a examiné les dix planches des tortues, aucun scientifique ne s'est intéressé à l'ensemble des autres reptiles. Cheke (2008) a identifié le Caméléon des Seychelles comme Calumna tigris, maintenant Archaius tigris; par erreur il a attribué les planches de couleuvres seychelloises à Jossigny, alors qu'elles portent le nom de Sonnerat. Si les lézards à une exception près sont identifiables au niveau spécifique, trois des quatre serpents ne montrent pas suffisamment de caractères distinctifs pour que l'on puisse leur attribuer avec sûreté un nom d'espèce ou même de genre. Par ailleurs, plus de la moitié des planches ne portent pas le nom de l'artiste, et, de toute façon, il se peut que l'identité du dessinateur ait été ajoutée, postérieurement à la création du dessin. Les trois planches 15,18 et 19 (Figs 18, 21 et 22) ont en commun plusieurs particularités : elles ont les mêmes dimensions; elles sont colorées; l'artiste n'est pas identifié; elles sont annotées, avec une signature de la main de Commerson; enfin, elles représentent des animaux de la baie d'Antongil, à Madagascar, une localité relativement précise mais étonnante, car Commerson ne s'y est pas rendu lui-même. L'utilisation de la couleur fait davantage penser à Sonnerat, aquarelliste, qu'à Jossigny, essentiellement dessinateur. Quelques uns, parmi les spécimens représentés, ont pu être rapportés à Paris : la brève liste établie par Maillart Dumesle (Morel 2011a) indique que la caisse $\mathrm{n}^{\circ} 14$ contenait " [...] des quadrupèdes, des reptiles et des insectes dans soixante-six flacons remplis d'esprit de vin » et la caisse $\mathrm{n}^{\circ} 30$ «[...] des flacons remplis d'oiseaux, serpents, poissons, etc. "
Dans l'ordre de leur numérotation, du folio 14 au folio 25, ces planches de reptiles montrent :

\section{Planche 14 (Fig. 17)}

Un lézard, agame (Calotes), des environs de Pondichéry - Jossigny. Annotation : "Lezard des environs de Pondicheri [...] En Grandeur Naturelle ». Longueur totale estimée : $35 \mathrm{~cm}$. Identification: Calotes versicolor (Daudin, 1802). Cet agame occupe un vaste territoire en Asie méridionale, de l'Iran à la Chine; introduit aux Mascareignes (île Maurice, La Réunion, récemment à Rodrigues) et aux Seychelles, mais postérieurement au séjour de Jossigny.

\section{Planche 15 (Fig. 18)}

Un lézard, caméléon (Furcifer), de la baie d'Antongil (aquarelle) Artiste inconnu. Annotation au verso, avec la signature de Commerson : «Le Chameleon de La Baye D'antongil». Identification : Furcifer pardalis (Cuvier, 1829). Espèce couvrant un vaste territoire à Madagascar, introduite à La Réunion.

\section{Planche 16 (Fig. 19)}

Un lézard, gecko nocturne (Hemidactylus), de l'Isle de FranceJossigny. Annotation : "L'un des plus Gros [...] Le Lezard Domestique de L'isle de France ». Identification : Hemidactylus frenatus Duméril \& Bibron, 1836. Espèce anthropophile, à vaste aire de répartition longeant les rivages de l'océan Indien et du Pacifique occidental, incluant Madagascar et les Mascareignes, devenue presque cosmopolite par suite d'introductions involontaires par les navigateurs.

\section{Planche 17 (Fig. 20)}

Un lézard, gecko diurne (Phelsuma), de l'Isle de France - Jossigny. Annotation au verso : "Hist. Nat. de l'Isle de France». Identification : Phelsuma ornata Gray, 1825. Lézard très coloré endémique de l'île Maurice. 


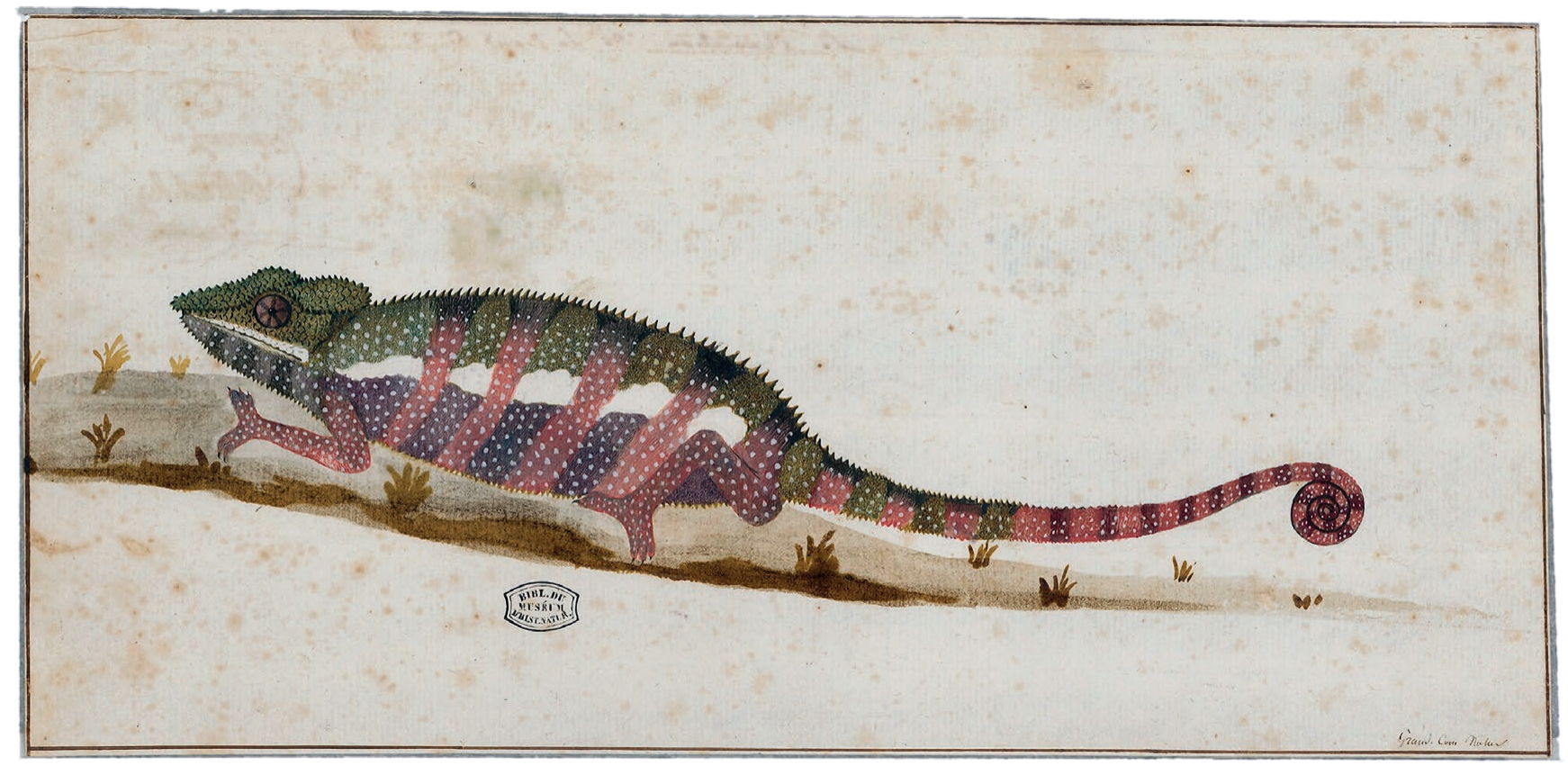

FIG. 18. - Un lézard, caméléon, de la baie d'Antongil, Madagascar (Furcifer). Annotation : « Grand. Cum Natur »; au verso, avec la signature de Commerson : «Le Chameleon de La Baye D'antongil ». Longueur estimée : $14 \mathrm{~cm}$ (sans la queue), $32 \mathrm{~cm}$ (avec la queue). Identification : Furcifer pardalis (Cuvier, 1829). Artiste inconnu, peut-être Sonnerat. Aquarelle, 332 × 157 mm. MNHN, Bibliothèque centrale, Ms 282-1, 15.

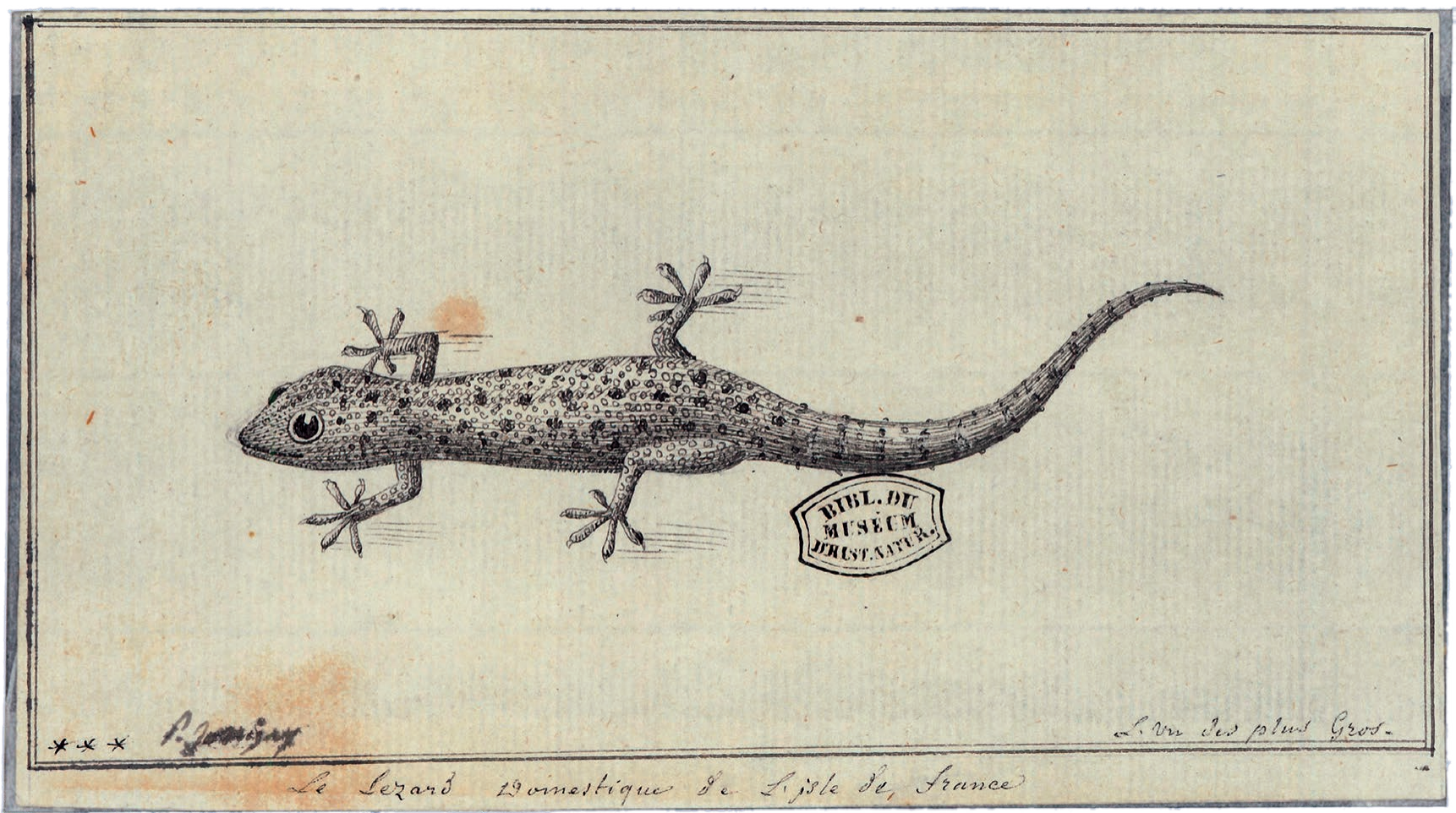

FIG. 19. - Un lézard, gecko nocturne, de l'île Maurice (Hemidactylus). Annotations : « L'un des plus Gros [...] Le Lezard Domestique de L'isle de France ». Identification: Hemidactylus frenatus Duméril \& Bibron, 1836. Dessin de Jossigny, $148 \times 78 \mathrm{~mm}$. MNHN, Bibliothèque centrale, Ms $282-1$, 16 .

Planche 18 (Fig. 21)

Un lézard (Zonosaurus), de la baie d'Antongil (aquarelle) Artiste inconnu. Annotation au verso, avec la signature de Commerson : "Lacertus [...] Lezard de Terre de La Baye
D'antongil». Identification : Zonosaurus madagascariensis (Gray, 1831). Lézard atteignant $30 \mathrm{~cm}$ de longueur totale présent à Madagascar, aux Glorieuses et à Cosmoledo (Seychelles). 


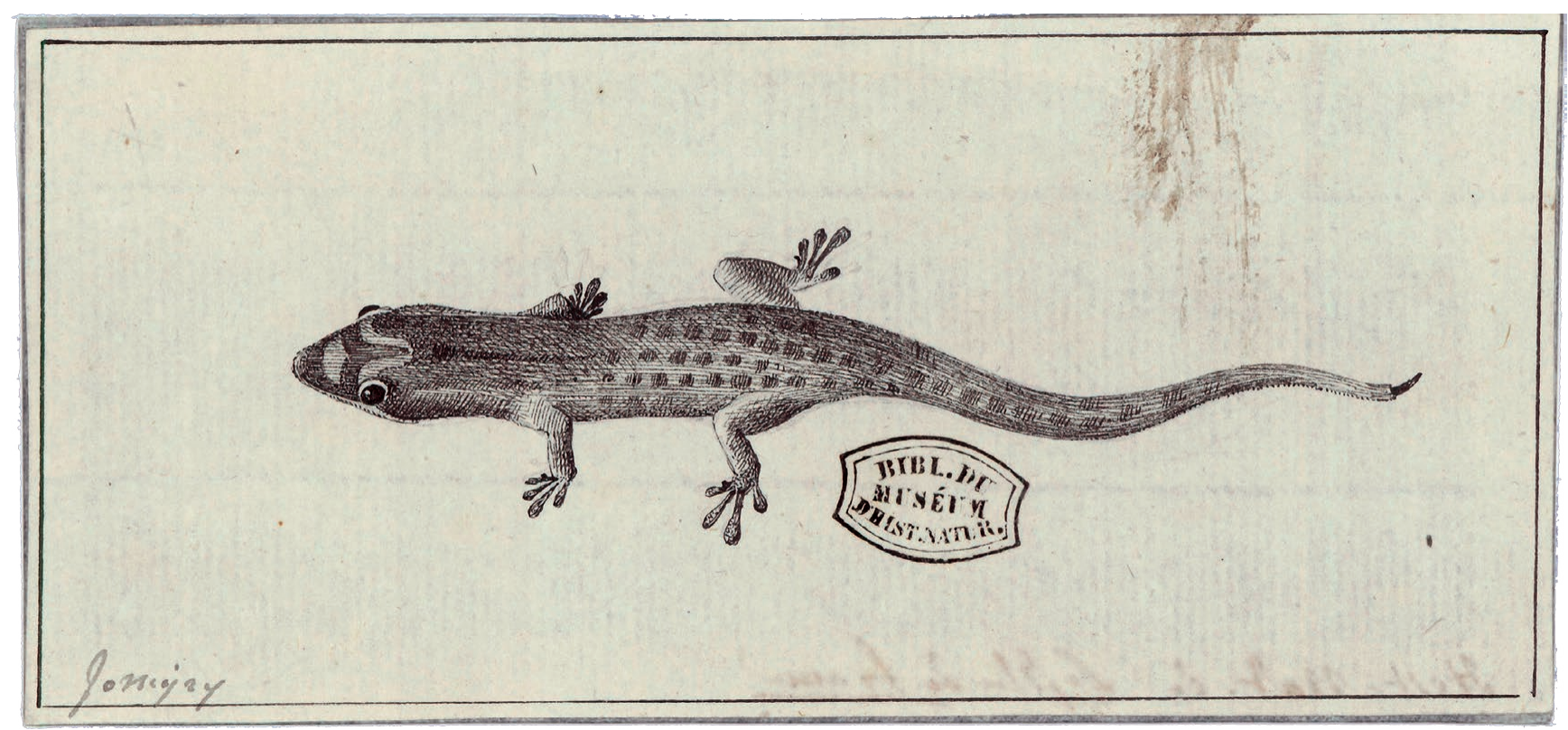

FIG. 20. - Un lézard, gecko diurne, de l'île Maurice (Phelsuma). Annotation au verso : "Hist. Nat. de l'Isle de France ". Identification : Phelsuma ornata Gray, 1825. Dessin de Jossigny, $30 \times 58 \mathrm{~mm}$. MNHN, Bibliothèque centrale, Ms 282-1, 17.

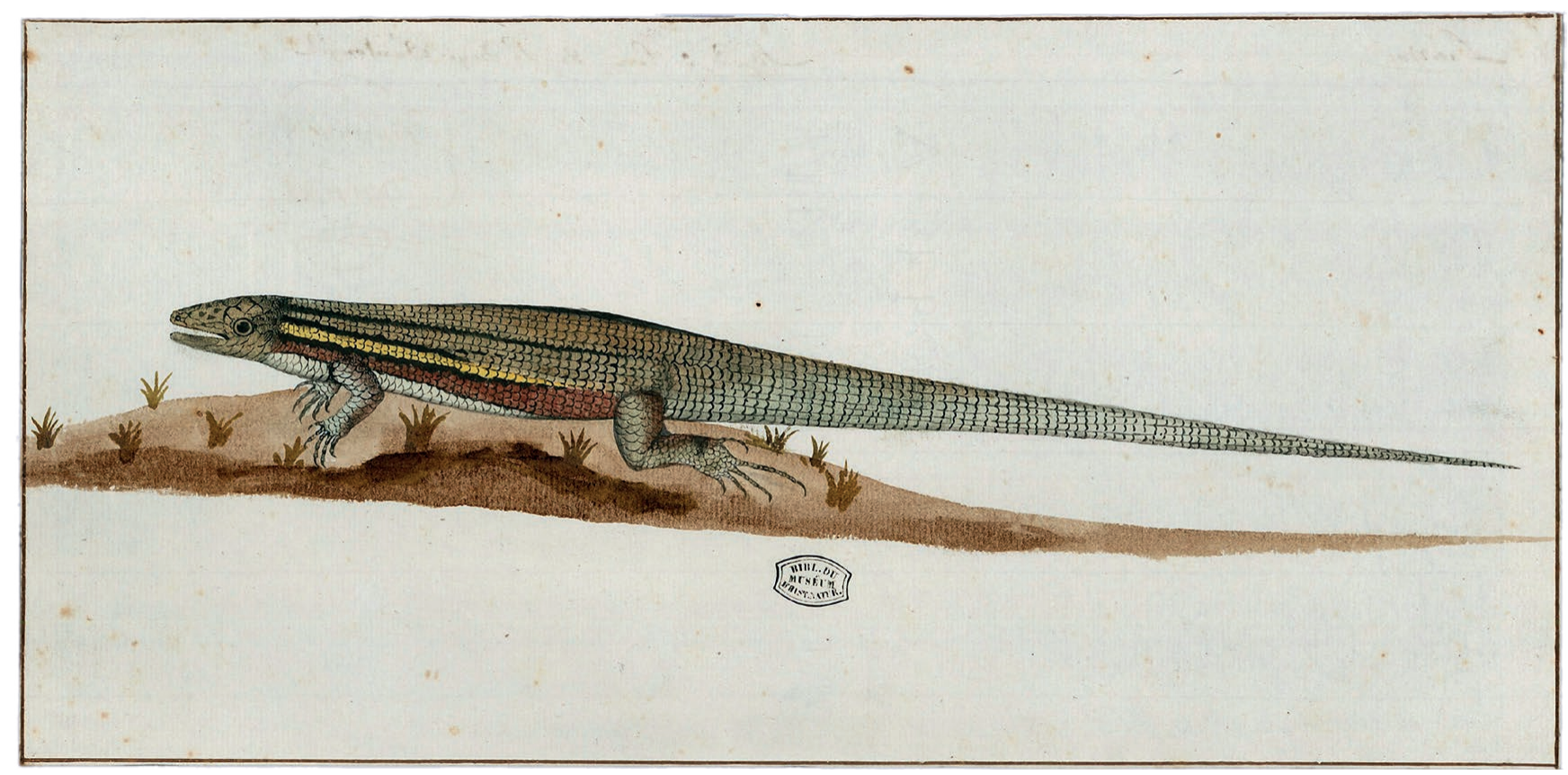

FIG. 21. - Un lézard, de la baie d'Antongil, Madagascar (Zonosaurus). Annotation au verso, avec la signature de Commerson : « Lacertus [...] Lezard de Terre de La Baye D'antongil ». Identification : Zonosaurus madagascariensis (Gray, 1831). Artiste inconnu, peut-être Sonnerat. Aquarelle, $328 \times 158$ mm. MNHN, Bibliothèque centrale, Ms 282-1, 18.

Planche 19 (Fig. 22)

Un lézard, gecko diurne (Phelsuma), de la baie d'Antongil (aquarelle) - Artiste inconnu. Annotation au verso, avec la signature de Commerson : «Lacertus [...] Petit Lezard de Maison de La Baye D’antongil». La représentation par petits points colorés est singulière. Identification : genre Phelsuma, espèce probable $P$. lineata Gray, 1842, espèce endémique de Madagascar, à aire de répartition étendue.
Planche 20 (Fig. 23)

Un lézard, caméléon (Archaius, précédemment Calumna), des Seychelles - Artiste inconnu. Annotation : «Cameleon des Isles Sechelles». Identification: Archaius tigris (Kuhl, 1820). Espèce endémique des Seychelles. Ni Commerson, ni Sonnerat ni Jossigny n'ont accosté aux Seychelles, il est donc vraisemblable que, vu le dessin de sa position, ce caméléon ait été rapporté vivant à l'Isle de France pour y être dessiné. 


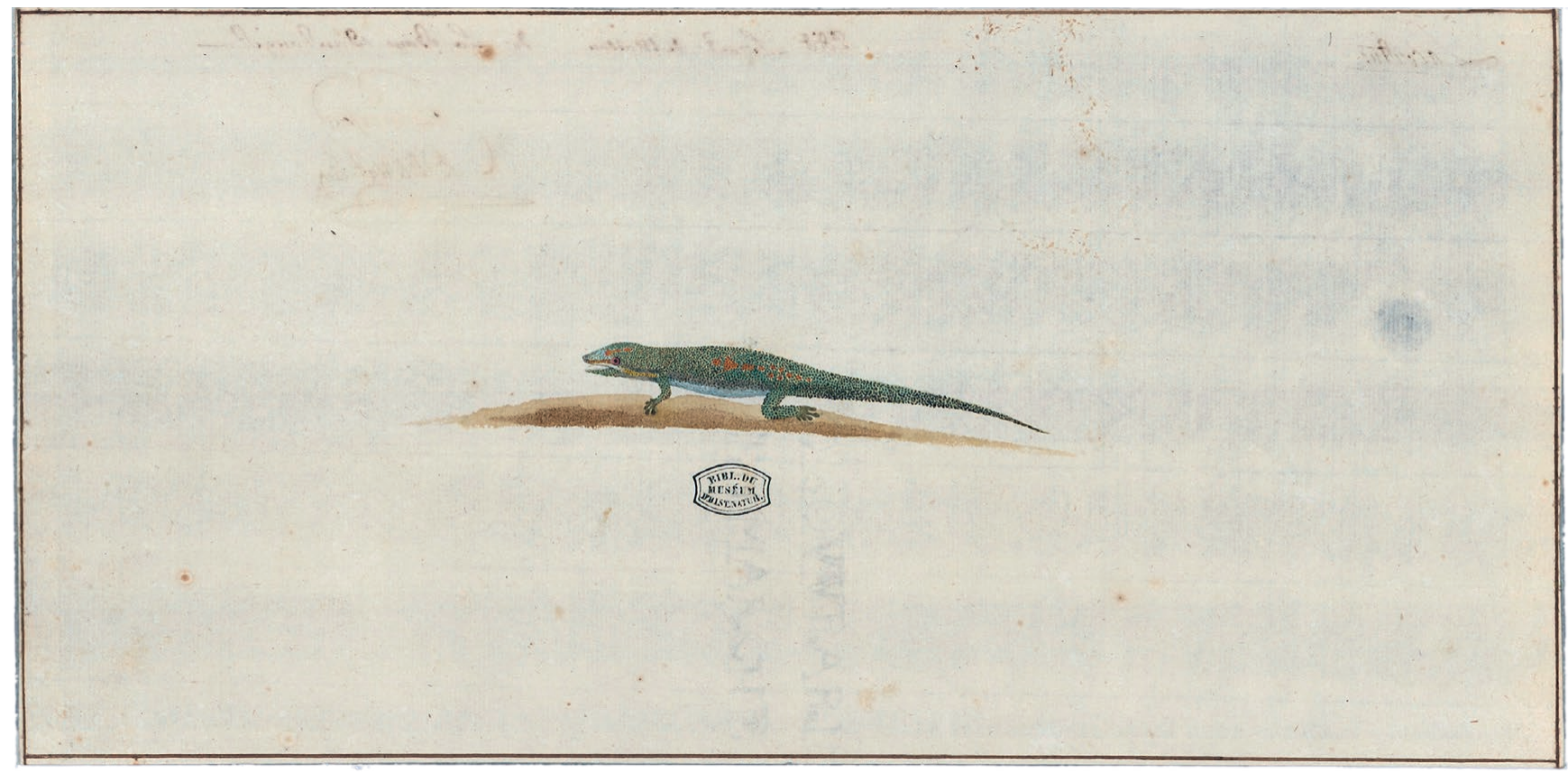

FIG. 22. - Un lézard, gecko diurne, de la baie d'Antongil, Madagascar (Phelsuma). Annotation au verso, avec la signature de Commerson : « Lacertus [...] Petit Lezard de Maison de La Baye D'antongil ». Identification : genre Phelsuma, espèce possible P. lineata Gray, 1842. Artiste inconnu, peut-être Sonnerat. Aquarelle (la représentation par petits points colorés est singulière), $325 \times 158 \mathrm{~mm}$. MNHN, Bibliothèque centrale, Ms 282-1, 19 .

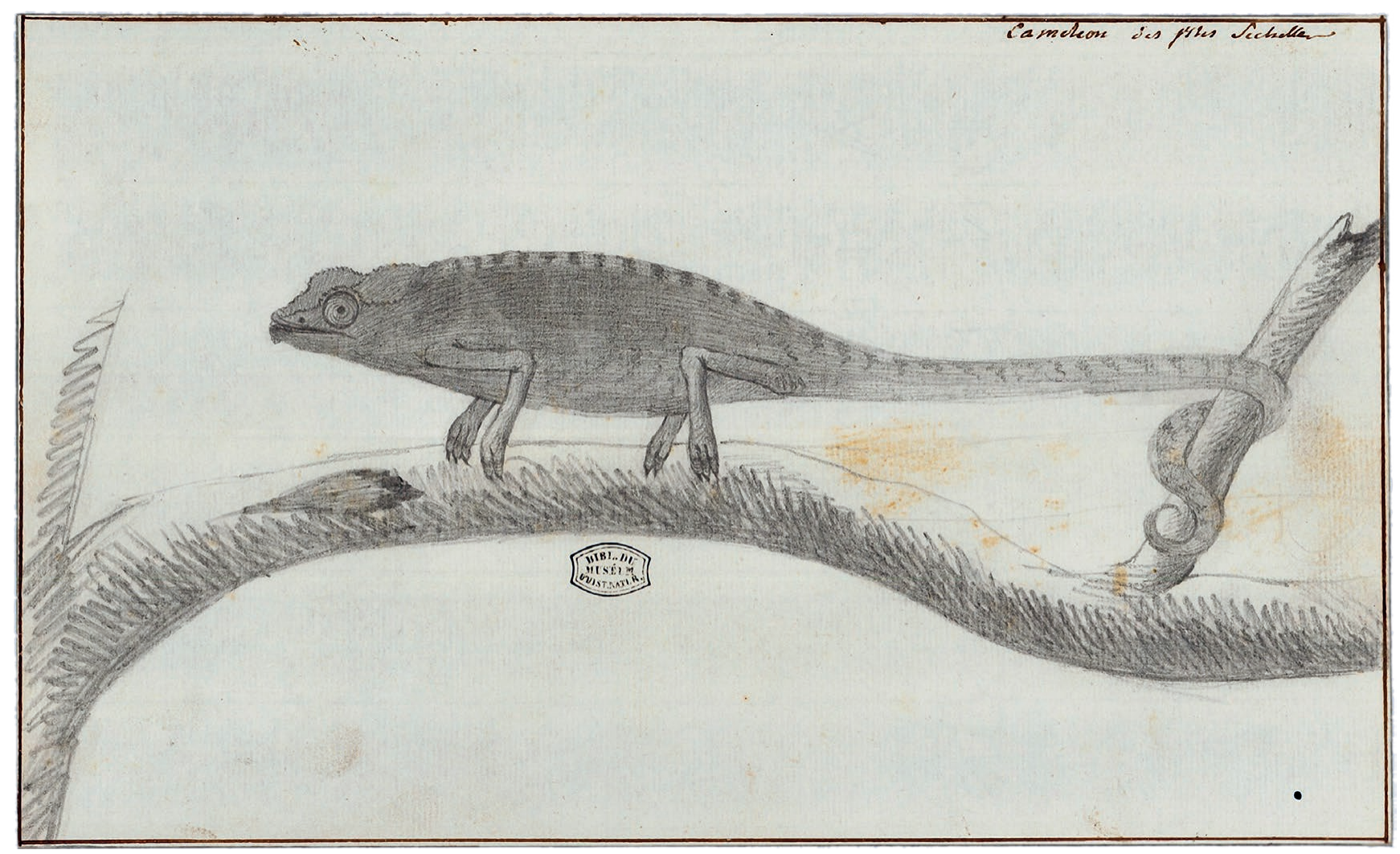

FIG. 23. - Un lézard, caméléon, des Seychelles (Archaius = Calumna). Annotation : "Cameleon des Isles Sechelles ». Identification : Archaius tigris (Kuhl, 1820). Artiste inconnu, $280 \times 167 \mathrm{~mm}$. MNHN, Bibliothèque centrale, Ms 282-1, 20. 


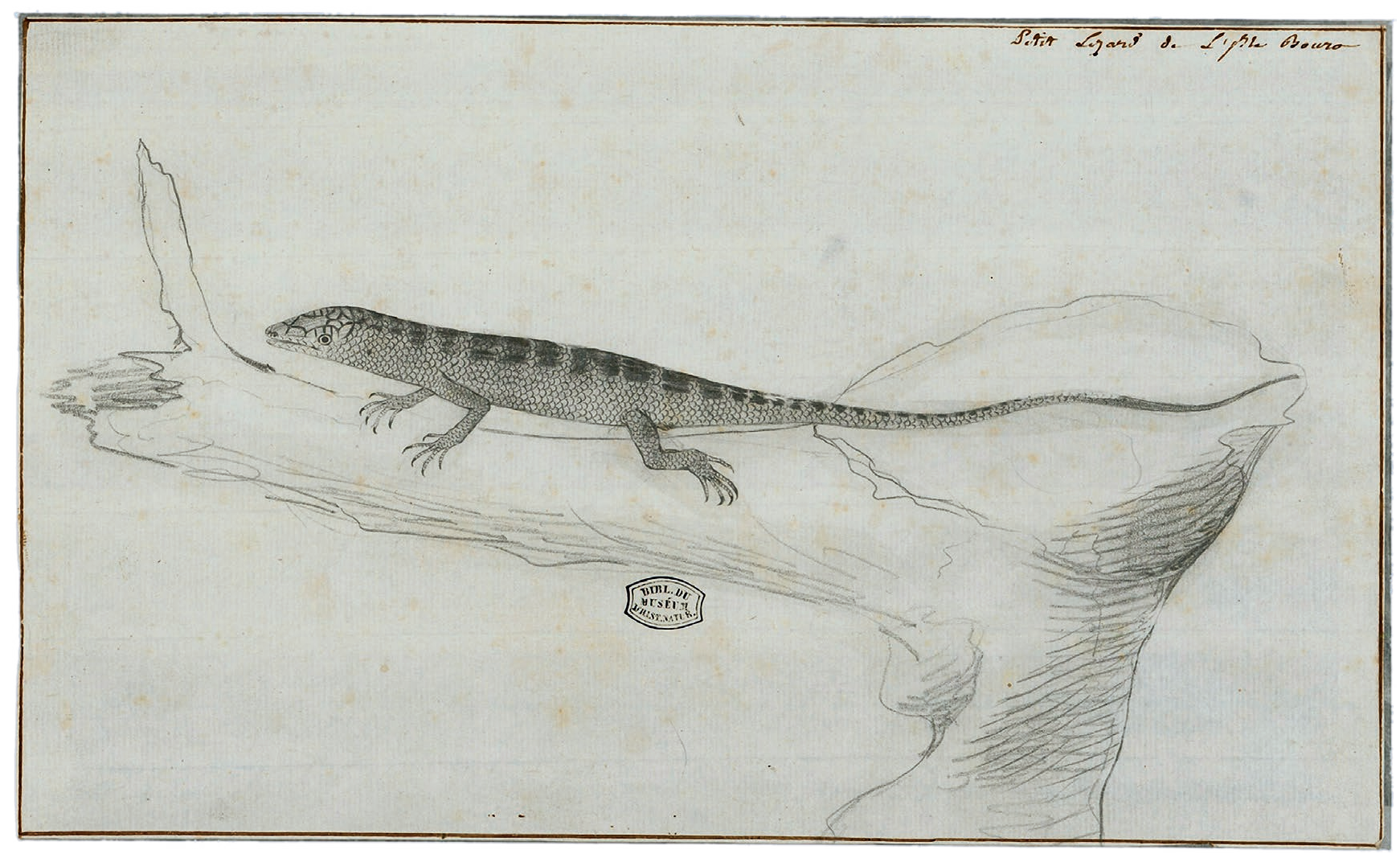

FIG. 24. - Un lézard, scinque, de l'île Buru, Indonésie (Lamprolepis ou Emoia ?). Annotation : « Petit Lezard de L'Isle Bouro ». Identification : probablement genre Lamprolepis ou Emoia, mais l'origine « Isle Bouro » peut être mise en doute. Artiste inconnu, $282 \times 168 \mathrm{~mm}$. MNHN, Bibliothèque centrale, Ms $282-1,21$.

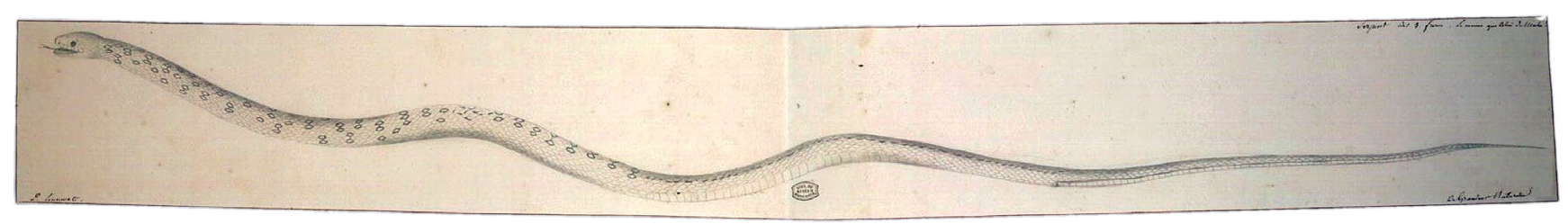

FIG. 25. - Une couleuvre, des Seychelles (Lamprophis ?). Annotation : “Serpent Des 3. frères. Le même que Celui de Mahé ? [...] De Grandeur Naturelle ». Longueur estimée : $95 \mathrm{~cm}$. L'identification n'est fondée que sur l'origine géographique présumée. Lycognathophis possède des écailles dorsales rhombiques et carénées, une tête très nettement distincte du tronc; ces caractères sont absents ici, ce qui permet de penser plutôt à Lamprophis. Sonnerat, $920 \times 110$ mm. MNHN, Bibliothèque centrale, Ms 282-1, 22.

Planche 21 (Fig. 24)

Un lézard, scinque (Lamprolepis ou Emoia ?), de l'île Bouro (Buru) - Artiste inconnu. Annotation : "Petit Lezard de L'Isle Bouro ". Identification : probablement une espèce du genre Emoia ou du genre Lamprolepis (famille des Scincidae), notamment d'après l'habitus, mais le patron de coloration est atypique. L'espèce n'a pas pu être déterminée et l'origine géographique donnée au spécimen pourrait être mise en doute.

\section{Planche 22 (Fig. 25 \& Fig. 28)}

Une couleuvre (Lamprophis ?), des "Trois Frères " (Seychelles) - Sonnerat. Annotation : "Serpent Des 3. frères. Le même que Celui de Mahé ? [...] De Grandeur Naturelle". Longueur estimée : $95 \mathrm{~cm}$. L'identification n'est fondée que sur l'origine géographique présumée : les quelques détails figurés ne permettent pas de reconnaître l'une ou l'autre des deux espèces endémiques des Seychelles, Lycognathophis seychellensis (Schlegel, 1837) et Lamprophis geometricus (Schlegel, 1837), pourtant relativement distinctes et identifiables. Lycognathophis possède des écailles dorsales rhombiques et carénées, une tête très nettement distincte du tronc; ces caractères sont absents ici, ce qui permet de penser plutôt à Lamprophis. Pour une description précise de ces deux genres et espèces, voir Schlegel (1837: 111 et 201) et Boulenger (1893: 317 et 329), avec les figures de Schlegel (1844: pl. 43, 9-14) et de Jan \& Sordelli (1870: pl. 3, 2), ainsi que Nussbaum (1984).

\section{Planche 23 (Fig. 26 \& Fig. 28)}

Une couleuvre (Lycognathophis ?), de Mahé (Seychelles) Sonnerat. Annotation : "Serpent Des Isles Mahé ou Sechelles [...] De Grandeur Naturelle ». Longueur estimée : $55 \mathrm{~cm}$. Les caractères donnés ci-dessus - tête distincte du cou, 


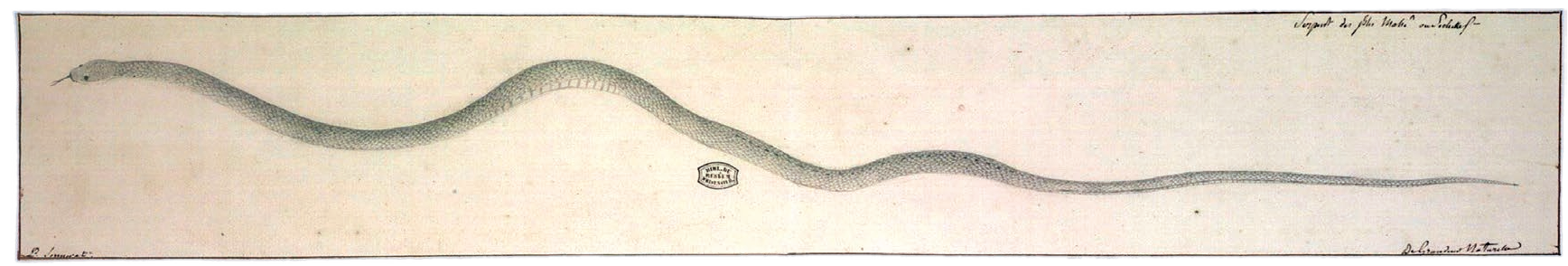

FIG. 26. - Une couleuvre, des Seychelles (Lycognathophis ?). Annotation : « Serpent Des Isles Mahé ou Sechelles [...] De Grandeur Naturelle ». Longueur estimée : $55 \mathrm{~cm}$. Voir les remarques à propos de la figure précédente. Le dessin montre un cou relativement bien marqué et des carènes sur les écailles dorsales plus ou moins rhombiques, caractères de Lycognathophis. Sonnerat, $630 \times 98$ mm. MNHN, Bibliothèque centrale, Ms 282-1, 23.

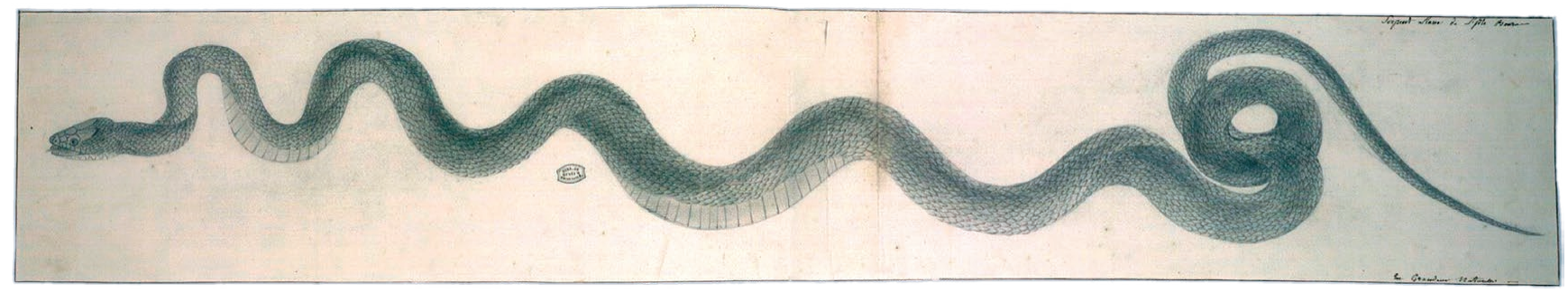

FIG. 27. - Une couleuvre, de l'île Buru, Indonésie (Boiga ou Stegonotus ?). Annotation : " Serpent Liane de L'Isle Bouro [...] Grandeur Naturelle ". Longueur estimée : $140 \mathrm{~cm}$. De même que le lézard de cette île des Moluques, cette couleuvre n'a pu être précisément déterminée, malgré la qualité plutôt bonne du dessin. Artiste inconnu, 900 × $157 \mathrm{~mm}$. MNHN, Bibliothèque centrale, Ms 282-1, 24.
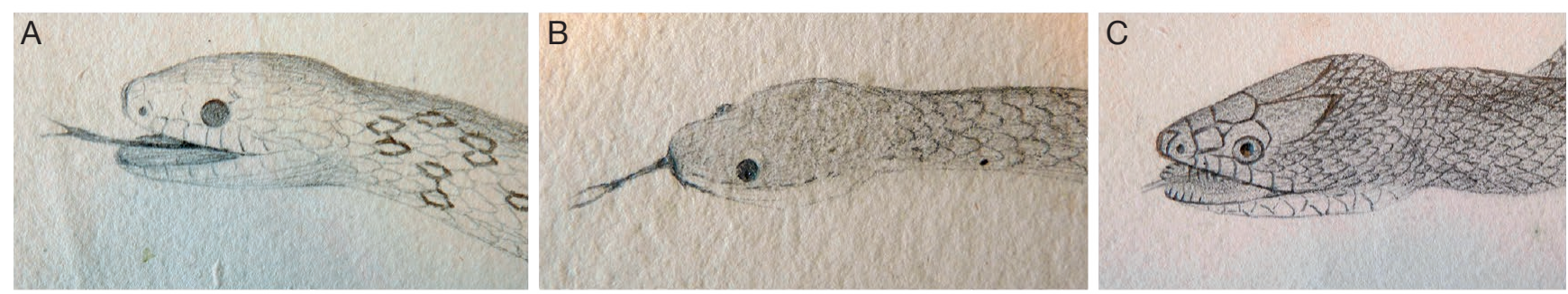

FIG. 28. - Gros plans des têtes des trois couleuvres précédentes; l'échelle n'est pas respectée : A, "Serpent Des 3 frères » (Fig. 25); B, « Serpent Des Isles Mahé ou Sechelles » (Fig. 26); C, « Serpent Liane de L'Isle Bouro " (Fig. 27).

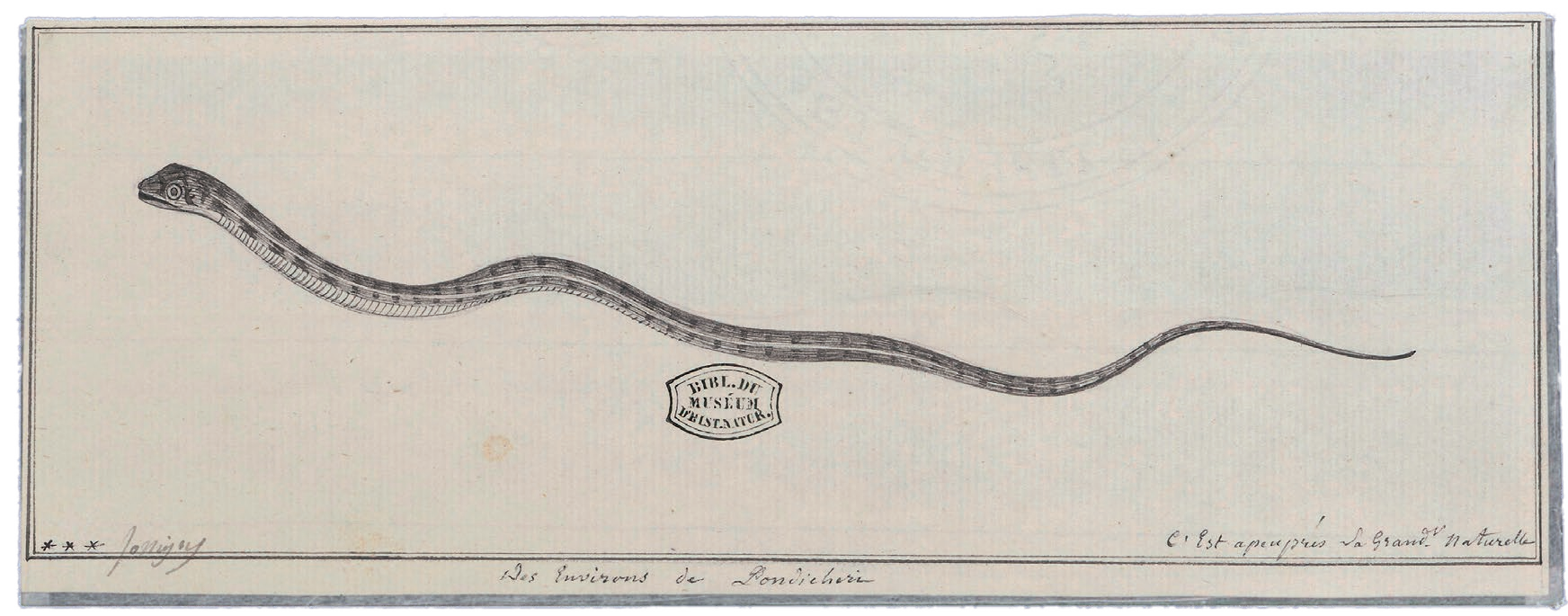

FIG. 29. - Une couleuvre, des environs de Pondichéry, Inde (Amphiesma). Annotation : « C'Est a peu près Sa Grandr. Naturelle [...] Des Environs de Pondicheri ». Longueur estimée : $18 \mathrm{~cm}$. Détermination spécifique : Amphiesma stolatum (Linnaeus, 1758). Dessin de Jossigny, $216 \times 77 \mathrm{~mm}$. MNHN, Bibliothèque centrale, Ms 282-1, 25. 
écailles dorsales portant une carène - sont présents ici, ainsi qu'une coloration du dessous plus claire, commençant aux écailles labiales : avec réserve, ce serpent est attribué au genre Lycognathophis.

\section{Planche 24 (Fig. 27 \& Fig. 28)}

Une couleuvre indéterminée (Boiga ou Stegonotus ?), de l'île Bouro (Buru) - Artiste inconnu. Annotation : "Serpent Liane de L'Isle Bouro [...] De Grandeur Naturelle». Longueur estimée : $140 \mathrm{~cm}$. L'identification formelle n'a pas été possible, l'ensemble des quelques caractères montrés avec suffisamment de précision ne correspondant pas à l'une des huit espèces actuellement connues de l'île Buru : tête large, déprimée, triangulaire, bien distincte du cou, yeux relativement petits à pupille ronde, écaille rostrale relevée, en coin, minuscule frontale (?), écailles dorsales petites, rhombiques, pointues en arrière, apparemment carénées... Peut-on se fier à l'exactitude du dessin, pourtant élégant et soigné, le serpent, bien que mort, ayant une attitude vraisemblable ? Si la localité est exacte, le plus plausible serait soit un représentant du genre Boiga, Boiga irregularis (Bechstein, 1802), espèce arboricole ornithophage, présente dans toute la région de la Nouvelle-Guinée, incluant plusieurs îles et archipels périphériques, soit un représentant du genre Stegonotus, Stegonotus batjanensis (Günther, 1865), espèce batrachophage propre aux îles situées entre Célèbes et la Nouvelle-Guinée (Moluques, Halmahera). Comme pour le lézard de cette même île Buru, l'origine géographique attribuée au spécimen peut être mise en doute.

\section{Planche 25 (Fig. 29)}

Une couleuvre (Amphiesma), des environs de Pondichéry Jossigny. Annotation : "C'est a peu près Sa Grandr. Naturelle [...] Des Environs de Pondicheri». Longueur estimée : $18 \mathrm{~cm}$. Détermination spécifique : Amphiesma stolatum (Linnaeus, 1758), selon Patrick David (comm. pers. janvier 2015). Parmi les serpents dessinés, c'est le seul qui soit reconnaissable avec certitude, par son ornementation caractéristique. L'espèce occupe un vaste territoire en Asie orientale, du Pakistan et du Sri Lanka au Vietnam et à la Chine méridionale.

L'expédition de Bougainville et Philibert Commerson ont fait escale du 2 au 7 septembre 1768 aux Moluques, à l'île Bouro (Bourou, Boeroe, aujourd'hui Pulau Buru en Indonésie) : c'est peut-être à cette occasion que le lézard et la couleuvre associés à cette île ont été collectés, mais seule leur identification au niveau de l'espèce permettrait de confirmer ou d'infirmer cette origine. En revanche la flûte Isle de France et Sonnerat n'ont pas atteint l'île Bouro : le collecteur ne peut donc être que Commerson. Le collecteur des spécimens des Seychelles - origine au moins certaine pour le caméléon - demeure inconnu. Cette même année 1768, d'octobre à décembre, l'expédition de La Digue et $\mathrm{La}$ Curieuse, capitaines Duchemin et Lampériaire, explora systématiquement l'ensemble des îles granitiques : conformément aux instructions données par Marc Joseph Marion du Fresne, alias Marion-Dufresne (1724-1772), armateur de l'expédition, divers échantillons remarquables de la flore (outre des Cocos de mer) et de la faune furent rapportés à l'Isle de France. L'année suivante, en juillet, l'abbé Rochon, déjà cité, rapporta lui aussi de l'île de Palme (Praslin) des Cocos de mer, que Jossigny dessina pour Commerson et on peut admettre qu'il aurait pu lui-même rapporter des Seychelles d'autres spécimens, incluant des animaux, certains dessinés par Jossigny. Les trois dessins de reptiles des Seychelles, deux couleuvres et un caméléon, les deux premiers attribués à Sonnerat, suggèrent que ce dernier, ne serait-ce que quelques heures, aurait débarqué à Mahé et peut-être aussi à Praslin. Sonnerat donna même quelques informations sur les îles : ainsi pour lui « Trois Frères », localité donnée pour une couleuvre qu'il a dessinée, ne désignait pas la montagne ainsi nommée qui domine Victoria, à Mahé, mais "... l'Archipel, connu autrefois sous le nom des TroisFrères, puis sous celui de Mahé, \& enfin aujourd'hui sous celui de Séchelles" (Sonnerat 1776: 6). Néanmoins, une escale de Sonnerat aux Seychelles au début de juillet 1771, au cours de son premier voyage aux Moluques à bord de l'Isle de France, est catégoriquement exclue par les spécialistes de l'histoire des Mascareignes (Ly-Tio-Fane 1976; Cheke 2008; Morel, comm. pers. décembre 2014) : selon le logbook de l'Isle de France, commandée par le Chevalier Le Borgne de Coëtivy, il n'y a pas eu d'accostage aux Seychelles. C'est pour cette même raison que l'authenticité de la description par Sonnerat du palmier de Praslin est mise en doute, texte et dessins étant considérés comme plagiat (Ly-Tio-Fane 1976: 77). Mais nous avons déjà vu plus haut que Sonnerat n’hésitait pas à copier...

\section{CONCLUSION}

Paul Philippe Sanguin de Jossigny, à travers ces quelques évènements qui ont marqué son existence, n'apparaît pas comme une "personnalité peu saillante ", bien au contraire. Intelligent et travailleur, il a su se faire apprécier de ses supérieurs par sa conduite, ses « talens » et son obéissance à une époque où le respect de la hiérarchie, surtout militaire, était une règle absolue. Par son activité artistique il a malgré lui obtenu une renommée qu'il n'a pu apprécier de son vivant en dessinant, tout en supportant son caractère difficile, pour le naturaliste Philibert Commerson. Il n'était certes pas naturaliste lui-même, mais la qualité de ses dessins, malgré la quantité, et en dépit de quelques figures simplement esquissées, est encore reconnue aujourd'hui : "Jossigny was a meticulous artist, and his drawings of vertebrates and large invertebrates are easily identifiable even (as often) when they are not annotated by Commerson " (Cheke 2008). Séducteur, il a su aussi, manifestement, plaire aux femmes, et au moins trois liaisons ont produit des fruits : le nom, ou le sang, de cet inconnu célèbre s'est peut-être transmis jusqu’à nous.

\section{Remerciements}

Je remercie Mesdames Michèle Lenoir, conservateur en chef, Pascale Heurtel et Alice Lemaire, et Messieurs Florent Jakubowicz et Antoine Monaque, de la Bibliothèque centrale du Muséum national d'Histoire naturelle, pour leur cordial accueil et la communication de l'ensemble des dessins des « manuscrits 
de Commerson » représentant les reptiles dessinés par Jossigny et par Sonnerat, que Madame Michèle Lenoir m'a autorisé à reproduire ici. Je remercie plusieurs collègues de diverses institutions (Cédric Bordes, Patrick David, Ivan Ineich, Ruud de Lang, Gernot Vogel, George Zug) pour leurs commentaires avisés sur la couleuvre et le lézard de l'île Bouro, mais je suis le seul responsable de leur détermination douteuse. Je remercie Madame Patricia Chasteauneuf de l'AMA (Association Maurice Archives: Anonyme 2012a) pour son intérêt, à l'origine d'échanges fructueux concernant Raphaël Duparc et Paul Philippe Sanguin de Jossigny, et mon ami Anthony Cheke, spécialiste de l'histoire naturelle des Mascareignes et des Seychelles, pour ses remarques constructives. Je remercie le Centre Généalogique Héraldique de la Marne, qui m’a fait connaître les relevés de Chastellux (1875). Je remercie pour leur accueil le personnel des Archives de l'état civil de Paris et celui des Archives d'outre-mer à Aix-en-Provence, ainsi que les National Archives of Mauritius pour l'autorisation d'accès à leurs documents numérisés. Je remercie chaleureusement Jean-Paul Morel, déjà présenté dans le texte, qui m’a corrigé plusieurs erreurs importantes dues à un manque de circonspection vis-à-vis de certaines sources; son site «Pierre Poivre et Compagnie " (Anonyme 2014a), fondé uniquement sur des documents contemporains, est une base de référence incontournable pour tous ceux qui s'intéressent à l'histoire des Mascareignes de 1740 à 1800 . Finalement, je remercie le comité éditorial de la revue Zoosystema et sa secrétaire d'édition, Anne Mabille, ainsi que les référé(e)s pour leur minutieuse relecture : Cécile Mourer-Chauviré, Annemarie Ohler et Thierry Frétey.

\section{RÉFÉRENCES}

Les accès aux liens à l'Internet ont été vérifiés le 20 mars 2015.

ANONYME 1822a. - Bulletin des Lois 7e sér., 13, 491: 654-655.

ANONYME 1822b, 1823, 1824, 1825, 1826, 1827, 1828, 1829. - Annuaire de l'état militaire de France... publié sur les documens du ministère de la Guerre avec l'autorisation du Roi. F. G. Levrault, Paris. i-x, 1-579; i-xii, 1-588; i-1-629; i-viii, 1-630; i-viii, 1-660 + [1-10]; i-viii, 1-663; i-xxv, 1-670; i-xv, 1-680.

ANONYME 1871. - L'herbier de Commerson. Revue coloniale. Annales de la Société d'émulation intellectuelle de l'âle Maurice 1: 64-66.

ANONYME 1873. - Histoire d'un naturaliste. Le Magasin pittoresque 41, 35: 277-279, 36: 286-288, 38: 302-303.

ANONYME 1892. - Le catalogue original des portraits au physionotrace de Quenedey. L'Intermédiaire des Chercheurs et des Curieux 25: 153-160, 193-200, 231-240.

ANONYME 2009. - APPL. Janguin [sic] de Jossigny Pierre (décédé en 1819). 13ème division (8ème ligne, 4). Page créée le 27 juillet 2009: http://www.appl-lachaise.net/appl/article.php3?id_article $=2484$

ANONYME 2012a. - Association Maurice Archives (AMA): http:// gw.geneanet.org/amamaurice

ANONYME 2012b. - Antoine Duparc (Wikipedia): http://fr.wikipedia. org/wiki/Antoine_Duparc

ANONYME 2013a. - Archives nationales d'outre-mer, dossier François de Jossigny (15 feuillets, non numérotés): http://anom. archivesnationales.culture.gouv.fr/ark:/61561/up424rlkmonc. num $=20$.referer=nominatif.persname_authfilenumber $=13120$
AnONYMe 2013b. - Archives nationales d'outre-mer, dossier Paul Philippe Sanguin de Jossigny (116 feuillets, numérotés): http://anom.archivesnationales.culture.gouv.fr/ark:/61561/ up $424 \mathrm{~g} 06288 \mathrm{w} \cdot$ num $=20$.referer=nominatif.persname_authfilenumber $=20227$

AnONYME 2013c. - Archives nationales d'outre-mer, dossier Philibert Commerson (50 feuillets, numérotés): http://anom. archivesnationales.culture.gouv.fr/ark:/61561/up424zwtvtm. num $=20 . q=$ commerson

Anonyme 2013d. - Plan de Saint-Germain-en-Laye signé par Duparc et Jossigny : http://archives.yvelines.fr/article. php?laref=499\&titre=plan-de-saint-germain-en-laye

ANONYME 2014a. - National Archives of Mauritius: http://nationalarchives.govmu.org/NationalArchivesServices/research.do

ANONYME 2014b. - Associations généalogiques consultées : http:// www.genealogie.com et http://www.geneanet.org

ANONYME 2014c-g. — Généalogie Sanguin de Livry: http://racineshistoire.free.fr/LGN/PDF/Sanguin.pdf; http://gw.geneanet. org/garric?lang=fr; $\mathrm{p}=$ francois + hippolyte; $\mathrm{n}=$ sanguin + de + livry ; http://gw.geneanet.org/pierfit?lang=fr\&p=francois+hippolyt e\&n=sanguin+de+livry ; http://bondy-histoire.chez-alice.fr/ Abondy/sanguin.htm ; http://roglo.eu/roglo?lang=fr\&m=NG $\& \mathrm{n}=$ sanguin \& $\mathrm{t}=\mathrm{N}$

ANONYME 2015. - Archives nationales. https://www.siv.archivesnationales.culture.gouv.fr/siv/rechercheconsultation/consultation/ multimedia/Galerie.action? mediaParam $==$ ?UTF-8? B?REFGQU5DSDk3XzEwOE1JQzAwOTAzX0wuanBnI0RBRkFOQ0g5N18xMDhNSUMwMDkyM19MLmpwZw==?=\&udTitle= $=$ ?UTF-8? B? TGlzdGUgY2hyb25vbG9naXF1ZSBkZXMgYWN0ZXMgcG91ciBsYSBww6lyaW9kZSBkdSAyIGphbnZpZXIgYXUgMzEgZMOpY2VtYnJlIDE4Mjg=?=\&xpointer=\&mmName=

ACHARD C. F. 1787. - Histoire des hommes illustres de la Provence. Imprimerie de Jean Mossy, Marseille. I: v-xv, 1-635. II: v-viii, 1-523.

Allorge L. \& IKOR O. 2003. - La fabuleuse odyssée des plantes. JC Lattès, Paris: 1-727.

Amanton C. N. 1832. - Notice historique sur Jacques Maillart Du Mesle, Intendant des Isles de France et de Bourbon. Mémoires de l'Académie des Sciences, Arts et Belles-lettres de Dijon. Partie des Lettres. Année 1832: 79-102.

Autheman J.-P \& Dethorey J.-P. 1999. - Le passage de Vénus. Tome 1. Dupuis, Charleroi: 1-64.

Autheman J.-P \& Dethorey J.-P. 2000. - Le passage de Vénus. Tome 2. Dupuis, Charleroi: 1-56.

BADIER [J.] 1786. - Recueil de généalogies, pour servir de suite ou de supplément au dictionnaire de la noblesse. Tome XV. Badier, Paris: i-iv, 1-645.

BEAUCHAMP A. DE 1818. - Biographie des jeunes gens, ou vies des grands hommes. Alexis Eymery, Paris. Deuxième édition, IV: 1-454. [Commerson: 412-420].

Belda Navarro C. \& Hernández Albaladejo E. 2006. - Arte en la Región de Murcia. De la reconquista a la ilustración. Editorial Regional de Murcia, Murcia: 1-586.

BeRTHELOT L. 2002. - La petite Mascareigne: aspects de l'histoire de Rodrigues. Centre Nelson Mandela pour la Culture Africaine, Port-Louis: i-vii, 1-255.

BILliARD A. 1822. - Voyage aux colonies orientales, ou lettres écrites des îles de France et de Bourbon pendant les années 1817, 1818, 1819 et 1820, Ladvocat, Paris: i-xix, 1-485.

BILLIOUd J. 1936. - Un sculpteur marseillais nomade au XVIII ${ }^{\mathrm{e}}$ siècle: Antoine Duparc (Provence, Espagne, Normandie). Bulletin Officiel du Musée du Vieux Marseille 51-52: 1-21, 165-167, $22 \mathrm{pl}$.

Billioud J. 1937. — Les Duparc, trois générations d'artistes marseillais. Mémoires de l'Institut historique de Provence 14: 165-187.

Bossu J. 1987. — « Fichier Bossu ». De Jossigny, Paul - De Jossigny, Pierre. Bibliothèque nationale de France, Paris : http://gallica. bnf.fr/ark:/12148/btv1b10000325v/f71.image ; http://gallica. bnf.fr/ark:/12148/btv1b10000325v/f72.image 
Boulenger G. A. 1893. - Catalogue of the Snakes in the British Museum (Natural History). British Museum, London. Volume I. i-xiii, 1-448, pl.1-28.

Bour R. 1982. - Pelomedusa subrufa (Lacépède, 1788), Pelusios subniger (Lacépède, 1788) (Reptilia, Chelonii) et le séjour de Philibert Commerson à Madagascar. Bulletin du Muséum national d'Histoire naturelle 4, 4, A, 3-4: 531-539.

BouR R. 1984. - Taxonomy, History and Geography of Seychelles land Tortoises and fresh-water Turtles, in STODDART D. R. (ed.), Biogeography and Ecology of the Seychelles Islands, Junk, The Hague: 281-307.

BouR R. 1985. - Les Tortues terrestres géantes des îles de l'océan Indien occidental: données géographiques, taxinomiques et phylogénétiques, in BroIN F. de \& JiMENEZ-FuENTES E. (eds), Studia Palaeocheloniologica I. Studia Geologica Salmanticensia, Vol. especial 1 [1984]: 17-76.

Bour R. 1987. - Les Tortues terrestres et d'eau douce de Madagascar et des îles voisines (seconde partie). Bulletin de l'AparsMad 20: 1-11.

BouR R. 1988. - Tortues et insularité: les Tortues des Seychelles. Bulletin de la Société zoologique de France 112, 3-4: 401-418.

BouR R. 1994. - Recherches sur des animaux doublement disparus: les Tortues géantes subfossiles de Madagascar. Mémoires et Travaux de l'Institut de Montpellier 19: 1-253.

Bour R., Frétey T. \& Cheke A. S. 2014a. - Philibert Marragon (1749-1826) and the Mémoire sur l'Isle de Rodrigue (1795). Bibliotheca Herpetologica 10, 2: 5-32.

Bour R., Mourer-Chauviré C. \& Ribes S. 2014b. — Morphology and paleontological exploration (up to 2000) of the extinct tortoises of the Mascarenes islands, in GERLACH J. (ed.), Western Indian Ocean Tortoises, Siri Scientific Books, Manchester: 121-202.

Bouton L. 1871. - Biographie. Les célébrités mauriciennes. Esquisses biographiques. Commerson. Revue coloniale. Annales de la Société d'émulation intellectuelle de l'âle Maurice 1: 35-43.

CAP A. 1860. - Philibert Commerson, naturaliste voyageur. Journal de Pharmacie et de Chimie 3, 38: 413-442.

CAP A. 1861. - Philibert Commerson, naturaliste voyageur. Étude biographique, Victor Masson et Fils, Paris. 1-199.

CHASTELLUX [H. P. C.] DE 1875. - Notes prises aux archives de l'État civil de Paris, avenue Victoria, 4, brûlées le 24 mai 1871. Librairie historique de J.-B. Dumoulin, Paris. 1-634.

CHEKE A. S. 1987. - An ecological history of the Mascarene Islands, with particular reference to extinctions and introductions of land vertebrates, in DiAmOND A. W. (ed.), Studies of Mascarene Island Birds. Cambridge University Press, Cambridge: 5-89.

CHeKe A. S. 2008. - Additional 18 th century records of endemic Seychelles fauna, Phelsuma 18: 68-70.

CHEKe A. S. 2009a. - Data sources for $18^{\text {th }}$ century French encyclopaedists - what they used and omitted: evidence of data lost and ignored from the Mascarene Islands, Indian Ocean. Journal of the National Museum (Prague), Natural History Series 177 (9): 91-117.

CHeKe A. S. 2009b. - Not lost but hiding - type material of the endemic Mauritian bat Mormopterus acetabulosus (Hermann, 1804) (Chiroptera: Molossidae), Journal of the National Museum [Prague], Natural History Series 178 (1): 1-3.

CHEKe A. S. \& Bour R. 2014. - Unequal struggle - how humans displaced the dominance of tortoises in island ecosystems, in Gerlach J., Western Indian Ocean Tortoises. Manchester, Siri Scientific Books: 31-120.

Cheke A. S. \& Hume J. P. 2008. - Lost Land of the Dodo. An ecological history of Mauritius, Réunion and Rodrigues. London, T. \& A. D. Poyser: 1-464, 16 pls.

ChenNEVIĖREs P. DE 1886. - Antoine, Raphaël et Françoise Duparc, architectes, sculpteurs et peintres (XVII et XVIII siècles). Nouvelles archives de l'art français 3e sér., 2: 322-326.

Christinat C. 1996. - Une femme globe-trotter avec Bougainville: Jeanne Barret (1740-1807). Revue française d'Histoire d'Outremer 83, 310: 83-95.
Christinat C. \& Forster S. 1993. - Aventures clandestines. Femmes Suisses 81, 12: 23-24.

Crestey N. 2010. - Les expéditions scientifiques au piton de la Fournaise. Cahiers scientifiques de l'océan Indien occidental 1: 7-26.

Cuvier G. \& DE SAINT-AGY T. M. 1845. - Histoire des sciences naturelles depuis leur origine jusqu'à nos jours, contenant la fin de la deuxième moitié du $18^{e}$ siècle et une partie du 19e. Tome cinquième complémentaire. Fortin, Masson et Cie, Paris:1-440.

Cuvier G. \& Valenciennes A. 1828. - Histoire naturelle des Poissons. Tome second. F. G. Levrault, Paris, Strasbourg, Bruxelles. v-xvii, 1-371, pls 1-40.

DAUDIN F. M. 1801. - Histoire naturelle, générale et particulière, des Reptiles. F. Dufart, Paris. Volume 2: 1-432, pls 16-28.

D'ÉPINAY A. 1890. — Renseignements pour servir à l'histoire de l'̂le de France jusqu'à l'année 1810, inclusivement. Nouvelle imprimerie Dupuy, Port-Louis. i-vii, 1-577, i-xxiv.

Doyen C. L. C. 1860. — Régiment de l'Isle de France. 1806. Papiers Doyen. Une collection de la Société Royale des Arts et des Sciences de l'île Maurice: 15985-16023: http://papiersdoyen. mu.refer.org/index.php?option=com_content\&view=category \& id $=6 \&$ Itemid $=6$

DuMÉRIL A. M. C. \& G. BiBRON 1835. - Erpétologie générale ou histoire naturelle complète des Reptiles. Roret, Paris, Tome II: i-ii, 1-680.

DupraT G. 1964. - Les dessinateurs d'histoire naturelle en France au XVIII siècle, in LAWRENCE G. H. (ed.), Adanson. The Bicentennial of Michel Adanson's "Familles des plantes». Hunt Botanical Library, Pittsburgh, Part Two: 451-470.

FITZINGER L. J. 1826. — Neue Classification der Reptilien nach ihren natürlichen Verwandtschaften. J. G. Heubner, Wien. [i-ii], $1-66,1$ tab.

FITZINGER L. J. 1835. — Entwurf einer systematischen Anordnung der Schildkröten nach den Grundsätzen der natürlichen Methode. Annalen des Wiener Museums der Naturgeschichte 1, 1: 103-128.

FRITZ U. \& HAVAŠ P. 2007. - Checklist of chelonians of the world. Vertebrate Zoology 57, 2: 149-368.

GERMAIN [DE MAIDY] L. 1884. — Un sculpteur normand, d'origine lorraine. Journal de la Société archéologique lorraine et du Musée historique lorrain 33: 51-54.

GRANDIDIER A. 1872. - Un voyage scientifique à Madagascar. La Revue scientifique de la France et de l'étranger 2e sér., 1, 46: 1077-1088.

Grant M. L., Fosberg F. R. \& Smith H. M. 1974. - Partial Flora of the Society Islands: Ericaceae to Apocynaceae. Smithsonian Institution Press, Washington: i-vii, 1-85.

GÜNTHER A. 1873. — Preliminary notice on some extinct tortoises from the islands of Rodriguez and Mauritius. Annals and Magazine of Natural History 4, 11: 397.

HENNEQUIN R. 1931. - Les portraits au physionotrace gravés de 1788 à 1830 . Essai d'un catalogue nominatif, biographique et critique. Deuxième série au temps de la Révolution: citadins de Paris et parisiens par occasion. Physionotracés dessinés et gravés par Quenedey (des Riceys), du milieu d'août 1789 au mois de mai 1796. Série cotée de H31 à R27. Mémoires de la Société académique d'Agriculture, des Sciences, Arts et Belles-lettres du département de l'Aube 93: 17-166.

HENNEQUin R. 1932. - Avant les photographies. Les portraits au physionotrace gravés de 1788 à 1830. Catalogue des 1800 premiers portraits de ce genre (cotés de " 1 » " $R 27 »)$. Édition nouvelle illustrée. J.-L Paton, Troyes: 1-345. [La page de titre interne a un libellé différent]

HENNET L. 1903. - État militaire de France pour l'année 1793. Société de l'histoire de la Révolution française, Paris. i-xiv, 1-468.

HoARAu S., JaniçON M.-P. \& RaCAUlt J.-M. 2004. — Voyage à Rodrigue, le transit de Vénus de 1761: la mission astronomique de l'abbé Pingré dans l'océan Indien. Éditions Orphie, Paris: 1-373.

HuPFELD T. 2007. - Zur Wahrnehmung und Darstellung des Fremden in ausgewählten französischen Reiseberichten des 16. bis 18. Jahrhunderts. Universitätsverlag, Göttingen: 1-454. 
JAN [G.] \& SORDELLI F. 1870. — Iconographie générale des Ophidiens. J. B. Baillière et fils, Paris, 36e livraison, pls 1-6.

Jouin H. 1886. — « Il a été question récemment d'Antoine Duparc » Nouvelles archives de l'art français 3e sér., 2: 326-328.

LACÉPÈDE B. G. É. DE 1788. — Histoire naturelle des quadrupèdes ovipares et des serpens. Tome premier. Hôtel de Thou, Paris. 1-17, 1-651, pls 1-41.

LACroIX A. 1938. — Les collaborateurs de Pierre Poivre. Philibert Commerson (1727-1773), in Figures de Savants. Paris, GauthierVillars. Tome IV: 1-13, pls 1-5.

LAISSUS Y. 1974. - Catalogue des manuscrits de Philibert Commerson (1727-1773) conservés à la bibliothèque centrale du Muséum national d'Histoire naturelle (Paris), in BoIssON J. M. (ed.), Cahiers du Centre universitaire de la Réunion. Numéro spécial. Colloque Commerson. Imprimerie Cazal, Saint-Denis: 76-101.

LAISSUS Y. 1978. - Catalogue des manuscrits de Philibert Commerson (1727-1773) conservés à la Bibliothèque centrale du Muséum national d'Histoire naturelle (Paris). Revue d'histoire des sciences 31, 2: 131-162.

La LANDE [J. J.] DE 1775. — Éloge de M. Commerson. Observations sur la physique, sur l'histoire naturelle et sur les arts 5, 2: 89-120.

LA LANDE [J. J.] DE 1776. — Lettre de M. de la Lande, de l'Académie Royale des Sciences, à l'Auteur de ce Recueil, Contenant des Notes sur l'Éloge de M. Commerson, publié dans ce Recueil, Cahier de Février 1775. Observations sur la physique, sur l'histoire naturelle et sur les arts 8, 5: 357-363.

LAMARCK [J.-B. P. A. DE MONET DE] 1808. —Encyclopédie méthodique. Botanique. Agasse, Paris. Tome 8. 1-879.

LA ROQUe, L. DE 1891. - Catalogue des Chevaliers de Malte appelés successivement Chevaliers de l'ordre militaire et hospitalier de SaintJean de Jérusalem, de Rhodes \& de Malte. 1099-1890. Alp. Desaide, Paris: i-xxiv, 1288 (col.).

Le BiHAn A. 1966. - Francs-maçons parisiens du Grand Orient de France (fin du XVIII siècle). Mémoires et documents, Commission d'histoire économique et sociale de la Révolution française, 19. Bibliothèque nationale, Paris: 1-491.

LEGUAT F. 1707. — Voyages et avantures de François Leguat, o de ses compagnons, en deux isles désertes des Indes orientales. Jean Louis Delorme, Amsterdam, Tome 1: [i-xii], i-xxx, 1-164, pl. 1, carte. [daté 1708, mais publié en 1707].

L'HéRITIER DE Brutelle C. L. 1784-1785. - Stirpes novae, aut minus cognite, descriptionibus et iconibus illustravit... Philippi Dionysii Pierres, Parisiis, Fasc.1-6: i-vi, 1-181, pls 1-84.

LignereuX Y. 2004. - Philibert Commerson, médecin-naturaliste du roi (1727-1773) ou la traversée inachevée. Bulletin du Centre d'Étude d'Histoire de la Médecine 47: 7-51.

LindHOLM W. A. 1929. - Revidiertes Verzeichnis der Gattungen der rezenten Schildkröten nebst Notizen zur Nomenklatur einiger Arten. Zoologischer Anzeiger 81 (2): 275-295.

Lislet Geoffroy [J.-B.] 1871. — Notice sur le voyage de M. de Crémont au volcan de Bourbon, en 1772 [sic, = 1771]. Revue coloniale. Annales de la Société d'émulation intellectuelle de l'île Maurice 1: 58-63.

Luminet J.-P. 1999. - Le rendez-vous de Vénus. JC Lattès, Paris: $1-359$.

Ly-Tio-Fane M. 1976. — Pierre Sonnerat 1748-1814. The Author, Imprimerie et papeterie commerciale, Cassis (Mauritius): i-xv, 1-157.

MagOn DE SAINT-Elier F. 1839. - Tableaux historiques, politiques \& pittoresques de l'Île de France, aujourd'hui Maurice, depuis sa découverte jusqu’à nos jours. Imprimerie du Mauricien, Port-Louis. i-iii, 1-236, i-vi.

Merceron F. 1988. - Dictionnaire illustré de la Polynésie, Te Aratai o Porinetia. Christian Gleizal / Les Editions de l'Alizé, Papeete. 4 vol.: 1-304, 1-304, 1-302, 1-304.

Monnier J., Lavondes A., JolinOn J.-C. \& Elouard P. 1993. — Philibert Commerson le découvreur du Bougainvillier. Association SaintGuignefort, Imprimerie Multitude, Châtillon-sur-Chalaronne: $1-191$.
MonTessus F. B. DE [DE BALLORE] 1889. - Martyrologe et biographie de Commerson, médecin-botaniste et naturaliste du Roi, médecin de Toulon-sur-Arroux (Saône-et-Loire) au XVIIIe siècle. L. Marceau, Chalon-sur Saône: i-vii, 1-225.

Morel J.-P. 2010. — Pierre Poivre \& Compagnie: http://www. pierre-poivre.fr/

MOREL J.-P. 2011a. - Maillart Dumesle, le 8 novembre 1773. État des effets d'histoire naturelle embarqués sur le vaisseau du Roi La Victoire commandé par M. de Joannis. Archives Nationales. A. N. Col C/4/34, fo196. $1+2$ pages : http://www.pierre-poivre. $\mathrm{fr} / \mathrm{doc}-74-6-3 . \mathrm{pdf}$

Morel J.-P. 2011b. - Desroches au duc de Praslin. Brest, Service Historique de la Défense, département Marine. Ms.91, n 17 . http://www.pierre-poivre.fr/doc-69-6-27.pdf

Morel J.-P. 2012a. - Philibert Commerson à Madagascar et à Bourbon. 15 pages: http://www.pierre-poivre.fr/CommersonMadagascar-Bourbon.pdf

Morel J.-P. 2012b. — Décès de M. Commerson, docteur en médecine et naturaliste du Roi. 1 page : http://www.pierre-poivre.fr/ doc-73-3-14.pdf

Morel J.-P. 2013. — Éléments biographiques sur Pierre Sonnerat. Premières années sous le regard de Pierre Poivre. 15 pages: http:// www.pierre-poivre.fr/Bio-Sonnerat.pdf

Morel J.-P. 2014a. - Bellecombe et Crémont à Desroches et Poivre. Archives Nationales. A. N. Col C/3/14. 1 page. http:// www.pierre-poivre.fr/doc-71-1-18.pdf

Morel J.-P. 2014b. - Poivre aux administrateurs de Bourbon. Archives départementales de La Réunion, dossier 12C. 1 page : http://www.pierre-poivre.fr/doc-71-2-8.pdf

Morel J.-P. 2014c. - Poivre à Crémont (arrivée de la Belle Poule). Archives départementales de La Réunion, dossier 12C. 1 page : http://www.pierre-poivre.fr/doc-72-8-21b.pdf

North-CoOmbes A. 1986. - Histoire des Tortues de terre de Rodrigues et le mouvement maritime de l'île de 1601 à 1808 . Service Bureau, Port-Louis, i-viii, 1-75, 6 pl. [2e édition en 1994].

Nussbaum R. A. 1984. - The Snakes of the Seychelles, in STODDART D. R., Biogeography and Ecology of the Seychelles Islands. Junk, The Hague: 361-377.

OLSEN P. 2001. - Feather and Brush: three Centuries of Australian Bird Art. Csiro publishing, Collingwood, Melbourne. i-xii, 1-227.

OUSTALET E. 1896a. - Notice sur la faune ornithologique ancienne et moderne des îles Mascareignes, d'après des documents inédits. Bulletin du Muséum d'Histoire naturelle 2: 220-226.

Oustalet E. 1896b. - Notice sur la faune ornithologique ancienne et moderne des îles Mascareignes et en particulier de l'île Maurice d'après des documents inédits. Annales des Sciences naturelles 8 e sér., 3: 1-128.

OustalET E. 1900. - Note sur une particularité de conformation de la patte chez les Manchots. Bulletin du Muséum d'Histoire naturelle 6: 531-539.

PAIN D. 2007. — Les commanditaires du château de Bénouville, in PAIN D., Bordet G., Patte E., Dujardin L., Jouet R., Lescroart Y., Houssaye P. \& BeCK B., Le château de Bénouville. Une cuvre de Claude-Nicolas Ledoux. Cahiers du temps, Cabourg: 9-12.

Perrault C. 1676. - Description anatomique d'une grande Tortuë des Indes. Suites des Mémoires pour servir à l'Histoire Naturelle des Animaux 2: 192-205.

Perret H. 2003. - Index des francs-maçons par loges: https:// archive.is/i8dRV

Pinault-Sørensen M. 1989. - La Diderota amphicarpa de Commerson, in Recherches sur Diderot et sur l'Encyclopédie 6, 6: 149-152.

Pingré A. G. 1761. - Voyage à Rodrigue. Ms n ${ }^{\circ} 1804$. Bibliothèque Sainte-Geneviève, Paris. [Voir Serviable \& Alby 1993; Hoarau et al. 2004].

RHODIN A. G. J. \& CARR J. 2009. - A quarter millenium of uses and misuses of the turtle name Testudo scabra: Identification of the type specimens of T. scabra Linnaeus 1758 (= Rhinoclemmys punctularia) and T. scripta Thunberg in Schoepff 1792 (= Trachemys scripta scripta). Zootaxa 2226: 1-18. 
Rochon A. 1791. - Voyage à Madagascar et aux Indes Orientales. Prault, Paris: i-lxiv, 1-322, carte.

Role A. 1973. - Vie aventureuse d'un savant: Philibert Commerson Martyr de la Botanique. Imprimerie Cazal, Saint-Denis: 1-27.

SALOMON F. T. 1855. - Le Père-Lachaise. Recueil général alphabétique des concessions perpétuelles établies dans ce lieu. L'Auteur, Ledoyen, H. Mansart, Paris: i-viii, 1-312, 1 plan.

SÁNCHEZ MorENO J. 1946. - Notas sobre arquitectos en Murcia, y noticia del escultor Pedro Federico. Anales de la Universidad de Murcia 1945-1946, 1-4: 351-355.

SÁNCHEZ-ROJAS FENOLl M. C. 1980. — La etapa murciana del escultor marsellés, Antonio Dupar. Anales de la Universidad de Murcia. Filosofía y Letras 37, 1-2: 151-189.

SCHIEBINGER L. 2004. - Plants and Empire. Colonial Bioprospecting in the Atlantic World. Harvard University Press, Cambridge: i-x, 1-306.

SCHLEGEL H. 1837. - Essai sur la physionomie des Serpens. II. H. M. Schoneat, Amsterdam: 1-606, i-xv, errata.

SCHLEGEL H. 1844. - Abbildungen neuer oder unvollständig bekannter Amphibien, nach der Natur oder dem Leben entworfen. Verlag Arnz \& Compnie, Düsseldorf, pls 1-50.

SchoepfF J. D. 1792-1801a. - Historia Testudinum iconibus illustrata. Johannis Jacobi Palm, Erlangae: i-xii, 1-136, pls 1-31.

SCHOEPFF J. D. 1792-1801b. - Naturgeschichte der Schildkröten mit Abbildungen erläutert. Johann Jakob Palm, Erlangen, (i-xii), 1-160, pls 1-31.

SCHWEIGGER A. F. 1809. - Classification des tortues. Manuscrit. Bibliothèque centrale du MNHN, Paris, Ms 2627: 34 fol.

SCHWEIGGER A. F. 1812. - Prodromus Monographiae Cheloniorum. Königsberger Archiv für Naturwissenschaft und Mathematik 1, III: 271-68; IV: 406-462.

Serviable M. 1998. - Philibert Commerson 18 novembre 1827-13 mars 1773, in Le Dictionnaire biographique de La Réunion 3. CLIP. Imprimerie Graphica, Saint-André (La Réunion): 51-52.

Serviable M. \& Alby J. (eds) 1993. - Abbé Alexandre-Gui Pingré. Courser Vénus. Voyage scientifique à l'Ile Rodrigue 1761. Fragments du Journal de Voyage de l'Abbé Pingré. Ars Terres Créoles - Éditions de l'océan Indien, Saint-Denis (La Réunion) et Stanley (Mauritius): 1-123.
SHAW G. 1802. - General Zoology, or Systematic natural history. G. Kearsley, London. Vol. III. Part I: Amphibia. i-viii, 1-312, pls 1-86.

SieBENROCK F. 1909. - Synopsis der rezenten Schildkröten mit Berücksichtigung der in historischer Zeit ausgestorbenen Arten. Zoologische Jahrbücher. Suppl. 10: 427-618.

SonNerAT P. 1776. - Voyage à la Nouvelle-Guinée. Ruault, Paris: i-xii, [xiii-xvi], 1-206, pls 1-120.

SuCKOW G. A. 1798. - Anfangsgründe der theoretischen und angewandten Naturgeschichte der Thiere. Weidmannischen Buchhandlung, Leipzig, Dritter Theil, Von den Amphibien: $1-298$.

TAILLEMITE E. 1977. - Bougainville et ses compagnons autour du monde 1766-1769. Imprimerie nationale, Paris. Tome 1: i-xiv, 1-516; Tome 2: 1-578.

TouChard M. C. 1974. - Les voyages de Bougainville. Éditions du Pacifique et Albin Michel, Papeete et Paris: 1-158.

TOUSSAINT A. 1972. — Histoire des îles Mascareignes. Berger Levrault, Paris: $1-351$.

TUETEY A. 1908. — Répertoire général des sources manuscrites de l'histoire de Paris pendant la Révolution française. Imprimerie nouvelle (Association ouvrière), Paris. Tome VIIIe: 1-847.

Turtles and Tortoises Taxonomic Group [Van Dijk P. P., Iverson J. B., Rhodin A. G. J., Shaffer H. B. \& Bour R.] 2014. — Turtles of the World, 7th Edition: Annotated Checklist of Taxonomy, Synonymy, Distribution with Maps, and Conservation Status. Chelonian Research Monographs 5, 7: 329-479.

VAillant L. 1898. — Dessins inédits de Chéloniens tirés des manuscrits de Commerson. Bulletin du Muséum d'Histoire naturelle 4: $133-138$.

WANQUET C. 1992. — Les premiers députés de La Réunion à l'Assemblée nationale. Quatre insulaires en Révolution (17901798). Karthala, Paris: 1-237.

WANQUET C. 2002. - Esclavage et abolitions dans l'océan Indien (1723-1860). L'Harmattan, Paris: 1-456.

ZirnsteIN G. 2015. - Entdeckung der Vielfalt in der Organismenwelt. Universität, Abteilung Wissenschaftsgeschichte, Leipzig. 1-1220: http://www.uni-leipzig.de/ zirnst/pdf/Pfl_Ti.pdf 